\title{
Electrophysiological properties and pharmacological modulation of several transmembrane ion currents in mammalian hearts
}

\author{
PhD Thesis
}

Amir Mohammad Geramipour, DPharm

Supervisor

Norbert Jost, PhD

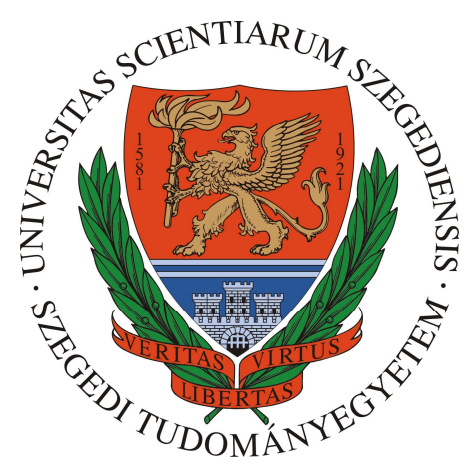

Department of Pharmacology and Pharmacotherapy

Faculty of Medicine, University of Szeged

Doctoral School of Multidisciplinary Medicine

University of Szeged

Szeged, Hungary 


\section{Table of contents}

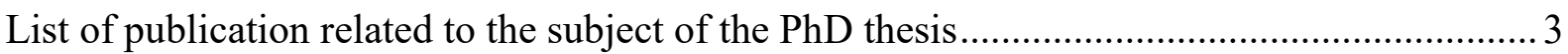

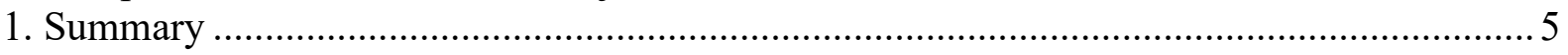

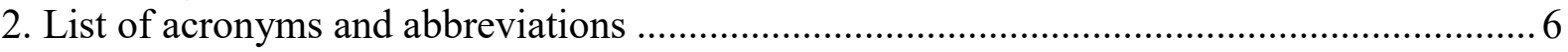

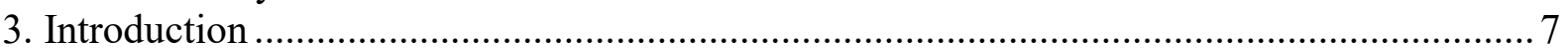

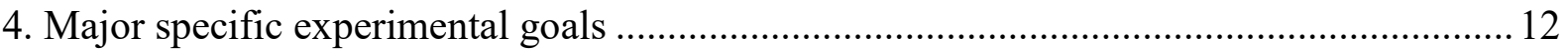

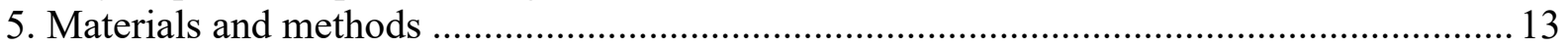

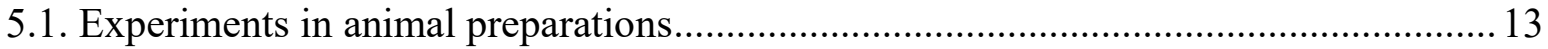

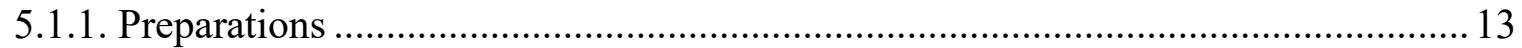

5.1.2. In vitro investigations: ion current measurements by applying the patch-clamp

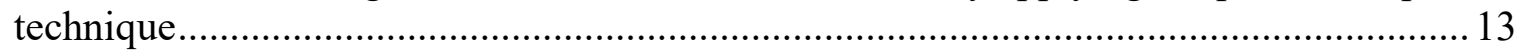

5.1.3. In vitro investigations, AP measurements by applying the standard microelectrode

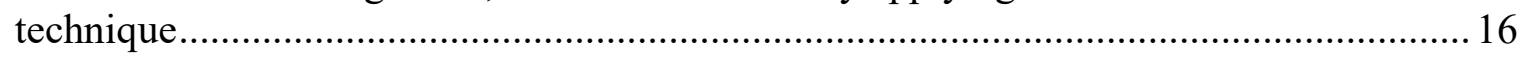

5.1.4. Ex vivo investigations: ECG measurements in isolated Langendorff perfused heart

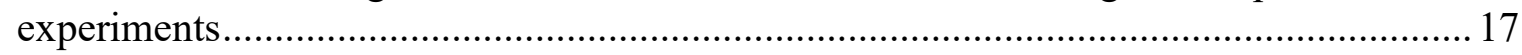

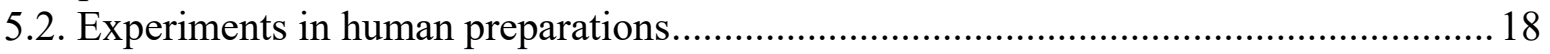

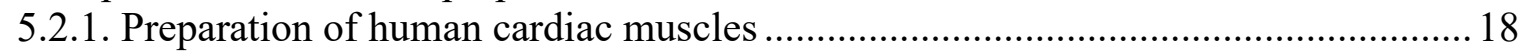

5.2.2. $\mathrm{I}_{\mathrm{K} 1}$ current measurements by applying the whole-cell patch-clamp technique ....... 18

5.2.3. mRNA expression investigations by applying the qRT-PCR technique................. 19

5.2.4. Protein expression investigation by applying the Western blot analysis..................20

5.2.5. Immunofluorescence investigations by applying confocal microscopy.................. 21

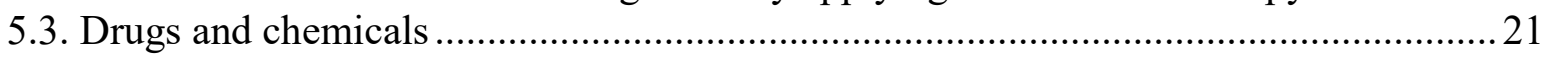

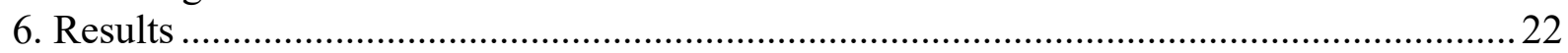

6.1. The investigation of the expression of genes for Kir ion channel isoforms in dilated

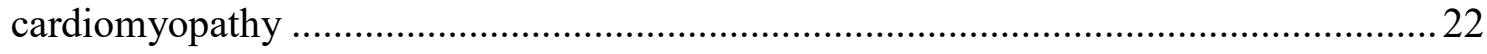

6.1.1. Testing DCM samples for characteristic marker gene expression ...........................22

6.1.2. Disease-related changes in mRNA and protein levels of Kir2.x isoforms ............... 22

6.1.3. Age-dependent and DCM-related changes in SAP97 mRNA expression................26

6.1.4. Altered inward rectifier current density in the heart of dilated cardiomyopathic

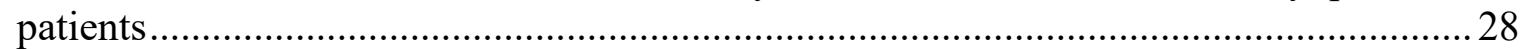

6.2. The investigation of several newly synthetized CNA compounds as novel selective NCX inhibitors. The selection of GYKB-6635 as lead compound ............................. 29

6.3. Investigation of the cellular electrophysiological and antiarrhythmic effects of GYKB-

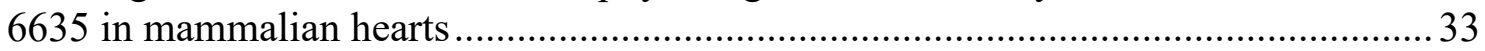

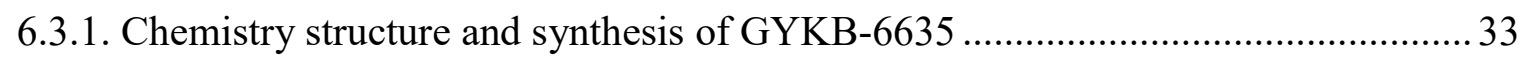

6.3.2. Effect of GYKB-6635 on the outward and inward NCX current .............................. 35

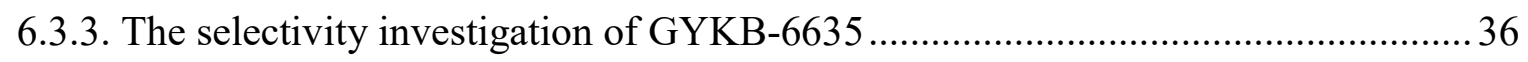

6.3.3. Effect of selective NCX inhibition on the AP waveform and repolarization ...........40

6.3.4. Ouabain induced arrhythmias in isolated guinea-pig hearts................................. 41

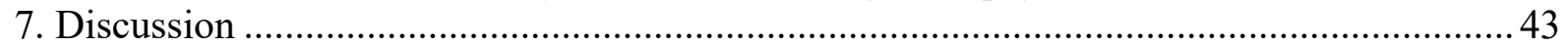

7.1. The effects of the expression of genes for Kir2.x ion channel isoforms in dilated

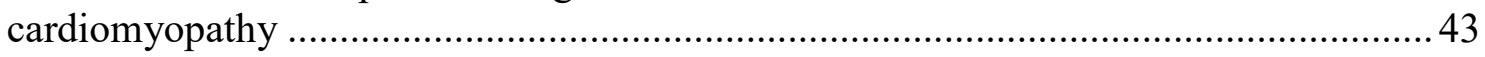

7.2. The investigation and comparison of the effects of several newly synthetized CNA analogues. The characterisation of GYKB-6635 as lead compound ............................ 46

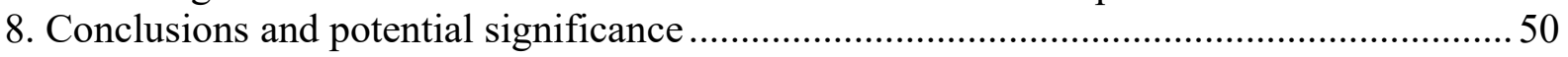

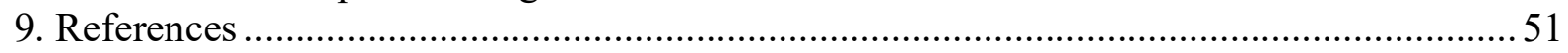

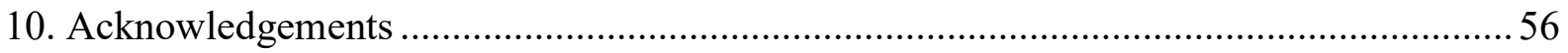

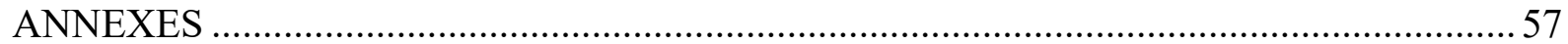




\section{List of publication related to the subject of the PhD thesis}

\section{Full length papers}

I. Szüts V, Ménesi Z, Varga-Orvos Z, Zvara A, Houshmand N, Bitay M, Bogáts G, Virág L, Baczkó I, Szalontai B, Geramipour A, Cotella D, Wettwer E, Ravens U, Deák F, Puskás LG, Papp, JG, Kiss I, Varró A, Jost N. Altered expression of genes for Kir ion channels in dilated cardiomyopathy.

Canadian Journal of Physiology and Pharmacology, 91(8), 648-656, 2013.

Impact factor (2013): $1.546 \quad$ Nr. independent citations: 10

II. Geramipour A, Kohajda Zs, Corici C, Prorok J, Szakonyi Zs, Oravecz K, Márton Z, Nagy N, Tóth A, Acsai K, Virág L, Varró A, Jost N. The investigation of the cellular electrophysiological and antiarrhythmic effects of a novel selective sodium-calcium exchanger inhibitor GYKB-6635 in canine and guinea pig hearts.

Canadian Journal Physiology and Pharmacology, 94(10), 1090-1101, 2016.

Impact factor (2015): 1.704

\section{Published abstracts}

III. Geramipour A, Kohajda Z, Oravecz K, Márton Z, Nagy N, Acsai K, Gruber A, Szepesi J, Kormos A, Tóth A, Prorok J, Virág L, Kiss L, Fülöp F, Levijoki J, Pollesello P, Koskelainen T, Otsomaa L,Varró A, Jost N. Comparison of the effect of several, newly synthetized sodium-calcium exchanger (NCX) blockers in mammalian hearts.

("Abstract book with Final program" of the $2^{\text {nd }}$ European Section Meeting of the International Academy of Cardiovascular Sciences, 8-10 October, 2015, Belgrade, Serbia; eds. D. Djuric and V. Jakovlevic, Kragujevac Family Press, ISBN: 978-86-904799-9-6) 
IV. Geramipour A, Kohajda Z, , Prorok J, Szakonyi Zs, Oravecz K, Márton Z, Nagy N, Tóth A Acsai K, Virág L, Varró A, Jost N. Comparison of the effect of several, newly synthetized The comparison of the effect of several carbocyclic nucleoside analogues as novel selective NCX inhibitors in mammalian hearts.

("Abstract book with Final program" of the Pharmacology 2017, Annual Meeting of the British Pharmacological Society Meeting, 13-15 December, 2016, London, UK)

\section{Publication not related to the subject of the thesis}

Kohajda Zs. Farkas-Morvay N, Jost N, Nagy N, Geramipour A, Horváth A, Varga RS, Hornyik T, Corici C, Acsai K, Horváth B, Prorok J, Ördög B, Déri Sz, Tóth D, Levijoki J, Pollesello P, Koskelainen T, Otsomaa L, Tóth A, Baczkó I, Leprán I, Nánási PP, Papp JGy, Varró A, Virág L. The effect of a novel highly selective inhibitor of the sodium/calcium exchanger (NCX) on cardiac arrhythmias in in vitro and in vivo experiments.

PLoS One, 11(11): e0166041. doi: 10.1371/journal.pone.0166041, 2016. Impact factor (2015): 3.057 


\section{Summary}

Cardiovascular diseases and in particular cardiac arrhythmias as ventricular fibrillation have a leading role in mortality in the developed countries. Accordingly, cardiac arrhythmias represent a major area of cardiovascular research. Drug therapy has traditionally been the major type of treatment for both ventricular and supraventricular arrhythmias. In spite of the important advances in cardiology, the pharmacological treatment of cardiac arrhythmias remained empiric to a large extent because of our incomplete understanding the mechanisms by which antiarrhythmic drugs prevent/suppress, or unfortunately even induce arrhythmias. Therefore, in order to develop new more effective agents with less proarrhythmic potency, it is important to understand the mechanism of action of antiarrhythmic drugs at the organ, tissue, cellular and also subcellular levels. Based on the promising results of recent cellular pathophysiological and pharmacological investigations in the present $\mathrm{PhD}$ thesis, we have focused our research especially on pharmacological modulation of repolarizing potassium and sodium-calcium exchanger (NCX) currents as key elements in generating arrhythmias.

\section{The aims of the present study were:}

a) To analyse the contribution of different auxiliary proteins to the altered expression of genes for Kir2.x ion channels in dilated cardiomyopathy.

b) To investigate and compare the effects of several newly synthetized NCX blockers on several mammalian hearts. Selection of a lead NCX blocker compound for further analysis.

c) To investigate the electrophysiological effects of the lead compound GYKB-6635, a newly synthetized specific NCX inhibitor, on the NCX, L-type $\mathrm{Ca}^{2+}$ and several potassium currents and on the triggered arrhythmias (formation of delayed afterdepolarizations).

\section{Our results demonstrate:}

1) The endogenous Kir2.x channels associate with SAP97 forming signalling complexes. In DCM, the levels of Kir2.1 and Kir2.3 were upregulated but those of Kir2.2 channels were down-regulated. These adaptations could offer a new aspect for the explanation of the generally observed physiological and molecular alterations found in DCM. The SAP97 and Kir2.x ion channels may be novel target molecules in the diagnosis and effective treatment of cardiomyopathy.

2) We have demonstrated in vitro the potential inhibitory NCX blocking effect and of several carbocyclic nucleoside analogues (CNA) having different structures than from already known selective NCX blockers.

3) GYKB-6635 is the first compound that inhibits forward and reverse mode of the NCX current at submicromolar concentrations, and does not affect any other important transmembrane mechanisms involved in $\mathrm{Ca}^{2+}$-homeostasis and cardiac repolarization. In addition, GYKB-6635 compound proved to be effective against DAD related arrhythmias, since in isolated Langendorff perfused heart experiments prevented disturbances of the heart rhythm in ouabain induced arrhythmias in guinea pigs.

4) In conclusion, in the present study we describe a new and highly selective NCX inhibitor compound that may be suitable to test whether NCX blockade offers beneficial antiarrhythmic effects. 


\section{List of acronyms and abbreviations}

$\mathrm{AF}=$ atrial fibrillation

$\mathrm{ANPP}=$ atrial natriuretic peptide precursors

$\mathrm{AP}=$ action potential

$\mathrm{APA}=$ action potential amplitude

$\mathrm{APD}, \mathrm{APD}_{25}, \mathrm{APD}_{50}, \mathrm{APD}_{90}=$ action potential duration at 25,50 and $90 \%$ repolarization time.

$\mathrm{BNPP}=$ brain natriuretic peptide precursors

$\beta \mathrm{MHC}=\beta$-myosin heavy chain

$\mathrm{dV} / \mathrm{dt}_{\max }=$ maximum upstroke velocity of action potential

$\mathrm{CNA}=$ carbocyclic nucleoside analogues

$\mathrm{DAD}=$ delayed afterdepolarization

$\mathrm{DCM}=$ dilated cardiomyopathy

$\mathrm{EAD}=$ early afterdepolarization

HPRT= hypoxanthine-guanine phosphoribosyl-transferase

$\mathrm{HP}=$ holding potential

$\mathrm{I}_{\mathrm{CaL}}=\mathrm{L}$-type calcium current

IL-6= Interleukin-6

$\mathrm{I}_{\mathrm{NCX}}=$ sodium/calcium exchanger current

$\mathrm{I}_{\mathrm{Na}}=$ fast sodium current

$\mathrm{I}_{\mathrm{K} 1}=$ inward rectifier potassium current

$\mathrm{I}_{\mathrm{Kr}}=$ rapid component of the delayed rectifier potassium current

$\mathrm{I}_{\mathrm{Ks}}=$ slow component of the delayed rectifier potassium current

$\mathrm{I}_{\mathrm{to}}=$ transient outward potassium current

$\mathrm{NCX}=$ sodium/calcium exchanger

$\mathrm{RMP}=$ resting membrane potential

$\mathrm{SCD}=$ Sudden cardiac death

SAP97 $=$ Synapse-Associated Protein 97

UCHL-1= ubiquitin carboxyl-terminal esterase L1

$\mathrm{VEB}=$ ventricular extrasystole and bigeminia

$\mathrm{VT}=$ Ventricular tachycardia

$\mathrm{VF}=$ Ventricular fibrillation 


\section{Introduction}

Cardiovascular diseases, and in particular, cardiac arrhythmias, such as ventricular fibrillation have a leading role in mortality in developed countries. The most serious ventricular arrhythmia - ventricular fibrillation - causes the death of more than 3.000 .000 people all over the world and 300.000 - 350.000 people in the USA and Europe annually, which statistically means that one person dies every minute on each continent. In Hungary exact data are not available, but according to calculations there are $25.000-26.000$ sudden cardiac death cases annually, or 50-60 deaths per day. In the majority of the cases sudden cardiac death occurs when victims are not in hospital, consequently, survival probability is very low. Most frequently (50\%) the background of the on-the-spot diagnosed circulation collapse is ventricular tachycardia /fibrillation/. Sudden cardiac death (SCD) is often the very first sign of the symptom-free cardiovascular disease. SCD is a complex national health problem affecting families and having significant social and economic consequences, since usually it is the head of the family, a seemingly healthy man, who dies tragically. Survivors of the crisis can live a life of full volume in good conditions provided that they get the most appropriate treatment. Accordingly, cardiac arrhythmias represent a major area of cardiovascular research (Volders et al. 2000; Pogwizd et al. 2001). One of the main goals of pharmacological research is to develop a safe ventricular antiarrhythmic drug that can be applied either in acute cases or for treating postinfarction patients.

According to the classification of Vaughan Williams (1970), based on electrophysiological actions, the antiarrhythmic drugs can be defined by four classes (Singh and Vaughan Williams, 1970; Singh, 1972; Nattel and Singh, 1999). Class I consist of antiarrhythmic agents that block sodium channels, reducing the maximum increase rate of depolarization $\left(\mathrm{V}_{\max }\right)$. Class II agents are the $\beta$-blockers, the Class III drugs act through delaying repolarization of cardiac myocytes (potassium-channel blockers), and thus cause a lengthening of action potential duration (APD), while Class IV antiarrhythmic drugs block calcium currents in cardiac tissue. Later The Sicilian Gambit (Table 1), introduced in 1991, was an attempt to provide a classification of antiarrhythmic drugs based on their mechanism of action and on arrhythmogenic mechanism (The Sicilian Gambit contributors, 1991; Singh, 1999). 
Table 1. The Vaughan Williams classification of antiarrhythmic drugs (adapted from Singh 1999).

\begin{tabular}{|l|l|l|l|}
\hline \multicolumn{1}{|c|}{$\begin{array}{c}\text { Drugs I } \\
\text { channel mediated conduction }\end{array}$} & $\begin{array}{c}\text { Class II } \\
\text { Sympathetic } \\
\text { antagonists }\end{array}$ & $\begin{array}{c}\text { Class III } \\
\text { Drugs that } \\
\text { prolong } \\
\text { repolarisation }\end{array}$ & $\begin{array}{c}\text { Class IV } \\
\text { Calcium } \\
\text { antagonists }\end{array}$ \\
\hline $\begin{array}{l}\text { IA } \\
\text { Depress phase 0 } \\
\text { Delay conduction } \\
\text { Prolong repolarisation } \\
\text { Disopyramide, Procainamide, } \\
\quad \text { Quinidine }\end{array}$ & $\begin{array}{l}\text { Acebutolol } \\
\text { Betaxolol } \\
\text { Bisoprolol } \\
\text { Bucindolol } \\
\text { Carvedilol } \\
\text { IB }\end{array}$ & $\begin{array}{l}\text { Amiodarone } \\
\text { Azimilide } \\
\text { Bretylium } \\
\text { Dofetilide } \\
\text { Ibutilide } \\
\text { Sotalol }\end{array}$ & $\begin{array}{l}\text { Diltiazem } \\
\text { Nifedipine } \\
\text { Nisoldipine } \\
\text { Verapamil }\end{array}$ \\
tissue effect on phase 0 in normal & $\begin{array}{l}\text { Metoprolol } \\
\text { Nadolol } \\
\text { Depress phase 0 in abnormal tissue } \\
\text { Shorten repolarisation or little effect } \\
\text { Diphenylhydantoin, Lidocaine, } \\
\quad \text { Mexiletine, Tocainide }\end{array}$ & $\begin{array}{l}\text { Propranolol } \\
\text { Timolol }\end{array}$ & \\
Others & & \\
IC & & \\
Markedly depress phase 0 & & \\
Markedly slow conduction & & \\
Slight effect on repolarisation & & \\
- Flecainide, Moricizine, & & \\
$\quad$ Propafenone & & & \\
\hline
\end{tabular}

In the past, drug treatment of cardiac arrhythmias has proven difficult, both because of inadequate effectiveness and a risk of serious complications. In spite of the important advances in cardiology, the pharmacological treatment of cardiac arrhythmias remained empiric to a large extent because of our incomplete understanding of either physiological and pathophysiological processes underlying the cardiac rhythm disturbances and the mechanisms by which antiarrhythmic drugs prevent, suppress, and in some cases also induce, arrhythmias. Therefore, in order to develop new more effective agents with less proarrhythmic potency, it is important to understand the mechanism of action of antiarrhythmic drugs at the organ, tissue, cellular and also subcellular levels (Nattel and Carlsson 2006; Nattel et al. 2008).

The appearance of cardiac arrhythmias can be explained by abnormal impulse formation or by abnormal impulse propagation, and often by the combination of the two. In acute ischaemia the myocytes become depolarised, mainly due to potassium accumulation in the ischaemic region, which results in slowing of the impulse conduction. The action potential 
duration (APD) and the effective refractory period (ERP) can be shortened as a result of the opening of ATP sensitive potassium channels ( $\mathrm{K}_{\text {ATP }}$ channels). These arrhythmogenic factors can facilitate re-entry type cardiac arrhythmias. These latter disadvantageous changes may be influenced by numerous alternative ways, among which we also have focussed in this study for example the possible antiarrhythmic mechanisms occurring via the blockade of the: $i$ ) one of the main potassium current present in ventricular tissue, the inward rectifier potassium current $\left(\mathrm{I}_{\mathrm{k} 1}\right)$; ii) the inhibition of sodium calcium exchanger $(\mathrm{NCX})$, which is considered as a crucial contributor to $\mathrm{Ca}^{2+}$ homeostasis in the myocardium (Bers, 2000; Bers, 2002).

Dilated cardiomyopathy $(\mathrm{DCM})$ is a myocardial disorder characterized by left ventricular dilation and systolic dysfunction often leading to progressive heart failure, arrhythmias and premature death (Csanády et al. 1991; Jefferies and Towbin 2010). DCM is associated with increased APD, decreased resting membrane potential (RMP), and the wholecell current slope conductance in cells of DCM is smaller than that for donor or ischemic cardiomyopathy (Koumi et al. 1995). As a chronic multifactorial disease, DCM is likely to affect multiple clusters of genes. Marked alterations were observed in the characteristics of the inward rectifier potassium current $\left(\mathrm{I}_{\mathrm{K} 1}\right)$, but not of the sodium current $\left(\mathrm{I}_{\mathrm{Na}}\right)$ in ventricular myocytes of DCM patients as compared to donors (Koumi et al. 1995). The $\mathrm{I}_{\mathrm{K} 1}$ current plays a major role for maintaining the cellular resting membrane potential and it is involved in the consequences of DCM such as in the arrhythmogenesis of coronary artery disease and ventricular arrhythmias with sudden cardiac death (Csanády et al. 1991; Hibino et al. 2010). However, the molecular mechanisms underlying these alterations of $\mathrm{I}_{\mathrm{K} 1}$ are still largely unknown.

$\mathrm{I}_{\mathrm{K} 1}$ current is conducted via ion channels consisting of heteromeric assemblies of Kir2.1, Kir2.2 and Kir2.3 $\alpha$-subunits (Marban 2002; Rook 2007). To shed more light on the contribution of $\alpha$-, $\beta$ - and auxiliary-subunits of Kir channels to the pathomechanism of DCM, we studied the alterations in gene expression at RNA and protein level in DCM diseased hearts as compared to undiseased controls.

$\mathrm{I}_{\mathrm{K} 1}$ can strongly influence the final repolarization in cardiac muscle (Muňoz et al. 2007). It also regulates diastolic membrane conductance (Rook 2007). The current is active during the time course of the action potential (AP), but the molecular basis is poorly characterized. $\mathrm{I}_{\mathrm{K} 1}$ is underlied mostly by Kir2.x (Kir2.1, Kir2.2, Kir2.3 and Kir2.4) ion channels (Karle et al. 2002; Marban 2002; Rook 2007). Earlier the asymmetrical distribution and apico-basal inhomogeneity of Kir ion channels were investigated by Szabó et al. (2005) 
and Szentandrássy et al. (2005) showing that there are no transmural differences at the protein level of Kir2.1 channels in human and dog ventricle.

The physiological functions of ion channels are strongly influenced by intracellular scaffolding, trafficking and regulatory proteins. It was recently demonstrated that the Kir2.1, Kir2.2 and Kir2.3 isoforms colocalize with membrane associated guanylate kinase (MAGUK) proteins such as Synapse-Associated Protein (SAP97) and PSD-95 in cardiac muscle (Leonuodakis et al. 2000, 2004). Evidence has accumulated that the Kir2.x isoforms interact with protein complexes that may be important to target and traffic ion channels, anchor and stabilize those into the plasma membrane (Vaidyanathan et al. 2010) and the altered function in patients may lead to severe heart diseases, even SCD.

One arrhythmogenic factor that can result in ventricular arrhythmias occurring in myocardial ischaemia or poisoning with digitalis is delayed afterdepolarization (DAD), which arises in heart muscle cells following $\mathrm{Ca}^{2+}$ overload. Reducing the incidence of these trigger mechanism, the delayed afterdepolarization (DAD) or their pharmacological blockade would be extremely desirable from a clinical point of view.

Among several other currents and transporters, maintenance of the $\mathrm{Ca}^{2+}$ homeostasis in the myocardium is mainly regulated by the sodium-calcium exchanger (NCX) (Bers, 2000; Bers, 2002; Baczkó et al. 2003 Venetucci et al. 2007; Voigt et al. 2012). Mammalian $\mathrm{Na}^{+} / \mathrm{Ca}^{2+}$ exchangers are members of three branches of a much larger family of transport proteins, the CaCA superfamily $\left(\mathrm{Ca}^{2+} /\right.$ cation antiporter), whose main role is to provide control of $\mathrm{Ca}^{2+}$ flux across the plasma membranes or intracellular compartments. Since cytosolic levels of $\mathrm{Ca}^{2+}$ are much lower than those found extracellularly or in sequestered stores, the major function of NCX is to extrude $\mathrm{Ca}^{2+}$ from the cytoplasm. The exchangers are, however, fully reversible and thus, under special conditions of subcellular localization and compartmentalized ion gradients, NCX may allow $\mathrm{Ca}^{2+}$ entry and may play more specialized roles in $\mathrm{Ca}^{2+}$ movement between compartments. The NCX branch of $\mathrm{Na}^{+} / \mathrm{Ca}^{2+}$ exchangers comprises three members: NCX1 has been most extensively studied, and is broadly expressed with particular abundance in heart, brain and kidney, NCX2 is expressed in brain, and NCX3 is expressed in brain and skeletal muscle (Lytton, 2007). By today $\mathrm{Na}^{+} / \mathrm{Ca}^{2+}$ exchange has been relatively well characterized and its role in cardiac $\mathrm{Ca}^{2+}$-homeostasis clarified (Reeves 1998; Egger et al. 1999a; Philipson et al. 2000, Hilgemann 2004), however, there are still many unanswered questions regarding its possible role in cardiac function, both in healthy and diseased conditions. During the cardiac cycle due to the dynamically changing membrane potential and intracellular $\mathrm{Na}^{+}$and $\mathrm{Ca}^{2+}$ concentrations, a transmembrane ion 
current can be generated by the NCX, which may contribute to intracellular $\mathrm{Ca}^{2+}$-gain and loss and due to its electrogenic nature can influence AP repolarization and depolarization as well (Venetucci et al. 2007). Indeed, while NCX has been unequivocally recognized as a promising target for the treatment of multiple diseases due to pathological $\mathrm{Ca}^{2+}$-homeostasis, progress is seriously hampered by theoretical and practical limitations. Neither our current knowledge on NCX structure/function relationship is complete, nor the selectivity of current NCX modulators are satisfactory. It is known that NCX, at the forward mode, extrudes $\mathrm{Ca}^{2+}$ from the cell to the extracellular space during diastole, at relatively low free cytoplasmic $\mathrm{Ca}^{2+}$ concentration and negative transmembrane potential. Since the extrusion of one $\mathrm{Ca}^{2+}$ is coupled with $3 \mathrm{Na}^{+}$entering the cell, during the forward mode of the NCX net inward current is carried, which can cause substantial depolarization leading to early (EAD) and delayed (DAD) after-depolarizations, especially when intracellular $\mathrm{Ca}^{2+}$ is elevated. EAD and DAD is generally thought to play an important role in arrhythmogenesis (Volders et al. 2000, Yang and Roden 1996; Pogwizd and Bers, 2002), especially in conditions where potassium conductance is decreased, such as heart failure (Pogwizd et al. 2001). Therefore, one may speculate that specific blockers of NCX could be potential antiarrhythmics in dysrhythmias related to $\mathrm{Ca}^{2+}$ overload (Pogwizd and Bers, 2002; Pogwizd, 2003). This hypothesis could not be directly tested since the available NCX inhibitors, at least in higher concentrations, also decreased $\mathrm{I}_{\mathrm{Ca}}$, which in turn decreased intracellular $\mathrm{Ca}^{2+}$ load, thereby indirectly changing the magnitude of NCX. In 1996 it was found that KB-R7943, an effective inhibitor of NCX in the reverse mode but not in the forward mode (Elias et al. 2001), reduced the incidence of ischaemia and reperfusion arrhythmia induced by calcium overload (Watano et al. 1999; Magee et al. 2003). However, KB-R7943 also inhibits the L-type calcium current (Birinyi et al. 2005) which makes the interpretation of its antiarrhythmic effect rather uncertain.

Summarizing all these, we may conclude that due to lack of highly selective and efficacious NCX blockers, there are still no direct clear experimental evidences regarding the effect of NCX inhibition on the cardiac action potential waveform and repolarization, and such effects can have a significant impact on arrhythmia substrate and arrhythmogenesis by influencing dispersion of repolarization and refractoriness. This unmet need provides a rationale for pharmacologists and medicinal chemists to get more involved in NCX research by designing and developing novel compounds to modulate NCX activity.

During the past decade, the discovery of carbocyclic nucleosides possessing potent antiviral and antitumor activity has led to an increasing demand for the production of new chiral, alicyclic nucleoside analogues (De Clerq E, 2005; Schneller, 2002; Ichikawa and Kato, 
2001). Bioisosteric replacement of the oxygen in the sugar moiety with a methylene unit makes these compounds more resistant to hydrolysis without loss of the biological activity. Some of the carbanucleotides possess noteworthy pharmacological activity, such as the antiviral North-methanocarbathymidine $(\mathrm{N}-\mathrm{MCT})$ or the species-independent $\mathrm{A}_{3}$ receptor-selective agonist ( $N$ )-methanocarba-adenosine 5'-uronamides (Ugliarolo et al. 2009; Kumamoto et al. 2009). Most of the articles and patents focused on the antiviral and anticancer activity of carbocyclic nucleosides, cardioprotective activity was described in a few cases only.

Therefore, in the present study carbocyclic nucleoside analogues (CNA) as potential novel selective inhibitors of NCX current and their effect on DAD related and ischemia-reperfusion (IR) induced cardiac arrhythmias are investigated. The structures of these CNA compounds basically differ from the already known selective NCX blockers, like KB-R7943 and SEA-0400 or from ORM-10103 (Jost et al. 2013). The compounds according to the present investigation belong to a chemically well-marked group of compounds the NCX inhibitor activity of which has not been described yet. Several compounds were synthetized and investigated. A particular attention was played to investigate the effects of the CNA derivate and highly selective novel NCX inhibitor GYKB-6635 [(4-amino-1-[((1R,2S,3S,5R)2,3-dihydroxy-6,6-dimethylbicyclo[3.1.1]heptan-2-yl)methyl]pyrim idin-2(1H)-one) on the NCX current, cardiac ventricular action potentials and to determine its antiarrhythmic effects.

\section{Major specific experimental goals}

The main goals of my $\mathrm{PhD}$ work was to investigate: (i) the remodelling effect of one specific cardiac disease on the repolarization; (ii) the pharmacological modulation of the cardiac arrhythmias by affecting a novel pharmacological target. Thereby the specific goals were as follows:

a) To analyse the contribution of different auxiliary proteins to the altered expression of genes for Kir2.x ion channels in dilated cardiomyopathy.

b) To investigate and compare the effects of several newly synthetized NCX blockers on several mammalian hearts. Selection of a lead NCX blocker compound for further analysis.

c) To investigate the electrophysiological effects of the lead compound GYKB-6635, a newly synthetized specific NCX inhibitor, on the NCX, L-type $\mathrm{Ca}^{2+}$ and several potassium currents and on the triggered arrhythmias (formation of delayed afterdepolarizations). 


\section{Materials and methods}

\subsection{Experiments in animal preparations}

The in vitro electrophysiological (standard microelectrode and patch-clamp techniques) measurements were performed in dog cardiac preparations. Langendorff perfused guinea hearts were used for ouabain induced arrhythmia studies.

\subsubsection{Preparations}

Adult mongrel dogs of either sex weighing 8 to $16 \mathrm{~kg}$ and guinea pigs of either sex weighing 300-500 obtained from a recognized supplier were used for the study. All experiments were conducted in compliance with the Guide for the Care and Use of Laboratory Animals (USA NIH publication No 85-23, revised 1996) and conformed to Directive 2010/63/EU of the European Parliament. The protocols were approved by the Review Board of the Department of Animal Health and Food Control of the Ministry of Agriculture and Rural Development, Hungary (XIII./1211/2012).

\subsubsection{In vitro investigations: ion current measurements by applying the patch-clamp technique}

\section{Cell isolation from dog left ventricular cardiac preparations}

Following sedation xylazine $(1 \mathrm{mg} / \mathrm{kg}, i . v$. $)$ and thiopental $(30 \mathrm{mg} / \mathrm{kg}$ i.v. $)$ induced anaesthesia, the dog heart was rapidly removed through a right lateral thoracotomy and immediately rinsed in oxygenated modified Locke's solution containing (in $\mathrm{mM}$ ): $\mathrm{NaCl} 120$, $\mathrm{KCl} 4, \mathrm{CaCl}_{2} 1.0, \mathrm{MgCl}_{2} 1, \mathrm{NaHCO}_{3} 22$, and glucose 11 . The $\mathrm{pH}$ of this solution was set between 7.35 and 7.4 when saturated with the mixture of $95 \% \mathrm{O}_{2}$ and $5 \% \mathrm{CO}_{2}$ at $37{ }^{\circ} \mathrm{C}$.

Ventricular myocytes were enzymatically dissociated from the canine hearts. A portion of the left ventricular wall containing an arterial branch large enough to cannulate was then perfused in a modified Langendorff apparatus, at a pressure of $60 \mathrm{~cm} \mathrm{H}_{2} \mathrm{O}$, with solutions in the following sequence: 1$)$ isolation solution supplemented with $\mathrm{CaCl}_{2}(1.25 \mathrm{mM})$ for $10 \mathrm{~min}$; 2) isolation solution for another $10 \mathrm{~min}$; 3) isolation solution (150 ml) containing collagenase (type I, $0.33 \mathrm{mg} / \mathrm{ml}$; Sigma Chemical, St. Louis, MO, USA) (10 min). Protease (type XIV, $0.04 \mathrm{mg} / \mathrm{ml}$; Sigma Chemical) was added to the final perfusate and another 15-20 min of digestion was allowed. The isolation solution $\left(\mathrm{Ca}^{2+}\right.$-free $)$ was Eagle, Minimum 
Essential Medium, Joklik modification (Sigma), supplemented with (in mM) HEPES 10 and $\mathrm{NaHCO}_{3} 4.4$ (pH 7.2, adjusted with $\mathrm{NaOH}$ ). Portions of the left ventricular wall judged to be well digested were diced into small pieces in isolation solution supplemented with $\mathrm{CaCl}_{2}$ $(1.25 \mathrm{mM})$ for $15 \mathrm{~min}$. These tissue samples were then gently agitated in a small beaker to dislodge single myocytes from the extracellular matrix. The resulting cell suspension contained a mixture of subepi-, midmyo- and subendocardial myocytes. Throughout the entire isolation procedure, solutions were gassed with $100 \% \mathrm{O}_{2}$ at $37{ }^{\circ} \mathrm{C}$. Myocytes were allowed to settle to the bottom of the beaker for $10 \mathrm{~min}$, after which half of the supernatant was replaced with fresh solution. This procedure was repeated 3 times. Myocytes placed in Tyrode solution were maintained at $12-14{ }^{\circ} \mathrm{C}$ prior to the experimentation.

\section{Experimental technique}

One drop of cell suspension was placed in a transparent recording chamber mounted on the stage of an inverted microscope (Olympus IX51, Olympus Inc., Tokyo, Japan), and individual myocytes were allowed to settle and adhere to the chamber bottom for at least 5-10 min before superfusion was initiated and maintained by gravity. Only rod-shaped cells with clear striations were used. HEPES-buffered Tyrode's solution (composition in mM: $\mathrm{NaCl}$ 144, $\mathrm{NaH}_{2} \mathrm{PO}_{4}$ 0.4, $\mathrm{KCl} 4.0, \mathrm{CaCl}_{2}$ 1.8, $\mathrm{MgSO}_{4}$ 0.53, glucose 5.5 and HEPES 5.0, at $\mathrm{pH}$ of 7.4) served as the normal superfusate.

Micropipettes were fabricated from borosilicate glass capillaries (Science Products GmbH, Hofheim, Germany), using a P-97 Flaming/Brown micropipette puller (Sutter Co, Novato, CA, USA), and had a resistance of 1.5-2.5 MOhm when filled with pipette solution. The membrane currents were recorded with Axopatch-200B amplifiers (Molecular Devices, Sunnyvale, CA, USA) by means of the whole-cell configuration of the patch-clamp technique. The membrane currents were digitized with $250 \mathrm{kHz}$ analogue to digital converters (Digidata 1440A, Molecular Devices, Sunnyvale, CA, USA) under software control (pClamp 10, Molecular Devices, USA). Experiments were carried out at $37^{\circ} \mathrm{C}$.

\section{Measurement of sodium/calcium exchanger (NCX) current}

For the measurement of the NCX current, the method of Hobai et al. (1997) was applied, in which special $\mathrm{K}^{+}$-free bath and pipette solutions were used in order to block the $\mathrm{Na}^{+}-, \mathrm{Ca}^{2+}-, \mathrm{K}^{+}$-currents and the $\mathrm{I}_{\mathrm{Na}+/ \mathrm{K}+}$ pump current. The I-V (current-voltage) relationship of NCX current was measured through the use of ramp pulses at $20 \mathrm{~s}$ intervals. The ramp pulse initially led to depolarization from the holding potential (HP) of $-40 \mathrm{mV}$ to $60 \mathrm{mV}$ with 
a rate of $100 \mathrm{mV} / \mathrm{s}$, then to hyperpolarization to $-100 \mathrm{mV}$, and depolarization back to the HP. The descending limb of the ramp was utilized to plot the I-V curve.

Compositions of solutions used (in $\mathrm{mM}$ ):

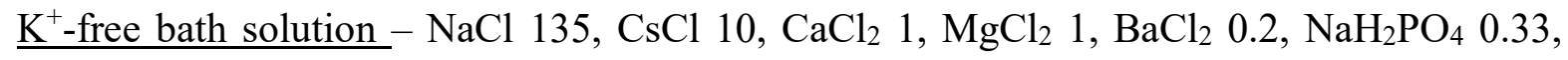
TEACl 10, HEPES 10, glucose 10 and ouabain $20 \mu \mathrm{M}$, nisoldipine $1 \mu \mathrm{M}$, and lidocaine 50 $\mu \mathrm{M}$, at $\mathrm{pH} 7.4$.

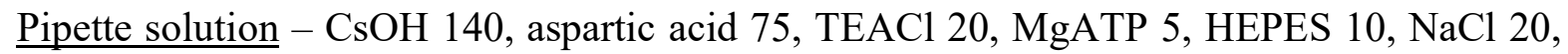
EGTA 20 and $\mathrm{CaCl}_{2} 10$ (pH adjusted to 7.2 with $\mathrm{CsOH}$ ).

The experimental protocol was as follows (Figure 1):

1) the whole cell configuration was established in HEPES-buffered Tyrode's solution; 2) the control $\mathrm{I}-\mathrm{V}$ curve was recorded in the special $\mathrm{K}^{+}$-free bath solution after 8-10 min from establishing whole cell configuration; 3) after $6-10$ min incubation the I-V relation was recorded in the presence of GYKB-6635; 4) at the end of the experiments the $\mathrm{Ni}^{2+}$ insensitive current was measured by the application of $10 \mathrm{mM} \mathrm{NiCl}_{2}$.

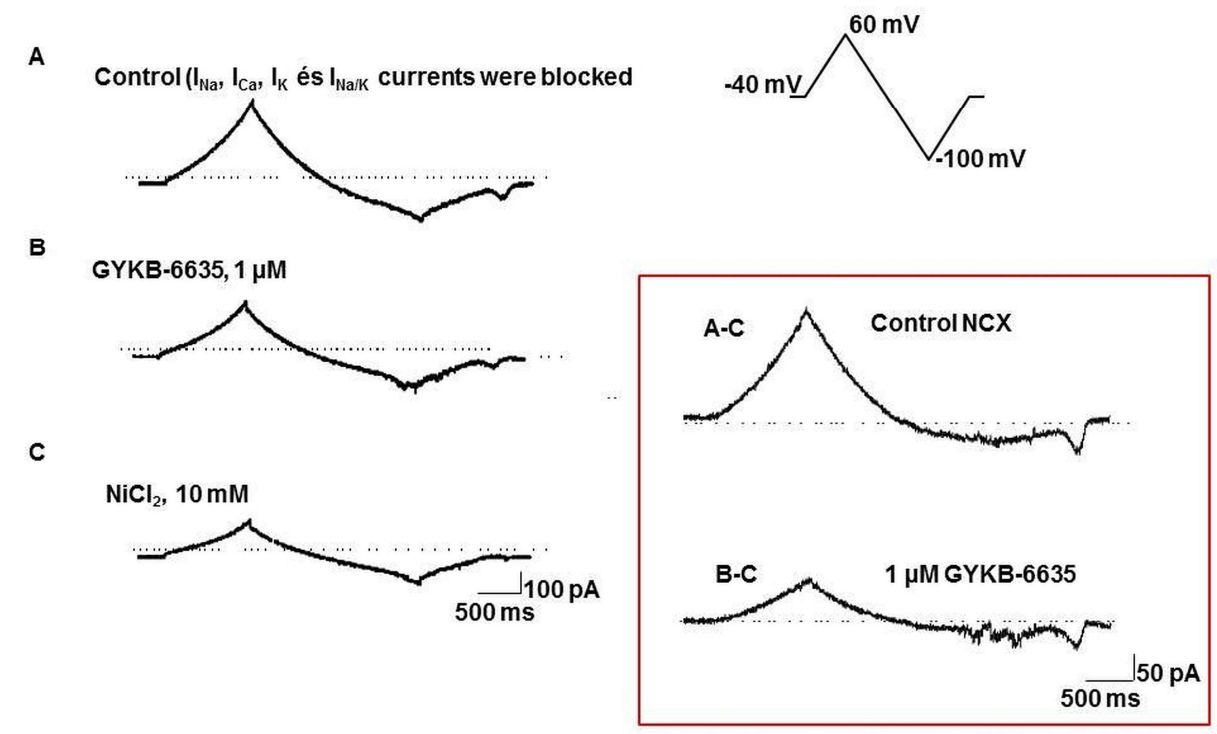

Figure 1. Determination of NCX current in canine ventricular myocytes. The protocol was adapted from Hobai et al. (1997). A: Recording obtained with the voltage protocol shown in the inset in control conditions (current trace after blockade of $\mathrm{Na}^{+}, \mathrm{Ca}^{2+}, \mathrm{K}^{+}$and $\mathrm{Na}^{+} / \mathrm{K}^{+}$pump currents. B: The current trace after superfusion with $1 \mu \mathrm{M}$ GYKB-6635. C: The current trace at the end of the measurements after the application of $10 \mathrm{mM} \mathrm{NiCl}_{2}$. On the right the control NCX current is shown, which is obtained by subtracting trace $\mathbf{C}$ from trace $\mathbf{B}$. The NCX current in the presence of $1 \mu \mathrm{M}$ GYKB-6635 is obtained by subtracting trace $\mathbf{B}$ from trace $\mathbf{C}$. Note the difference in the intensity-time calibration in the left and right panels.

Accordingly, the NCX current was defined as the $\mathrm{Ni}^{2+}$ - sensitive current i.e. the trace recorded in the presence of $10 \mathrm{mM} \mathrm{NiCl}_{2}$ subtracted from that measured in the absence of 
$\mathrm{NiCl}_{2}$. In separate experiments, the effect of ORM-10103 on the $\mathrm{Ni}^{2+}$ - insensitive current was also tested.

\section{Measurement of L-type calcium current}

The L-type calcium current $\left(\mathrm{I}_{\mathrm{CaL}}\right)$ was recorded in HEPES-buffered Tyrode's solution supplemented with $3 \mathrm{mM}$ 4-aminopyridine. The pipette solution contained (mM): $\mathrm{CsOH} 110$, $\mathrm{CsCl}$ 20, TEACl 10, MgATP 5, EGTA 5, HEPES 10 and GTP 0.1, pH was adjusted to 7.2 by aspartic acid). $\mathrm{I}_{\mathrm{CaL}}$ current was evoked by $400 \mathrm{~ms}$ long depolarizing voltage pulses to various test potentials ranging from $-35 \mathrm{mV}$ to $+55 \mathrm{mV}$ from the $\mathrm{HP}-80 \mathrm{mV}$. A short prepulse to -40 $\mathrm{mV}$ served to inactivate $\mathrm{I}_{\mathrm{Na}}$. The amplitude of $\mathrm{I}_{\mathrm{CaL}}$ was defined as the difference between the peak inward current at the beginning of the pulse and the current at the end of the pulse.

\section{Measurement of $K^{+}$currents}

The inward rectifier $\left(\mathrm{I}_{\mathrm{K} 1}\right)$, transient outward $\left(\mathrm{I}_{\mathrm{to}}\right)$, rapid $\left(\mathrm{I}_{\mathrm{Kr}}\right)$ and slow $\left(\mathrm{I}_{\mathrm{Ks}}\right)$ delayed rectifier potassium currents were recorded in HEPES-buffered Tyrode's solution. The pipette solution contained (mM): $\mathrm{KOH} \mathrm{110,} \mathrm{KCl} 40, \mathrm{~K}_{2} \mathrm{ATP} 5, \mathrm{MgCl}_{2}$ 5, EGTA 5, and HEPES 10 ( $\mathrm{pH}$ was adjusted to 7.2 by aspartic acid). $1 \mu \mathrm{M}$ nisoldipine was added to the external solution to eliminate $\mathrm{I}_{\mathrm{CaL}}$. When $\mathrm{I}_{\mathrm{Kr}}$ was recorded $\mathrm{I}_{\mathrm{Ks}}$ was inhibited by using the selective $\mathrm{I}_{\mathrm{Ks}}$ blocker HMR $1556(0.5 \mu \mathrm{M})$. During $\mathrm{I}_{\mathrm{Ks}}$ measurements, $\mathrm{I}_{\mathrm{Kr}}$ was blocked by $0.1 \mu \mathrm{M}$ dofetilide.

\subsubsection{In vitro investigations, AP measurements by applying the standard microelectrode technique}

For these experiments we have used the hearts extracted from the same adult mongrel dogs of either sex weighing 8-16 kg as described for voltage-clamp experiments. Papillary muscle pieces (subendocardial) obtained from the right ventricle were mounted individually in a tissue chamber superfused with oxygenated Locke's solution at $37{ }^{\circ} \mathrm{C}$. The average diameter of the papillary muscles was $2-3 \mathrm{~mm}$. In order to avoid core hypoxia the action potential measurements were measured from the surface layer of the papillary muscles. Each preparation was stimulated (HSE stimulator type 215/II), initially at a constant cycle length of $1000 \mathrm{~ms}$ (frequency $1 \mathrm{~Hz}$ ), with rectangular constant current pulses $2 \mathrm{~ms}$ in duration. The current pulses were isolated from ground and delivered through bipolar platinum electrodes in contact with the preparations. At least $1 \mathrm{~h}$ was allowed for each preparation to equilibrate during continuous superfusion with modified Locke's solution, warmed to $37^{\circ} \mathrm{C}$ before the 
experimental measurements commenced. Transmembrane potentials were recorded with the use of conventional 5-20 M, $3 \mathrm{M} \mathrm{KCl-filled} \mathrm{microelectrodes} \mathrm{connected} \mathrm{to} \mathrm{the} \mathrm{input} \mathrm{of} \mathrm{a}$ high-impedance electrometer (Experimetria Ltd., type 309, Budapest, Hungary). The maximum diastolic potential, action potential amplitude, maximum upstroke velocity $\left(\mathrm{V}_{\max }\right)$ and action potential duration measured at $50 \%$ and $90 \%$ of repolarization $\left(\mathrm{APD}_{50}\right.$ and $\mathrm{APD}_{90}$, respectively) were off-line determined using a home-made software running on an IBM compatible computer equipped with an ADA3300 analogue-to-digital data acquisition board (Real Time Devices Inc., State College, PA, USA) having a maximum sampling frequency of $40 \mathrm{KHz}$. In each experiment, the baseline action potential characteristics were first determined during continuous pacing at $1 \mathrm{~Hz}$, the preparations were next superfused with the drug for 40 $60 \mathrm{~min}$ and the parameters were measured again. Efforts were made to maintain the same impalement throughout each experiment. In case an impalement became dislodged, however, electrode adjustment was attempted and, if the action potential characteristics of the reestablished impalement deviated by less than 5\% from those of the previous measurement, the experiment was continued. When this $5 \%$ limit was exceeded, the experiment was terminated and all the data involved were excluded from the analyses.

Statistics

All data are expressed as means \pm SEM. Statistical analysis was performed with Student's $t$-test for paired data. Results were considered statistically significant when $\mathrm{P}<0.05$.

\subsubsection{Ex vivo investigations: ECG measurements in isolated Langendorff perfused heart experiments}

Guinea-pigs of either sexes weighing 300-500 g were used for these experiments. Animals were anaesthetised with sodium-pentobarbital $(500 \mathrm{mg} / \mathrm{kg}$, i.p.) and injected with heparin sodium (300 IU i.v.). Hearts were rapidly excised, mounted via the aorta on a Langendorff apparatus and perfused retrograde with warm $\left(37^{\circ} \mathrm{C}\right)$, modified Krebs-Henseleit bicarbonate (KHB) buffer at a constant pressure $(80 \mathrm{mmHg})$. The KHB solution contained (in mmol/l): $\mathrm{NaHCO}_{3} 25 ; \mathrm{KCl} 4.3 ; \mathrm{NaCl} 118.5 ; \mathrm{MgSO}_{4}$ 1.2; $\mathrm{KH}_{2} \mathrm{PO}_{4} 1.2 ;$ glucose 10; $\mathrm{CaCl}_{2} 1.8$, having a $\mathrm{pH}$ of $7.4 \pm 0.05$ when gassed with carbogene $\left(95 \% \mathrm{O}_{2}+5 \% \mathrm{CO}_{2}\right)$. Perfusion flow and the electrocardiogram (ECG) were simultaneously recorded using the open access WinWCP software developed by John Demspter (V4.9.1. Whole Cell Electrophysiology Analysis Program, University of Strathclyde, UK). 
Arrhythmia diagnosis: For the induction of arrhythmia we used ouabain $(4 \mathrm{mg} / \mathrm{L}$, Sigma Chemical) and the drug (GYKB-6635) or solvent were administered 10 minutes before starting ouabain perfusion. The GYKB-6635 was solved in DMSO, and the control group contained only DMSO solvent. Ventricular extra beat (VEB), bigeminia, salvo, ventricular tachycardia (VT) and ventricular fibrillation (VF) were defined according to the Lambeth Conventions I and II, respectively (Walker et al. 1988; Curtis et al. 2013).

Statistics: All data from independent samples. Following data were expressed as mean \pm standard error of the mean (S.E.M.) and the groups were compared in pairs by means of the "t-test". Statistically significant differences are marked in figures by $* p<0.05$.

\subsection{Experiments in human preparations}

\subsubsection{Preparation of human cardiac muscles}

Hearts were obtained from organ donors whose hearts were explanted to obtain pulmonary and aortic homografts for valve surgery. Before cardiac explantation, organ donors $(n=31)$ did not receive medication apart from dobutamine, furosemide, and plasma expanders. The investigations conform to the principles of the Declaration of Helsinki. Experimental protocols were approved by the University of Szeged and National Scientific and Research Ethical Review Boards (No. 51-57/1997 OEj and 4991-0/2010-1018EKU (339/PI/010.)). Before explantation, each heart was perfused with cardioplegic solution (University of Debrecen, Hungary) and kept cold $\left(4-6{ }^{\circ} \mathrm{C}\right)$ for 2-4 hours prior to dissection (Gaborit et al. 2009). Failing heart tissues were obtained from patients with diagnosed dilated cardiomyopathy (DCM) who underwent heart transplantation and had end-stage heart failure (class of failing according to the New York Heart Association (NYHA), class III or IV). The DCM patients were 4 females and 13 males aged between 13-55 years (average 41.53 \pm 14.50 years). Left ventricular biopsy samples were dissected from free wall of undiseased donor hearts and patients with DCM representing altogether epi-, mid- and endocardial layers.

\subsubsection{IK1 current measurements by applying the whole-cell patch-clamp technique}

Cardiomyocytes were isolated from left ventricular tissues (31 undiseased donors and 4 failing) by enzymatic dissociation as previously described (Jost et al. 2005). HEPESbuffered Tyrode's solution (composition in mM: $\mathrm{NaCl} 144, \mathrm{NaH}_{2} \mathrm{PO}_{4} 0.33, \mathrm{KCl} 4.0, \mathrm{CaCl}_{2}$ 
1.8, $\mathrm{MgCl}_{2}$ 0.53, glucose 5.5 and HEPES 5.0, at $\mathrm{pH}$ of 7.4) served as the normal superfusate. For measuring $\mathrm{K}^{+}$currents electrodes were filled with pipette solution containing $100 \mathrm{mM} \mathrm{K}$ -

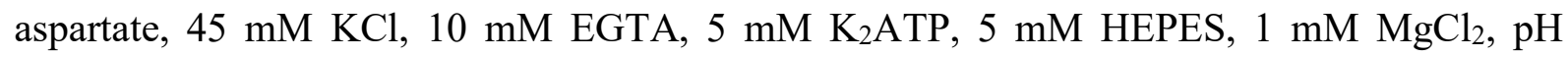
adjusted to 7.2 with $\mathrm{KOH}$. All reagents were purchased from SIGMA, St. Louis, MO, USA.

Transmembrane potassium currents were recorded and analysed in similar conditions as described earlier at Chapter 5.1.2.

\subsection{3. mRNA expression investigations by applying the qRT-PCR technique}

Real-time quantitative reverse transcriptase-polymerase chain reaction (qRT-PCR) RNA samples were isolated using the RNeasy_Fibrous Tissue Kit (Qiagen). Total RNA concentration and quality were determined by NanoDrop (ND-1000, USA) and the integrity of all total RNA samples was confirmed measuring 18S rRNA content. For in vitro reverse transcription, $2 \mu \mathrm{g}$ of total RNA was reverse transcribed using the Stratagene Reverse Transcriptase Kit (Invitrogene, BioMedica Hungarian Ltd, Hungary) following the instruction manual $\left(25^{\circ} \mathrm{C}, 10 \mathrm{~min}, 37^{\circ} \mathrm{C}, 120 \mathrm{~min}, 85^{\circ} \mathrm{C}, 5 \mathrm{~min}\right.$ and kept at $\left.4^{\circ} \mathrm{C}\right)$ (Zvara et al. 2005).

Each RNA sample was tested for the presence of genomic DNA contamination. Genespecific primers were designed using Primer Express software (PE Applied Biosystems, Life Technologies, USA) according to the software guidelines. These primers were purchased from Avidin Ltd. (Szeged, Hungary). Quantitative PCR was carried out using the Brillant II SYBRGreen QPCR Master Mix Kit (Stratagene, Agilent Tech., USA), following the

instruction manual. PCR reactions were then performed first on the Open Array ${ }^{\mathrm{TM}}$ platform (OpenArray system formerly Biotrove, now Applied Biosystems, Life Technologies, USA) (12 undiseased, control and 12 diseased, DCM), and then validated with the Rotor Gene 3000 (Corbett Research, Australia; 31 control and 17 DCM patients).

Specific primers selected for their cardiac expression were designed for: (i) Kir ion channels coding genes Kir2.1, Kir2.2, Kir2.3, Kir2.4 (KCNJ2, KCNJ12, KCNJ4, KCNJ14), Kir3.1, Kir3.4, Kir6.1 and Kir 6.2); (ii) SUR1, SUR2 (KCNJ3, KCNJ5, KCNJ8, KCNJ9 and $A B C C 8, A B C C 9$ ); (iii) $\mathrm{K}^{+}$channel $\alpha$ - and $\beta$-subunits, and SAP97 (DLG1); (iv) marker genes 8 for ubiquitin carboxyl-terminal esterase L1 (ubiquitin thiolesterase, UCHL1); (v) interleukin-6 (IL-6), three hypertrophy as well as end-stage markers for atrial natriuretic peptide precursor, brain natriuretic peptide precursors, $\beta$-myosin heavy-chain (ANPP, BNPP, $\beta$-MHC); (vi) four reference genes for normalization: hypoxanthine guanine phosphoribosyl 
transferase (HPRT), glycerol-6-phosphate dehydrogenase (GAPDH), S18 and $\beta$-actin $(A C T B)$.

All data were collected with instrument spectral compensation with Rotor Gene 3000 SDS 2.1 software and analyzed with the threshold cycle $\left(C_{\mathrm{t}}\right)$ relative-quantification method (Livak and Schmittgen 2001). The most uniformly distributed genes were selected for data normalization as HPRT gene and GAPDH (for comparison with literature data). The relative expression of each gene versus HPRT and/or GAPDH was calculated for each sample $\left(\Delta C_{\mathrm{t}}\right.$ indicates normalized data).

Data were analyzed in two independent ways. (1) Open Array ${ }^{\mathrm{TM}}$ software was applied to the gene-expression profile. Then Kir2.x and SAP97 mRNA levels were validated with RT-qPCR using the Rotor Gene 3000 version 6.0 software. For each compartment, the relative expression of each gene versus HPRT ( $2^{-\Delta C t}$ values) and/or GAPDH were calculated. Throughout the paper values are given as mean \pm SEM. Data for undiseased hearts versus diseased samples were calculated by Pfaffl method as described earlier (Pfaffl 2001; Zvara et al. 2005). Pair-wise comparisons between cardiac compartments were conducted on withinpatient matched samples by Student's paired $t$ test ( $p<0.05$ considered significant, $\mathrm{n}=12-17$ ). Unpaired $t$ tests were used for unmatched samples. The repeated measurements were analyzed by ANOVA followed by Bonferroni's multiple comparison post-tests. Significance values are labelled as $*, p<0.05 ; * *, p<0.03 ; * * *, p<0.01$.

\subsubsection{Protein expression investigation by applying the Western blot analysis}

Membrane proteins were extracted from the ventricle of human undiseased donor or DCM heart using Lysis buffer. Aliquots of equal protein content were separated using 8\% SDS-polyacrylamide gel electrophoresis and transferred to polyvinylidine difluoride (PVDF) filter (EMD Millipore, USA) at $280 \mathrm{~mA}$ for $2.5 \mathrm{~h}$ at $4^{\circ} \mathrm{C}$, in order to evaluate immunoreactivity. All materials were purchased from Sigma Chemical. Then filters were incubated overnight at $4{ }^{\circ} \mathrm{C}$ with the primary antibodies in Tris-buffer supplemented with Tween-20 (TBST): anti-Kir2.1, anti-Kir2.2, anti-Kir2.3 antibodies (Alomone, diluted 1:100), anti-Kir2.4 (SantaCruz, USA, diluted 1:100), anti-SAP97 (LifeSpan, Bioscience Ltd., Hungary), anti- $\alpha$-actin (Dako Corporation, USA; diluted 1:500) and anti-GAPDH antibodies (Sigma, diluted 1:5000). Filters were washed and incubated with horseradish peroxidaseconjugated IgG (Dako Corporation, Agilent Tech., USA or Sigma Chemical, USA) specific to the source of the primary antibody. The immune complexes were detected using the ECL- 
Western blotting detection system (Amersham Pharmacia Biotech, UK) following the manufacturer's instructions. The membranes, stripped at $60{ }^{\circ} \mathrm{C}$ for $30 \mathrm{~min}$ in stripping buffer (100 mM 2-mercapto-ethanol and $62.5 \mathrm{mM}$ Tris-HCl, $\mathrm{pH}$ 7.6), were re-probed with antiGAPDH and/or anti $\alpha$-actin antibody to normalize for loading differences.

Data analysis of the bands

X-ray films (Kodak, USA) were scanned and evaluated with Image J software v. 1.32 (NIH, www.nih.gov). Densities of specific bands were measured and corrected for the densities of the GAPDH on the same membrane. Corrected optical densities were calculated and the differences between undiseased and DCM samples were evaluated using ANOVA and Student $t$ - test. Data are represented as means \pm SEM.

\subsubsection{Immunofluorescence investigations by applying confocal microscopy}

Cryostat sections $(10 \mu \mathrm{m})$ of undiseased and DCM heart ventricle biopsies were treated with $0.5 \%$ collagenase, blocked with $2 \%$ BSA in calcium-free phosphate-buffered saline (PBS) and incubated for $2 \mathrm{~h}$ at room temperature with rabbit anti-Kir2.x (diluted 1:100; Alomone and Sigma) and mouse anti-SAP97 antibodies (diluted 1:300; LifeSpain, Biosience, BioMedica Ltd.). Sections were then washed and incubated with Alexa 488-labeled anti rabbit IgG (diluted 1:400; Molecular Probes) plus Cy3-conjugated anti- mouse IgG (diluted 1:400; Jackson Immunoresearch Lab. Inc., USA) for $1 \mathrm{~h}$ at room temperature. Nuclei were stained with $1 \mu \mathrm{g} / \mathrm{ml}$ Hoechst 33258 in PBS for 10 min (method modified after Piecha et al. 1999). After rinsing, the sections were mounted with fluorescent mounting medium (Dako Corporation, USA), viewed and photographed with a Nikon Eclipse E600 microscope equipped for epifluorescence and Spot RT Slider camera or confocal laser scanning microscope using an Olympus Fluoview FV1000 (Olympus GmbH, Hamburg, Germany). For each specimen ( $\mathrm{n}=2-3$ for each anti-Kir2.x antibody staining) 20-80x field images were selected from the free wall of ventricle to represent the variability in Kir2.x expression.

\subsection{Drugs and chemicals}

With the exception of nisoldipine (gift from Bayer AG, Germany) and HMR-1556 (gift from Aventis Pharma, Germany) all chemicals were purchased from Sigma Chemical or Sequoia Chem (UK). Test drugs were dissolved in general mainly by DMSO, respectively to yield appropriate stock solutions. These stock solutions were diluted to reach the desired final concentration (DMSO concentration not exceeding $0.1 \%$ ) in the bath. 


\section{Results}

\subsection{The investigation of the expression of genes for Kir ion channel isoforms in dilated cardiomyopathy}

Dilated cardiomyopathy (DCM) is a multi-factorial disease characterized by left ventricular dilation that is associated with systolic dysfunction and increased action potential duration. The Kir2.x $\mathrm{K}^{+}$channels (encoded by KCNJ genes) regulate the inward rectifier current $\left(I_{K 1}\right)$ contributing to the final repolarization in cardiac muscle. Here, we describe the transitions in the gene expression profiles of four $K C N J_{S}$, from non-diseased to dilated cardiomyopathic human hearts.

\subsubsection{Testing DCM samples for characteristic marker gene expression}

To confirm the diseased status several marker genes known to be associated with heart disease were selected and relative mRNA levels were checked in the left ventricle of DCM hearts. As in previous reports (Gaborit et al. 2007, 2009; Borlak and Thum 2003; Soltysinska et al. 2009; Barrans et al. 2002), steady state mRNA levels for atrial natriuretic peptide precursor (ANPP/NPPA) and brain natriuretic peptide precursors (BNPP/NPPB) were increased to $>5$-fold and 3.5-fold, respectively, in patients relative to controls (Figure 2a). Significant increase was also found for ubiquitin carboxyl-terminal esterase L1 (ubiquitin thiolesterase, UCHL1) (Figure 2b), whereas mRNA level for $\beta$-myosin heavy chain ( $\beta$-MHC) did not change significantly in the left ventricle of DCM hearts as compared to undiseased hearts. As expected, relative mRNA levels for interleukin-6 (IL-6) and $\beta$-actin were significantly lower in DCM patients than in controls.

To bridge over the differences in previous studies (Borlak and Thum 2003; Soltysinska et al. 2009; Barrans et al. 2002) we were interested to inspect the molecular basis of $\mathrm{I}_{\mathrm{K} 1}$ current in dilated cardiomyopathy.

\subsubsection{Disease-related changes in mRNA and protein levels of Kir2.x isoforms}

Cardiac left ventricular samples were obtained from 12 hearts of DCM patients and compared with those of 12 undiseased donors. As a first step, we determined the relative mRNA levels for $\mathrm{K}^{+}$ion channel $\alpha$-subunits Kir2.1, Kir3.1, Kir3.4, Kir6.1, Kir 6.2, also for $\beta$ - 
subunits SUR1 and SUR2 by high through-put technique using the Open Array ${ }^{\mathrm{TM}}$ platform (designed in our laboratory). We observed marked changes in the relative mRNA levels of $\mathrm{I}_{\mathrm{K} 1-\mathrm{related}}$ genes in the ventricle of DCM patients as compared to controls (Figure 2c). Thus Kir2.1 and SUR1 mRNA levels increased, while those for Kir6.1 $\alpha$-subunit and SUR2 $\beta$ subunit were declined relative to undiseased controls. Relative mRNA level for Kir3.4 was also reduced in patients, whereas the mRNA levels of Kir3.1 and Kir6.2 did not differ between hearts of control and DCM patients (Figure 2c).

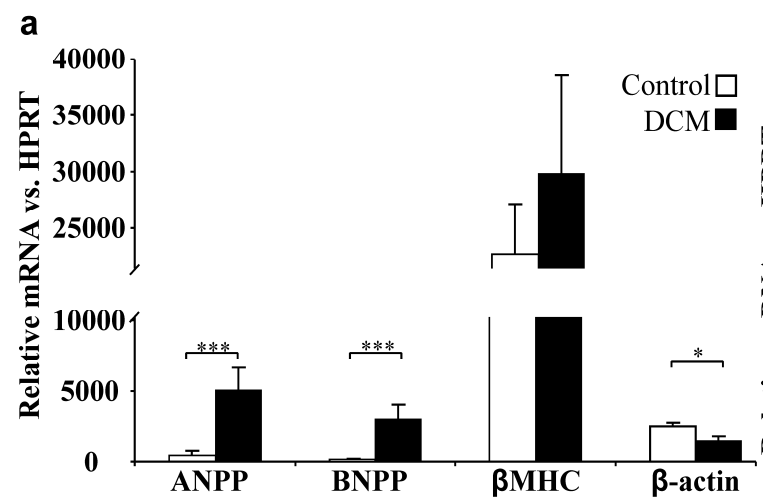

b
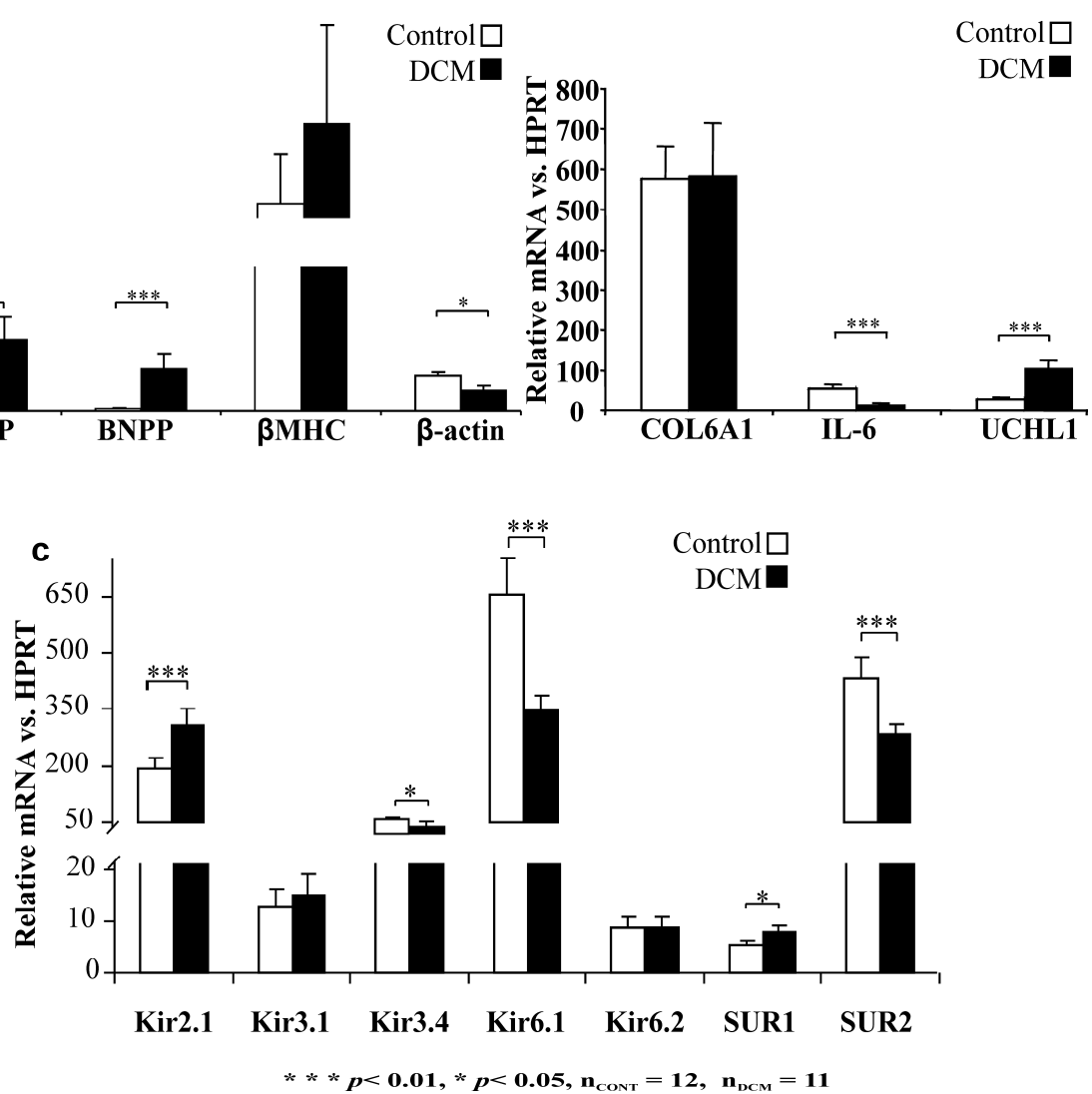

Figure 2. Marker gene expression in the left ventricle of DCM hearts. Relative mRNA levels for the indicated markers were determined by qRT-PCR in the left ventricle of DCM hearts and compared with those in healthy hearts. (a) Relative mRNA levels for atrial natriuretic peptide precursors (ANPP) and brain natriuretic peptide precursors (BNPP) were increased $>5$-fold and 3.5 -fold $(p \leq 0.01$ ), respectively, while $\beta$-actin was decreased in DCM samples $(p<0.05)$. $\beta$ MHC, $\beta$-myosin heavy chain. (b) Interleukin-6 (IL-6) and ubiquitin carboxyl-terminal esterase L1 (UCHL-1) expression were significantly $(\mathrm{p} \leq 0.01)$ lower or higher, respectively, in DCM compared with control hearts. (c) The mRNA expression pattern of $\mathrm{I}_{\mathrm{K} 1}$-related genes for Kir channel $\alpha$ - and associated subunits. Bars, calculated as relative mRNA of Kir channels $v s$ hypoxanthine-guanine phosphoribosyltransferase (HPRT), show the mean \pm SEM of 3 independent experiments conducted in duplicate.

Following nanomole scale qRT-PCR screening of Kir2.x isoforms, the most important differences in gene expression were verified by conventional qRT-PCR assay, using a 
different set of primers. The sample sources were extended to left ventricles of 17 DCM patients and 15 undiseased donors. We also investigated the protein levels using immunoblotting and immunofluorescence methods.

As Kir2.1, Kir2.2 and Kir2.3 are known to contribute markedly to the repolarization phase of action potentials in cardiomyocytes, we validated the alterations in the steady state levels of mRNAs encoding these $\mathrm{K}^{+}$channel subunits in the heart of DCM patients. The data were normalized to both HPRT and GAPDH mRNA levels and showed similar differences between DCM and control heart samples (Figures 3a and 3b).
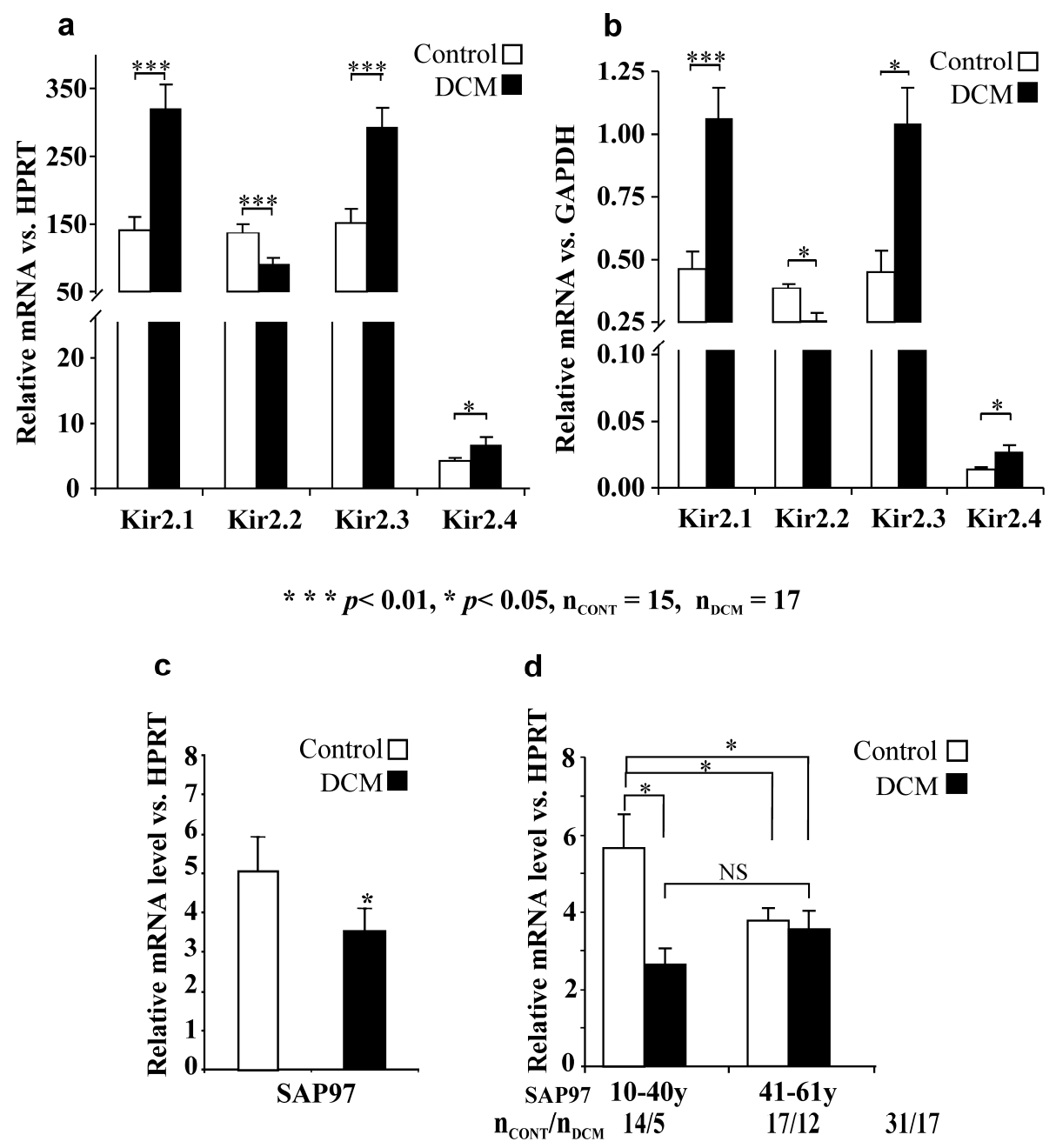

Figure 3. Relative mRNA levels for Kir2.x isoforms and synapse-associated protein 97 (SAP97) validated by qRT-PCR. (a) mRNA analysis confirmed that both Kir2.1 and Kir2.3 mRNA levels were significantly elevated in dilated cardiomyopathic (DCM) hearts compared with controls. Values of mRNA for Kir2.1-Kir2.4 were normalized to hypoxanthine-guanine phosphoribosyl-transferase (HPRT). (b) mRNA levels for Kir2.x isoforms relative to those of GAPDH were measured by $\Delta \Delta \mathrm{Ct}$ values. (c) Gene expression for SAP97 in the human left ventricle of healthy and DCM patients $(\mathbf{n C O N T}=31$ and $\mathbf{n D C M}=17) .{ }^{*}, \mathbf{p}<0.05$ compared with the control. ( $\left.\underline{\mathbf{d}}\right)$ Age-dependent expression of SAP97 mRNA in donor and DCM hearts $\left(\mathrm{n}_{\mathrm{CONT}}=31\right.$ and $\left.\mathrm{n}_{\mathrm{DCM}}=17\right) ;{ }^{*}, \mathrm{p}<0.05$; NS, no significant difference. Values are expressed as the mean \pm SEM. 
Because mRNAs for Kir channel subunits were commeasurable with HPRT transcripts, but did not reach $1 \%$ of GAPDH mRNA level, mRNA levels relative to that of HPRT are presented only in the rest of the paper. Extended analysis confirmed that both Kir2.1 and Kir2.3 mRNA levels were significantly elevated, relative to the control in DCM heart (Figures 3a and 3b). The Kir2.4 mRNA level also increased in diseased ventricle. In contrast, the Kir2.2 transcript was significantly down-regulated in DCM.

Next we performed immunoblotting analysis of protein samples matching the RNA sources to reveal if differences in steady state mRNA levels were manifested in protein content. As expected, anti-human Kir2.1, Kir2.2, and Kir2.3 antibodies recognized bands of $55 \mathrm{kDa}, 45 \mathrm{kDa}$ and $57 \mathrm{kDa}$, respectively (Figure 4a).

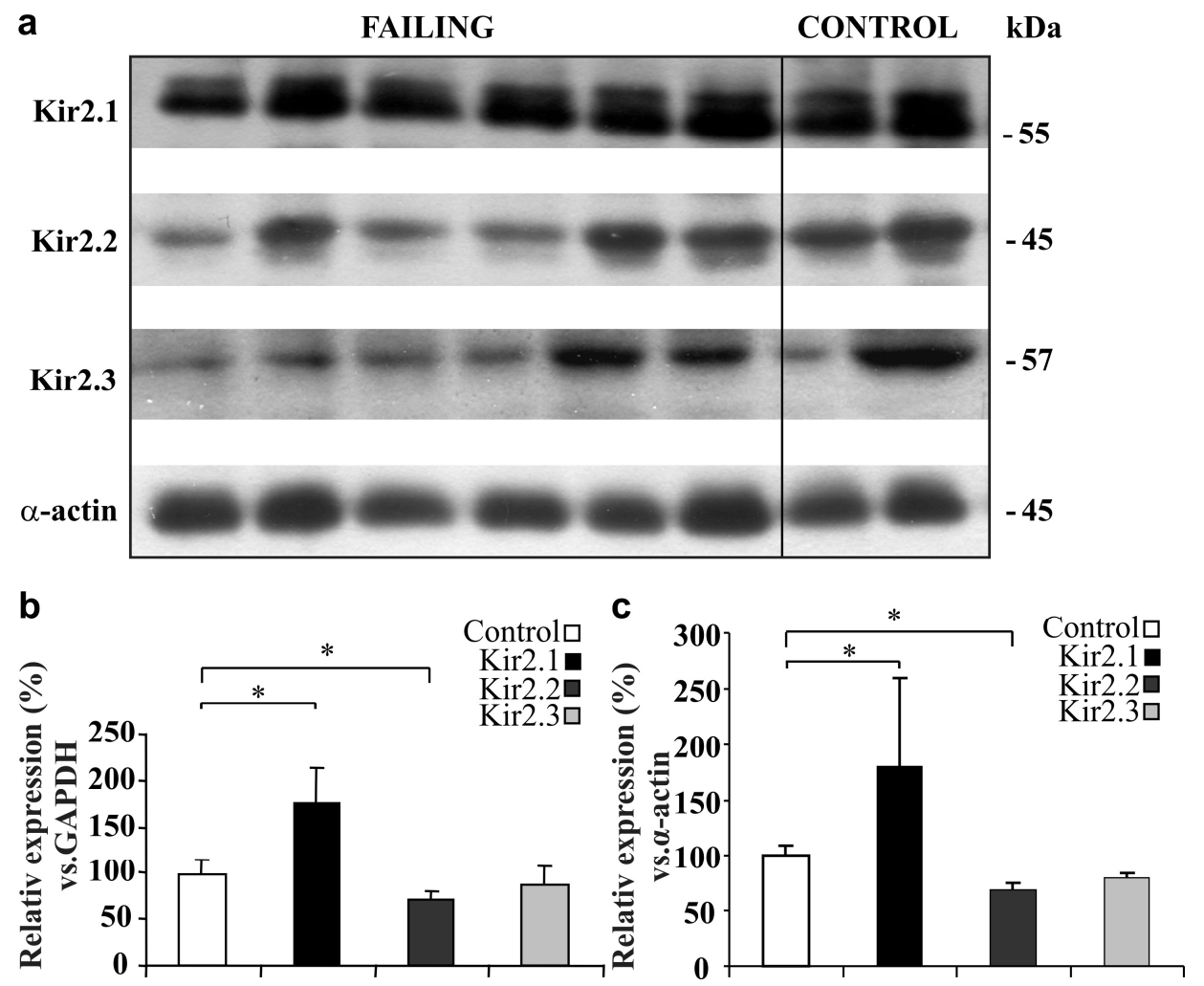

Figure 4. Differentially altered expression of Kir2.x isoforms in dilated cardiomyopathy (DCM). (a) Representative immunoblots of membrane proteins extracted from ventricles of 2 healthy control and 6 DCM patients. (b) Immunoblots were subjected to densitometry for semiquantitative determination of relative expression levels of Kir2.x isoforms normalized to GAPDH levels. (c) Kir2.x isoforms from Western blot analysis normalized to $\alpha$-actin levels. Values are expressed as the mean \pm SEM $\left(\mathrm{n}_{\mathrm{CONT}}=10\right.$ and $\left.\mathrm{n}_{\mathrm{DCM}}=10\right) ; * \mathrm{p}<0.05$.

Kir2.1 protein expression was increased in the ventricles of DCM hearts confirming thus the mRNA data. Immunoblots were reprobed with anti-GAPDH and/or $\alpha$-actin antiserum and the intensity of immunosignals was then quantified by image analysis software relative to 
GAPDH or $\alpha$-actin internal controls (Figures $4 \mathbf{b}$ and $4 \mathbf{c} \mathbf{c}$ ). The normalized protein amount of Kir2.1 isoform was higher (with about $70 \%$ ) showing some individual variability, while the Kir2.2 isoform was lower (by about $29 \%$ ) in DCM compared to control hearts. The Kir2.3 protein content, however, did not differ considerably between donor and DCM ventricular tissue samples.

Taken all these data together we may conclude that, qRT-PCR analysis confirmed that mRNA expression for Kir2.1 (KCNJ2), Kir2.3 (KCNJ4) and Kir2.4 (KCNJ14) coding genes significantly increased (2.26-fold, 1.94-fold and 1.6-fold, respectively), while mRNA level for Kir2.2 (KCNJ12) was reduced to $66 \%$ in DCM ventricle versus control. In agreement with RNA data, Western analysis revealed increased Kir2.1 and decreased Kir2.2 protein levels in DCM patients, but the Kir2.3 level was not markedly altered as compared to control.

\subsubsection{Age-dependent and DCM-related changes in SAP97 mRNA expression}

Considering that SAP97 can associate with Kir2.2 and Kir2.3 isoforms in the heart samples (Leonuodakis et al. 2000, 2004), we observed significant changes in Kir2.1 and Kir2.2 mRNA and protein levels, it was interesting to check whether mRNA level for SAP97 regulatory protein has also changed in DCM. Both the Open Array ${ }^{\mathrm{TM}}$ approach and the classical qRT-PCR study on a larger set of samples indicated down-regulation of SAP97 mRNA expression in DCM samples (not shown). Using the Open Array ${ }^{\mathrm{TM}}$ system, we measured 27\% decrease in SAP97 mRNA level in ventricular samples of DCM patients relative to donors, similarly to the decreased Kir2.2 mRNA expression. Then we validated the differences in the relative SAP97 mRNA levels in 31 control and 17 DCM samples using different primer set. SAP97 mRNA expression was reduced by $34 \%$ in DCM compared to that in undiseased heart (Figure 3c, $\mathrm{n}_{\mathrm{CONT}}=31, \mathrm{n}_{\mathrm{DCM}}=17, p<0.05$ ).

Gene expression for SAP97 was validated by qRT-PCR. The SAP97 mRNA level decreased significantly in DCM patients using Open Array ${ }^{\mathrm{TM}}$ method $\left(\mathrm{n}_{\mathrm{CONT}}=12, \mathrm{n}_{\mathrm{DCM}}=12\right)$ and qRT-PCR. Furthermore, we observed robust age-dependent changes in SAP97 mRNA expression even in donor hearts, when we compared 31 undiseased and 17 DCM samples (Figures 3c and 3d). SAP97 mRNA level decreased about 50\% at age of 40 years or higher. SAP97 mRNA levels were high at ages between 12-40 years in control cardiac ventricles and decreased by $52 \%$ in DCM patients. After 40 years of age, however, the differences in the SAP97 mRNA levels diminished between control and DCM hearts. 


\subsubsection{Kir2.x and SAP97 colocalize in both control and DCM human ventricles}

Based on the robust changes in Kir2.x and SAP97 mRNA expression in DCM versus normal heart, we hypothesized that SAP97 binding to Kir2x isoforms and distribution of their complexes might have changed in cardiomyocytes of DCM heart. To address the potential differences in the distribution of SAP97-Kir2.x complexes in DCM, we used indirect immunofluorescence. Using isoform-specific antibodies, we detected Kir2.1, Kir2.2, Kir2.3 and SAP97 in the sarcolemma. Lining up with qRT-PCR and immunoblot data (Figures 3 and 4), immunofluorescent visualization of Kir2.1 clearly showed more intense immunostaining in DCM heart than in control cryosections. On the other hand, Kir2.2 and SAP97 clearly exhibited less intense immunofluorescence in DCM versus undiseased heart ventricular sections (Figures 5a and 4b).

a
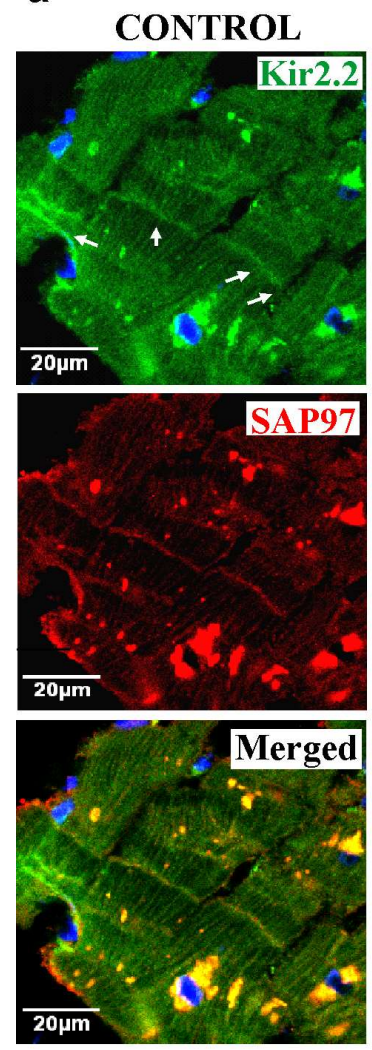
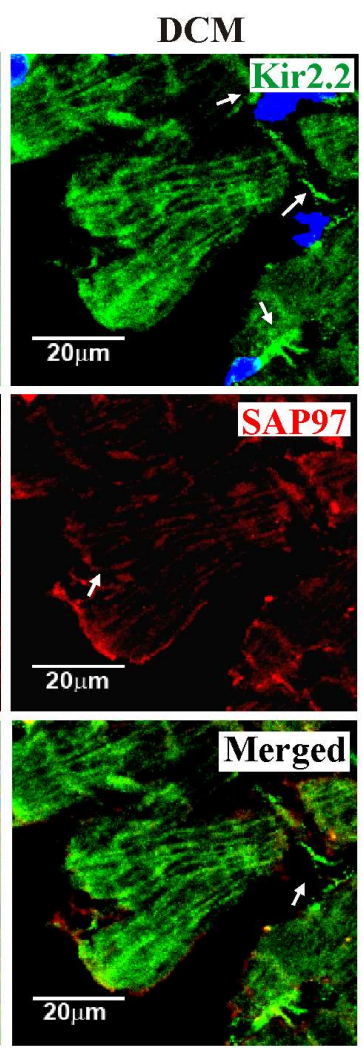

b
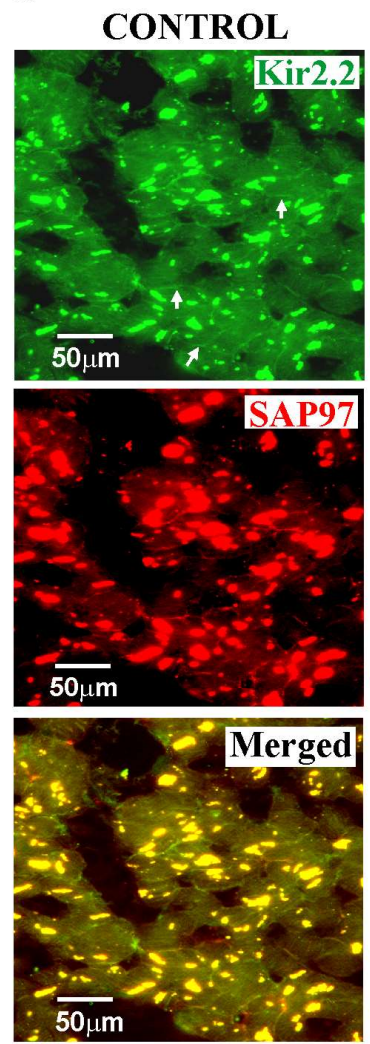
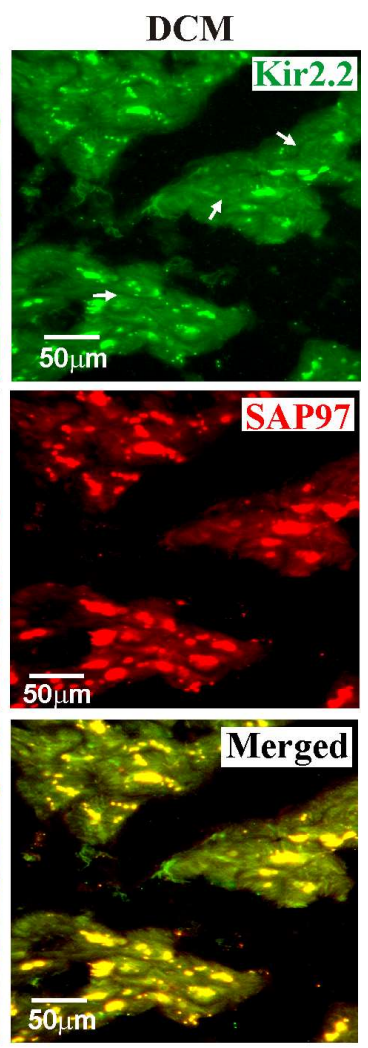

Figure 5. Immunofluorescence of Kir2.2 and SAP97 colocalization. (a) The Kir2.2 channel colocalizes with SAP97 in the intercalated discs of undiseased myocytes. For labeling the nucleus we used DAPI. (b) Crossection of left ventricle shows less intense fluorescence in DCM myocytes.

Double immunofluorescence showed the colocalization of SAP97 with type of Kir2.1 or Kir2.2 isoforms in cardiomyocytes of ventricular tissues in both control and DCM hearts. Whereas the distribution of Kir2.1 and SAP97 partially overlapped in the intercalated discs of 
control sections, their colocalization was more obvious in failing human ventricle as judged by the number and intensity of merged yellow spots (fata not shown). Kir2.2 also colocalized at the optical level of confocal microscopy with SAP97 in both control and failing samples, but the expression pattern was different in healthy and DCM heart sections (Figures 5a and 5b). The differences in the distribution of merged Kir2.x and SAP97 yellow spots in the diseased tissue section suggest that the intracellular structures may be disorganized or disrupted in cardiomyocytes of DCM patients. We concluded that the altered distribution of Kir2.x and SAP97 complexes revealed by immunofluorescence may be due to changes in assembly of Kir2.x heteromers at the plasmamembrane of DCM cardiomyocytes.

\subsubsection{Altered inward rectifier current density in the heart of dilated cardiomyopathic patients}

During the last decade a few publications have suggested from the altered action potential (AP) shape in DCM that the properties of $\mathrm{I}_{\mathrm{K} 1}$ current could be changed (Koumi et al. 1995). Therefore, we studied the $I_{K 1}$ current in human cardiomyocytes derived from the heart of undiseased donors and DCM patients. We measured $I_{K 1}$ by whole cell patch-clamp technique in the isolated ventricular myocytes as shown in Figure 6.

a

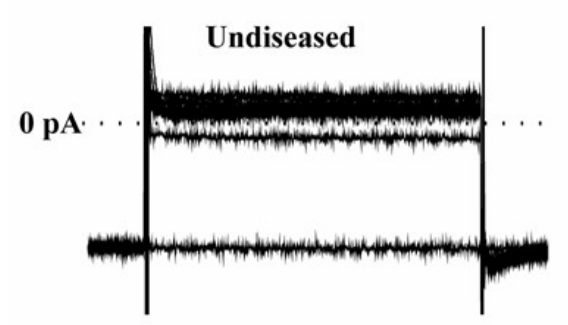

b

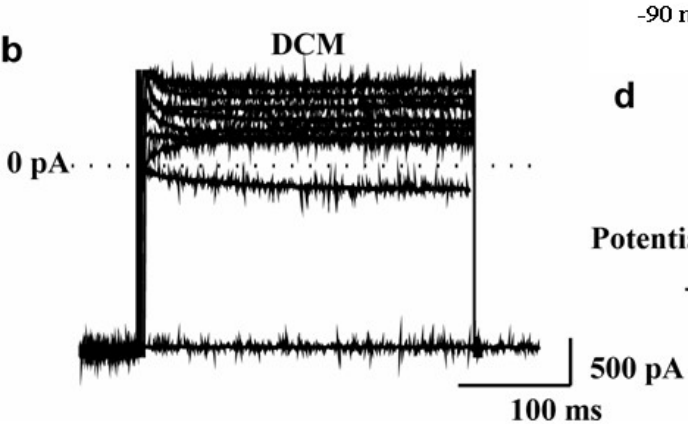

c
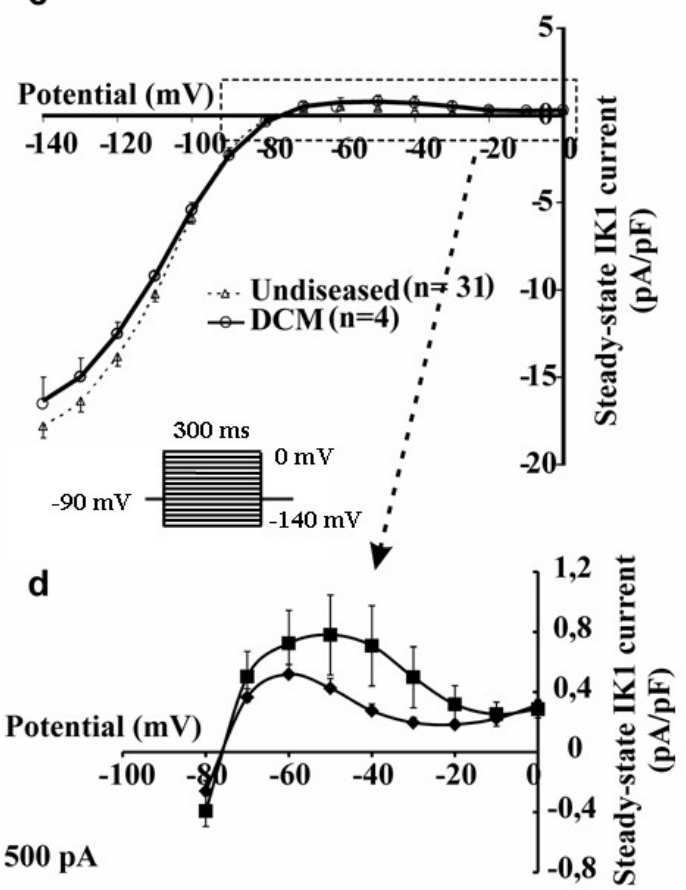

Figure 6. Alteration of $\mathrm{I}_{\mathrm{K} 1}$ currents in ventricular myocytes of DCM patients. Original current traces recorded from (a) undiseased and (b) DCM ventricular myocytes at test potential ranging from -90 to $0 \mathrm{mV}$. (c) Steady-state inward $\mathrm{I}_{\mathrm{K} 1}$ current density is measured in isolated myocytes from DCM and 
undiseased hearts (at test potential from -140 to $0 \mathrm{mV}$; inset shows the applied pulse protocol). (d) The outward component of $\mathrm{I}_{\mathrm{K} 1}$ tends to increase in DCM, but the differences from controls have not reached the level of statistical significance $\left(\mathrm{n}_{\mathrm{CONT}}=31, \mathrm{n}_{\mathrm{DCM}}=4\right)$. Data are expressed as means $\pm \mathrm{SEM}$.

$\mathrm{I}_{\mathrm{K} 1}$ current was recorded by applying $300 \mathrm{~ms}$ long depolarizing voltage pulses in the voltage range of $-140 \mathrm{mV}$ to $0 \mathrm{mV}$ with $3 \mathrm{~s}$ pulse intervals from the $\mathrm{HP}$ of $-90 \mathrm{mV}$. IK1 was measured as the steady-state current at the end of the test pulse. Representative current traces and the density of $I_{K 1}$ in ventricular myocytes obtained from undiseased $(n=31)$ and DCM diseased hearts (representative cells $n=4$ ) are shown in Figures 6a and $6 \mathbf{b}$.

At $-60 \mathrm{mV} \mathrm{I}_{\mathrm{K} 1}$ density was moderately lower in the undiseased donor cardiomyocytes than in DCM human ventricular myocytes (Figures 6a and 6b). Steady-state inward $I_{K 1}$ density (Figure 6c) was reduced in cells isolated from DCM ventricle compared with undiseased myocardium. On the contrary, the outward component increased in myocytes of diseased hearts, although these data did not reach the level of statistical significance.

However, we must emphasize as limitation of our study the small number of examined myocytes originated from diseased hearts $(n=4)$. Data are means \pm SEM. The increased tendency of the outward component of $I_{K 1}$ (Figure 6d) supports the hypothesis that the expression pattern of Kir2.x isoforms might have changed in the plasmamembrane of diseased cardiomyocytes. The altered heteromeric association of these Kir2.x channels between healthy and DCM cardiomyocytes may explain the increased outward component.

\subsection{The investigation of several newly synthetized CNA compounds as novel selective NCX inhibitors. The selection of GYKB-6635 as lead compound}

In the present study carbocyclic nucleoside analogues (CNA) as potential novel selective inhibitors of NCX current and their effect on DAD related and ischemia-reperfusion (IR) induced cardiac arrhythmias are investigated in mammalian hearts. The structures of these CNA compounds basically differ from the already known selective NCX blockers, like KB-R7943 and SEA-0400 or from ORM-10103 (Jost et al. 2013).

The compounds according to the present investigation belong to a chemically wellmarked group of compounds the NCX inhibitor activity of which has not been described yet. The present development relates to a compound represented by formula (I) or a pharmaceutically acceptable salt thereof, 


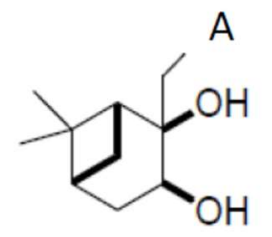

(I)

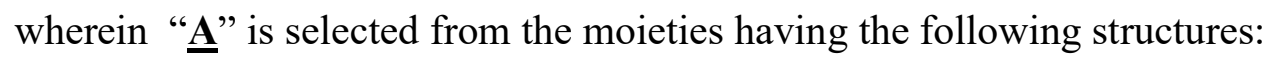<smiles>Cn1ccc(N)nc1=O</smiles><smiles>Cn1cnc2c(N)ncnc21</smiles><smiles>Cn1ccc(O)nc1=O</smiles>

for use in the treatment or prevention of cardiovascular diseases and disorders influenced by blocking up-regulated sodium/calcium exchanger current. The chemical IUPAC name of the formula (I) is: 4-amino-1-[((1R,2S,3S,5R)-2,3-dihydroxy-6,6-dimethylbicyclo[3.1.1]heptan-2-yl)methyl]pyrimidin-2(1H)-one.

The compounds of formula (I) according to our development possess excellent NCX inhibitor activity. Formula (I) covers the following compounds, which were synthetized and investigated. The following compounds were synthetized and investigated. Detailed structures are given in Table 2.

\section{GYKB-6635; GYKB-6704; GYKB-6707}

For the NCX activity of these compounds both the 3-amino-1,2-diol function and the lipophilic, rigid bicyclic ring system of monoterpene structure appear to be essential, as were shown in the pharmacological studies. The activities of the above compounds were disclosed in comparison with other carbonucleosides used as reference compounds. The following reference compounds were synthetized. Detailed structures are given in Table 2.

\section{GYKB-6703; GYKB-6705; GYKB-6706; GYKB-6708; GYKB-6709; UGI-314; UGI-305}

Table 2. The identification numbers (ID No.) and structures of the newly carbocyclic nucleoside analogues compounds

\begin{tabular}{|c|c|c|}
\hline ID No. & Chemical structure & IUPAC chemical name \\
\hline GYKB 6635 & & $\begin{array}{c}\text { 4-Amino-1-[((1R,2S,3S,5R)- } \\
\text {-2,3-dihydroxy-6,6- } \\
\text { dimethylbicyclo[3.1.1]heptan } \\
\text { 2-yl)methyl]pyrimidin- } \\
\text {-2(1H)-one }\end{array}$ \\
\hline
\end{tabular}




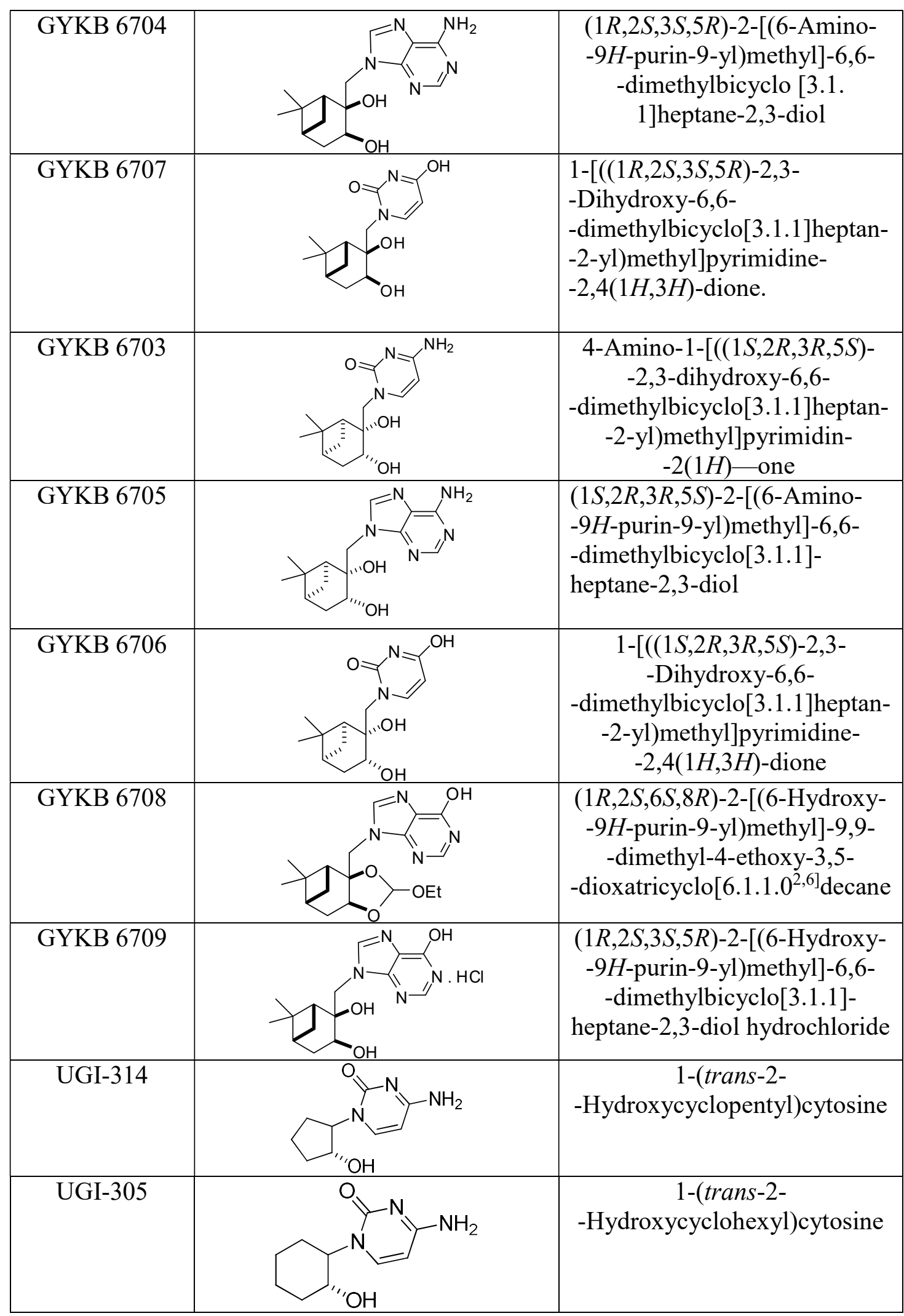

The carbonucleosides according to formula (I) and of with reversed stereochemistry, i.e. reference compounds can be prepared by analogous processes using the monoterpene starting compound of corresponding space formula (described by Szakonyi and Fülöp, 2010). 
Effect of the CNA compounds on outward and inward NCX current in dog ventricular myocytes

For recording the NCX current, the method of Hobai et al. (1997) was adapted and applied. $\mathrm{I}_{\mathrm{NCX}}$ was measured as a $\mathrm{Ni}^{2+}$ sensitive current using voltage ramp waveforms for the command potential (see earlier Figure 1). The effect of various concentrations of the compounds on outward NCX current (reverse mode) was calculated at $20 \mathrm{mV}$, and on inward current (forward mode) was determined at $-80 \mathrm{mV}$. As Table 3 shows three CNA compounds (marked with red colour) exerted significant NCX current blocking effect. $1 \mu \mathrm{M}$ GYKB-6635 reduced the reverse NCX current by $66 \%$ (from $98.6 \pm 18.5 \mathrm{pA}$ in controls to $33.4 \pm 11.9 \mathrm{pA}$ after drug administration, $\mathrm{n}=5, \mathrm{p}<0.05$ ), and the forward current was reduced by $68 \%$ (from $-71.7 \pm 44 \mathrm{pA}$ in controls to $-23.8 \pm 24.3 \mathrm{pA}$ after drug administration, $\mathrm{n}=5, \mathrm{p}<0.05$ ). As Table 3 indicates, GYKB-6704 and GYKB-6707 have comparable inhibiting effect at a higher concentration of $10 \mu \mathrm{M}$ only. Accordingly, $10 \mu \mathrm{M}$ GYKB-6704 reduced the reverse NCX current by $54 \%$ (from $554 \pm 27.7 \mathrm{pA}$ in controls to $256.8 \pm 87.0 \mathrm{pA}$ after drug administration, $\mathrm{n}=5, \mathrm{p}<0.05$ ), and the forward current was reduced by $50 \%$ (from $-558 \pm 33 \mathrm{pA}$ in controls to $-281 \pm 134$ pA after drug administration, $n=5, p<0.05) .10 \mu \mathrm{M}$ GYKB-6707 reduced the reverse NCX current by $65 \%$ (from $177 \pm 22 \mathrm{pA}$ in controls to $63.1 \pm 70.0 \mathrm{pA}$ after drug administration, $n=4, p<0.05$ ), and the forward current was reduced by $52 \%$ (from $-165 \pm 27$ $\mathrm{pA}$ in controls to $-97.6 \pm 109 \mathrm{pA}$ after drug administration, $\mathrm{n}=4, \mathrm{p}<0.05)$. The other CNA compounds did not affect the outward and inward NCX current (Table 3).

Table 3. Screening of the effects of all CNA compounds on the forward and reverse NCX currents in isolated dog cardiac ventricular myocytes measured at different membrane voltages by applying a ramp protocol.

\begin{tabular}{|c|c|c|c|c|c|c|}
\hline \multirow{2}{*}{ Drug } & \multicolumn{3}{|c|}{$\begin{array}{c}\text { Forward current } \\
(+20 \text { mV) }\end{array}$} & \multicolumn{3}{c|}{$\begin{array}{c}\text { Reverse current } \\
(-80 \text { mV) }\end{array}$} \\
\cline { 2 - 7 } & $\begin{array}{c}\text { Control } \\
(\mathbf{p A})\end{array}$ & $\begin{array}{c}\text { Test } \\
(\mathbf{p A})\end{array}$ & $\begin{array}{c}\Delta \text { Effect } \\
(\%)\end{array}$ & $\begin{array}{c}\text { Control } \\
(\mathbf{p A})\end{array}$ & $\begin{array}{c}\text { Test } \\
(\mathbf{p A})\end{array}$ & $\begin{array}{c}\Delta \text { Effect } \\
(\%)\end{array}$ \\
\hline \hline $\begin{array}{c}\text { GYKB-6635, } 10 \mu \mathrm{M} \\
(\mathrm{n}=3)\end{array}$ & $131 \pm 70$ & $8.3 \pm 2.2^{*}$ & 93 & $-65 \pm 15$ & $-4.4 \pm 2.3^{*}$ & 93 \\
\hline $\begin{array}{c}\text { GYKB-6703, } 10 \mu \mathrm{M} \\
(\mathrm{n}=3)\end{array}$ & $161 \pm 39$ & $168 \pm 30$ & 4 & $-77 \pm 13$ & $-69 \pm 21$ & 10 \\
\hline $\begin{array}{c}\text { GYKB-6704, } 10 \mu \mathrm{M} \\
(\mathrm{n}=5)\end{array}$ & $344 \pm 15$ & $173 \pm 48^{*}$ & 50 & $-443 \pm 23$ & $-215 \pm 100^{*}$ & 52 \\
\hline $\begin{array}{c}\text { GYKB-6705, } 10 \mu \mathrm{M} \\
(\mathrm{n}=3)\end{array}$ & $152 \pm 50$ & $139 \pm 47$ & 9 & $-65 \pm 15$ & $-60 \pm 18$ & 8 \\
\hline
\end{tabular}




\begin{tabular}{|c|c|c|c|c|c|c|}
\hline $\begin{array}{c}\text { GYKB-6706, } 10 \mu \mathrm{M} \\
(\mathrm{n}=3)\end{array}$ & $188 \pm 55$ & $175 \pm 35$ & 7 & $-61 \pm 36$ & $-55 \pm 25$ & 10 \\
\hline $\begin{array}{c}\text { GYKB-6707, } 10 \mu \mathrm{M} \\
(\mathrm{n}=4)\end{array}$ & $102 \pm 12$ & $35 \pm 39 *$ & 65 & $-127 \pm 19$ & $-75 \pm 80 *$ & 42 \\
\hline $\begin{array}{c}\text { GYKB-6708, } 10 \mu \mathrm{M} \\
(\mathrm{n}=3)\end{array}$ & $221 \pm 62$ & $210 \pm 98$ & 5 & $-221 \pm 132$ & $-200 \pm 147$ & 10 \\
\hline $\begin{array}{c}\text { GYKB-6709, } 10 \mu \mathrm{M} \\
(\mathrm{n}=3)\end{array}$ & $320 \pm 121$ & $290 \pm 133$ & 10 & $-59 \pm 20$ & $-65 \pm 2.3$ & 10 \\
\hline $\begin{array}{c}\text { UGI-305, } 10 \mu \mathrm{M} \\
(\mathrm{n}=3)\end{array}$ & $37 \pm 3$ & $33 \pm .2$ & 11 & $-20 \pm 8$ & $-16 \pm 5$ & 8 \\
\hline $\begin{array}{c}\text { UGI-314, } 10 \mu \mathrm{M} \\
(\mathrm{n}=3)\end{array}$ & $208 \pm 70$ & $228 \pm 89$ & 9 & $-119 \pm 45$ & $-131 \pm 60$ & 10 \\
\hline
\end{tabular}

Values represent Mean \pm SEM; $n=$ number of independent experiments; ${ }^{*} \mathrm{p}<0.05$. The results corresponding to the most three potent compounds, GYKB-6635, GYKB-6704 and GYKB-6707 are highlighted with red colour.

Based on these results we conclude that GYKB-6635, GYKB-6704 and GYKB-6707 effectively inhibit the NCX current at micromolar concentration ranges. The most potent compound seems to be GYKB-6635, therefore this compound has been selected for further analysis described in the chapter 6.3 .

\subsection{Investigation of the cellular electrophysiological and antiarrhythmic effects of GYKB-6635 in mammalian hearts}

Based on the results of the investigations described in Chapter 6.2., the aim on the present investigations was the systematic investigation of the carbocyclic nucleoside analogue compound GYKB-6635, as lead highly selective NCX blocker compound. The potential antiarrhythmic potency of GYKB-6635 compound was also investigated in detail.

\subsubsection{Chemistry structure and synthesis of GYKB-6635}

In the past decade, the discovery of carbocyclic nucleosides wherein the oxygen in the sugar moiety was bioisosterically replaced with a methylene unit led to an increasing demand for the production of new chiral, alicyclic nucleoside analogues (Rodriguez and Cormin, 2003; De Clerq, 2005; Matyugina et al. 2014; Bessieres et al. 2015). Some of these compounds possess noteworthy pharmacological activity, such as the antiviral Northmethanocarbathymidine (N-MCT, Choi et al. 2003) or the species-independent $\mathrm{A}_{3}$ receptorselective agonist $(N)$-methanocarba-adenosine 5'-uronamides with cardioprotective properties (Melman et al. 2008) (Figure 7a). N-MCT and (N)-methanocarba-adenosine 5'-uronamide bear lipophylic carbo-bicyclic ringsystem with aminodiol functional groups, whereas the 
amino function is incorporated into a nucleotide base. As part of our systematic studies on chiral building blocks, in the recent years we have developed the synthesis of chiral aminodiol-based monoterpenic nucleosides from pinane-based aminodiol enantiomers (Szakonyi and Fülöp 2010), structural analogues of the above mentioned compounds.

A

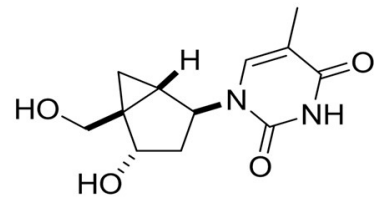

N-MCT

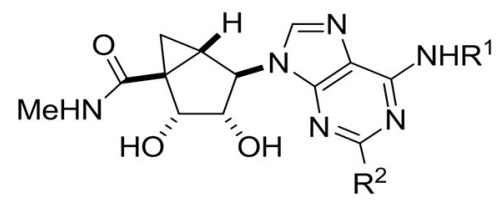

(N)-methanocarba-adenosine 5'-uronamides

B

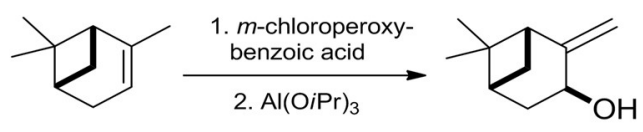

1

2<smiles></smiles>

m-chloroperoxy benzoic acid

$-\frac{\text { cytosine }}{\mathrm{K}_{2} \mathrm{CO}_{3}, \mathrm{DMF}}$

4, GYKB-6635

4-amino-1-[((1R,2S,3S,5R)-2,3-dihydroxy-

6,6-dimethylbicyclo[3.1.1] heptan-2-yl)-

methyl]pyrimidin-2(1H)-one

Figure 7. (a) Pharmacologically active nucleoside analogues bearing an aminodiol moiety related to GYKB-6635. (b). Stereoselective step by step synthesis of GYKB-6635 compound from $\alpha$-pinene, a natural monoterpene. Compound $\underline{4}$ on the figure represents the chemical structure of the GYKB-6635 compound[(4-amino-1-[((1R,2S,3S,5R)-2,3-dihydroxy-6,6-dimethylbicyclo[3.1.1]heptan-2-yl)methyl] pyrimidin-2(1H)-one)].

GYKB-6635 was synthesized from commercially available natural monoterpene, (-)$(1 S, 5 S)$ - $a$-pinene by combination of literature methods (Scheidl, 1982; Lavallee and Bouthillier, 1986; Lakshmi et al. 2005; Szakonyi et al. 2008; Szakonyi and Fülöp 2010). Epoxidation of (-)- $a$-pinene (1) with $m$-chloroperbenzoic acid (MCPBA), followed by allylic rearrangement resulted in allylic alcohol 2, wich underwent subsequent epoxidation with MCPBA to obtaine a stereohomogeneous $\beta$-epoxy alcohol 3 (Lavallee and Bouthillier, 1986; Lakshmi et al. 2005; Szakonyi et al. 2008). The regioselective, base catalysed ring opening of 3 with cytosine furnished the cytosine-based carbocyclic nucleoside 4, GYKB-6635 (Szakonyi and Fülöp, 2010).

The structure and IUPAC chemical name of the GYKB-6635 compound is: (4-amino1-[((1R,2S,3S,5R)-2,3-dihydroxy-6,6-dimethylbicyclo[3.1.1]heptan-2-yl)methyl]pyrimidin2(1H)-one): $\mathrm{mp} 258-259{ }^{\circ} \mathrm{C},[\alpha]_{\mathrm{D}}{ }^{20}=-17.0(c=0.13, \mathrm{MeOH})$. The synthesized compound 
had all physical and analytical property data similar to those described in the literature (Szakonyi and Fülöp, 2010) (Figure 7b).

\subsubsection{Effect of GYKB-6635 on the outward and inward NCX current}

Measuring $\mathrm{Na}^{+} / \mathrm{Ca}^{2+}$ exchanger current

For recording the $\mathrm{Na} / \mathrm{Ca}$ exchanger current (NCX), the method of Hobai et al. (1997) was adapted and applied. $\mathrm{I}_{\mathrm{NCX}}$ was measured as a $\mathrm{Ni}^{2+}$ sensitive current using voltage ramp waveforms for the command potential (see earlier Figure 1). The ramp pulse initially depolarized from the $\mathrm{HP}$ of $-40 \mathrm{mV}$ to $60 \mathrm{mV}$ (1s in duration), then hyperpolarized to -140 $\mathrm{mV}$ ( $2 \mathrm{~s}$ in duration), and depolarized back to the HP. The descending limp of the ramp was used to plot the I-V curve. Current traces were recorded after blocking $\mathrm{Na}^{+}, \mathrm{Ca}^{2+}, \mathrm{K}^{+}$and $\mathrm{Na}^{+} / \mathrm{K}^{+}$pump currents. Then, GYKB-6635 was applied and the current was recorded with the same voltage waveform. The NCX current was defined as the $\mathrm{Ni}^{2+}$-sensitive current i.e. subtracting the trace recorded in the presence of $10 \mathrm{mM} \mathrm{NiCl}_{2}$ from that measured in the absence of $\mathrm{NiCl}_{2}$. Therefore, $10 \mathrm{mM} \mathrm{NiCl}_{2}$ was added to the bath solution for the complete blockade of the NCX current and this trace was subtracted from the control record and from the GYKB-6635 record resulting in $\mathrm{Ni}^{2+}$ sensitive current traces in control conditions and in the presence of $1 \mu \mathrm{M}$ GYKB-6635 (Figure 8a).

A
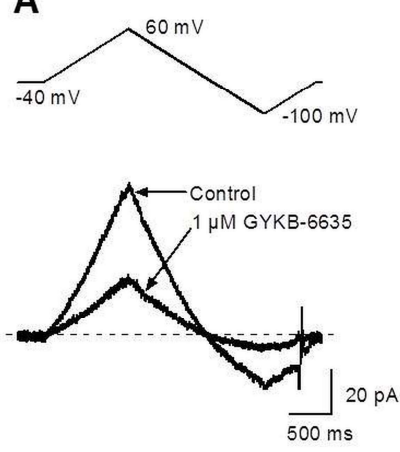
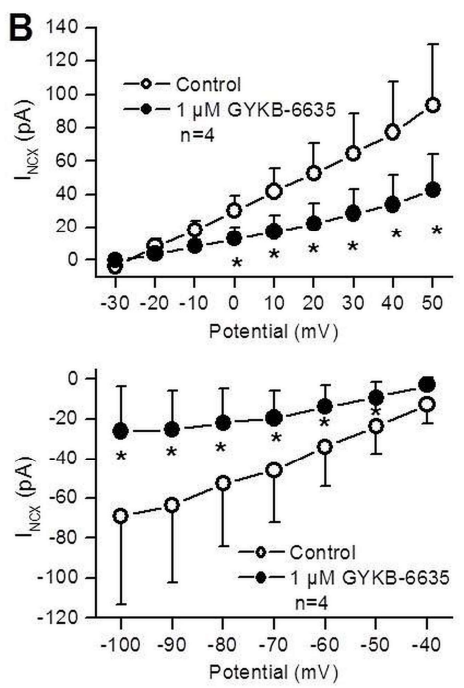

Figure 8. The effect of GYKB-6635 on the NCX current in dog ventricular myocytes. (a) Original $\mathrm{Ni}^{2+}$-sensitive (NCX) current traces before and after superfusion of the cells with $1 \mu \mathrm{M}$ GYKB-6635 compound. Inset shows applied voltage protocol. (b) The amplitude of the inward (top) and the outward (bottom) NCX currents in the absence and in the presence of $1 \mu \mathrm{M}$ GYKB-6635. Values represent \pm SEM, $n=4-4,{ }^{*}<0.05$. 
In 3-3 separate experiments, in which the $\mathrm{Ca}^{2+}, \mathrm{Na}^{+}, \mathrm{K}^{+}, \mathrm{Na}^{+} / \mathrm{K}^{+}$pump and $\mathrm{NCX}$ currents were blocked, $10 \mu \mathrm{M}$ GYKB-6635 did not change the $\mathrm{Ni}^{2+}$ resistant current (not shown). These latter measurements indicate that the current, which was reduced by GYKB6635, was indeed the NCX current and not a $\mathrm{Ni}^{2+}$ insensitive leakage or other non-specific time dependent current or an experimental artefact. The effect of the drug at different concentrations on the outward NCX current (reverse mode) was calculated at $20 \mathrm{mV}$ and on the inward current (forward mode) was determined at $-80 \mathrm{mV}$. As Figure 8b shows $1 \mu \mathrm{M}$ GYKB-6635 reduced by $57 \%$ the reverse NCX current (from $52.5 \pm 18.5$ pA in controls to $22.4 \pm 11.9 \mathrm{pA}$ after drug administration, $\mathrm{n}=4, \mathrm{p}<0.05$ ), while the forward current was reduced by $58 \%$ (from $-52.7 \pm 21 \mathrm{pA}$ in controls to $-21.8 \pm 12.3 \mathrm{pA}$ after drug administration, $\mathrm{n}=4$, $\mathrm{p}<0.05)$.

\subsubsection{The selectivity investigation of GYKB-6635}

Lack of effect of GYKB-6635 on the L-type inward calcium and fast inward sodium current

$\mathrm{I}_{\mathrm{CaL}}$ calcium current was evoked by $400 \mathrm{~ms}$ long depolarization test pulses (ranging from $-30 \mathrm{mV}$ to $+60 \mathrm{mV}$ ) from $-40 \mathrm{mV}$ HP. The amplitude of $\mathrm{I}_{\mathrm{Ca}}$ was defined as the difference between the peak inward current at the beginning of the pulse and the current at the end of the pulse. These experiments showed that GYKB-6635 even at high $(10 \mu \mathrm{M})$ concentration did not influence $\mathrm{I}_{\mathrm{CaL}}$, The left panel of the Figure 9a presents original current recordings in control and after superfusion of the cell with GYKB-6635), while right panel presents the result of the corresponding I-V curves in the average of 5 cells.

Though, after application of GYKB-6635 a small decrease of the current occurred (from $-714.8 \pm 37.4 \mathrm{pA}$ to $615.1 \pm 22.5 \mathrm{pA}, \mathrm{n}=5 \mathrm{p}=\mathrm{N} . \mathrm{S}$.), after washing out of the drug the current decreased slightly further which revealed that the slight reduction of the current amplitude in the presence of GYKB-6635 was a consequence only of the run-down phenomenon.

The effect of GYKB-6635 on the fast inward sodium current $\left(\mathrm{I}_{\mathrm{Na}}\right)$ was studied by measuring the maximal rate of depolarization $\left(\mathrm{V}_{\max }\right)$ in dog right ventricular papillary muscle by applying the conventional microelectrode technique. GYKB-6635, at the high concentration of $10 \mu \mathrm{M}$, did not change $\mathrm{V}_{\max }$ significantly at stimulation cycle length range between 300-5000 ms, suggesting no effect on $\mathrm{I}_{\mathrm{Na}}$ (Figure 9b and inset of Figure 12a). 


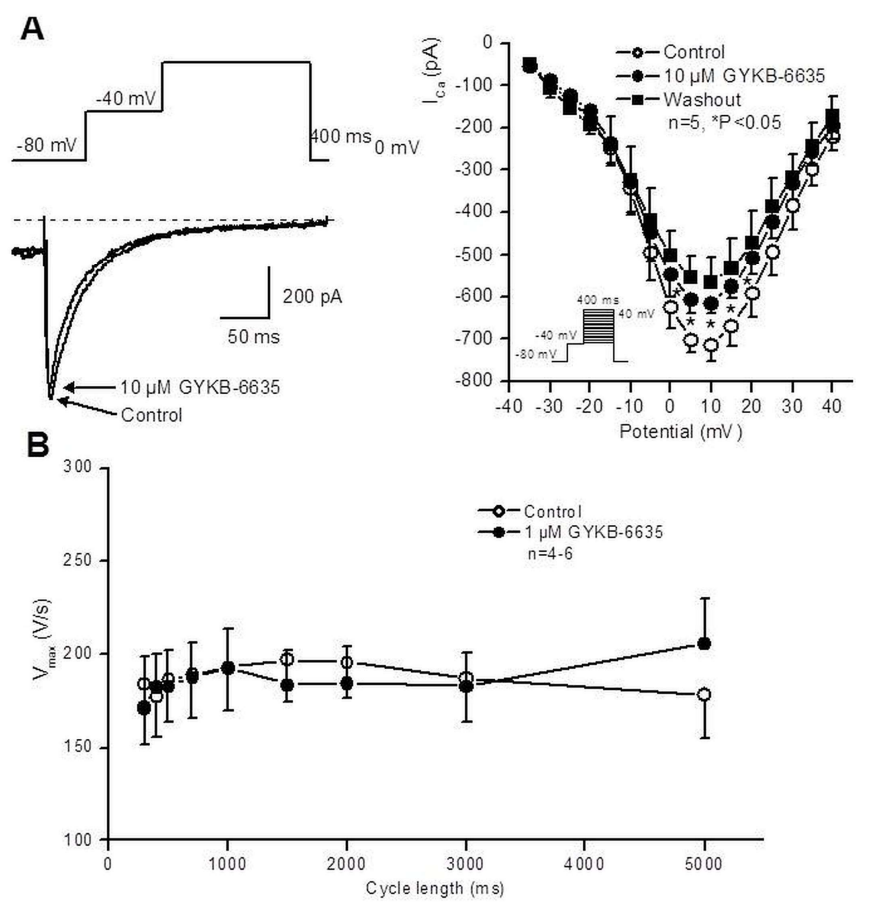

Figure 9. (a). The lack of effect of $10 \mu \mathrm{M}$ GYKB-6635 on the L-type $\mathrm{I}_{\mathrm{Ca}}$ in dog ventricular myocytes. In the inset at the top the voltage protocol is shown. The left panels indicate original current traces before and after superfusion with $10 \mu \mathrm{M}$ GYKB-6635 measured after depolarizing test pulse to $0 \mathrm{mV}$. Right panel illustrates the average current voltage relation of $\mathrm{I}_{\mathrm{CaL}}$ in the absence and presence of 10 $\mu \mathrm{M}$ GYKB-6635 in 5 experiments $(\mathrm{n}=5, \mathrm{p}=\mathrm{N}$.S.). Insets show applied voltage protocols. (b). The lack of effect of $10 \mu \mathrm{M}$ GYKB-6635 on the $V_{\max }$ indicative of $\mathrm{I}_{\mathrm{Na}}$ in dog right ventricular papillary muscles. In the ordinate the $\mathrm{V}_{\max }$ values, in the abscissa the stimulation cycle lengths are shown in the absence (control) and presence of $10 \mu \mathrm{M}$ GYKB-6635. Values represent \pm SEM, $n=4-6, p=N . S$.

\section{Lack of effect of GYKB-6635 on the main repolarizing potassium currents}

The effect of GYKB-6635 on the four main repolarizing currents, $\mathrm{I}_{\mathrm{to}}, \mathrm{I}_{\mathrm{K} 1}, \mathrm{I}_{\mathrm{Kr}}$ and $\mathrm{I}_{\mathrm{Ks}}$ currents were also investigated.

\section{Effect of GYKB-6635 on the transient outward potassium current (Ito)}

$\mathrm{I}_{\text {to }}$ current was activated by $1000 \mathrm{~ms}$ long depolarizing voltage pulses from the HP of $90 \mathrm{mV}$ to test potentials ranging from 0 to $+60 \mathrm{mV}$ with a pulse frequency of $0.33 \mathrm{~Hz}$ (Figure 10a). The amplitude of $I_{t o}$ was measured as the difference between the peak and the sustained current at the end of the voltage pulse. Figure 10a (left panel) shows typical recordings of Ito measured at $+50 \mathrm{mV}$ depolarising voltage step, before and after the superfusion of the cells with nutrient solution containing the high concentration of GYKB-6635 $(10 \mu \mathrm{M})$, while the 
right panel of Figure 10a (right panel) presents the I-V current-voltage relation of $\mathrm{I}_{\mathrm{to}}$, before and the after drug superfusion measured on the average of $n=13$ cells.
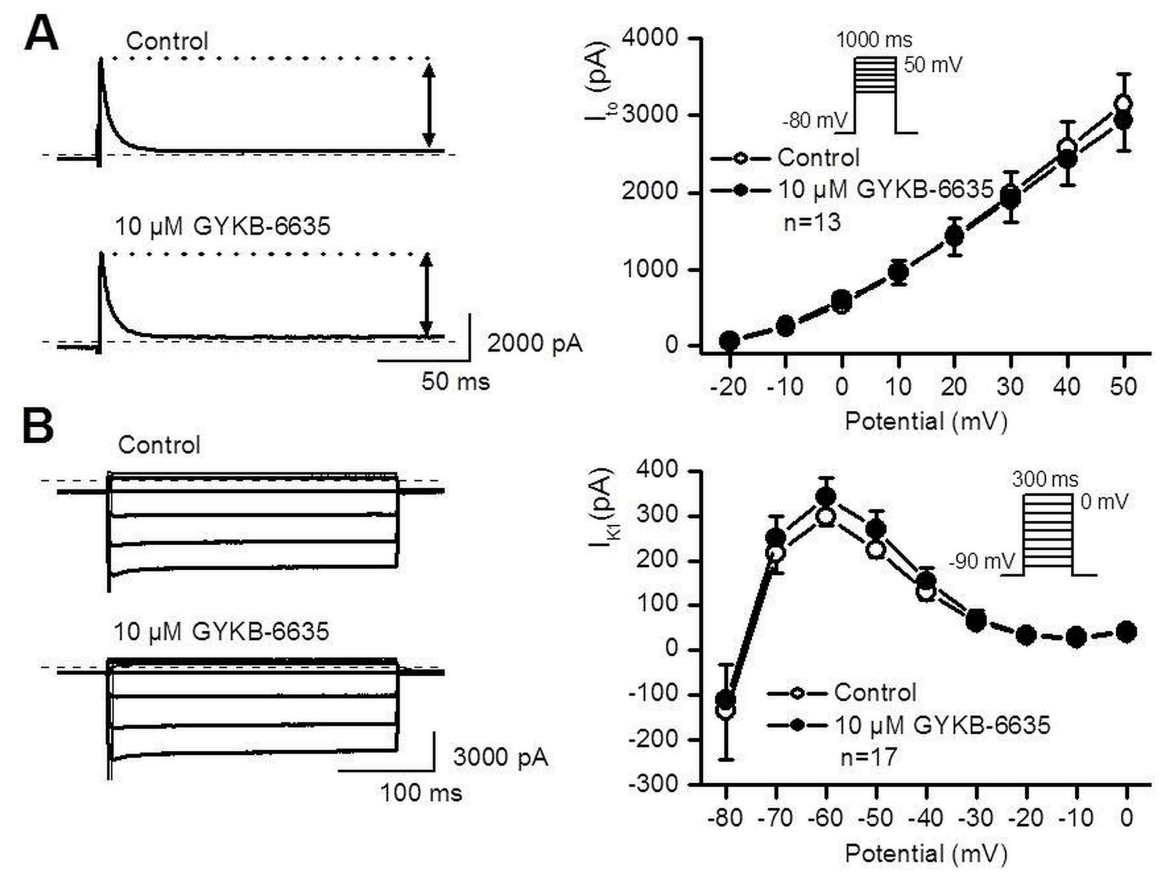

Figure 10. Lack off effect of GYKB-6635 on the transient outward $\left(I_{t o}\right)$ and inward rectifier $\left(I_{K 1}\right)$ potassium currents. (a). Left panel indicates original $\mathrm{I}_{\text {to }}$ current traces before and after superfusion with $10 \mu \mathrm{M}$ GYKB-6635 measured after depolarizing test pulse to $50 \mathrm{mV}$. Right panel illustrates the average I-V relation of $\mathrm{I}_{\mathrm{to}}$ in the absence and presence of $10 \mu \mathrm{M}$ GYKB-6635 in 13 experiments $\left(\mathrm{n}=13, \mathrm{p}=\right.$ N.S.). (b). . Left panel indicates original $\mathrm{I}_{\mathrm{K} 1}$ current traces before and after superfusion with $10 \mu \mathrm{M}$ GYKB-6635. Right panel illustrates the average $\mathrm{I}-\mathrm{V}$ relation of $\mathrm{I}_{\mathrm{K} 1}$ in the absence and presence of $10 \mu \mathrm{M}$ GYKB-6635 in six experiments $(\mathrm{n}=17, \mathrm{p}=\mathrm{N}$.S.). Insets show applied voltage protocols. Values represent \pm SEM on both $\mathrm{I}-\mathrm{V}$ curves.

As Figure 10a shows, the amplitude of the current (measured at the depolarizing voltage step of $+50 \mathrm{mV}$ ) was not decreased by GYKB-6635 even at this high concentration (at $50 \mathrm{mV}, 3146 \pm 402 \mathrm{pA}$ for control and $2938 \pm 395 \mathrm{pA}$ after application of $10 \mu \mathrm{M}$ GYKB6635 , respectively, $n=13, p=N . S$.), suggesting the lack of effect of the drug on $I_{\text {to. }}$.

\section{Effect of GYKB-6635 on the inward rectifier potassium current $\left(I_{K 1}\right)$}

The effect of GYKB-6635 $(10 \mu \mathrm{M})$ on the inward rectifier potassium current $\left(\mathrm{I}_{\mathrm{K} 1}\right)$ was studied by measuring the steady-state current level at the end of the $300 \mathrm{~ms}$ long voltage pulse in the voltage range of -120 to $0 \mathrm{mV}$ with a pulse frequency of $0.33 \mathrm{~Hz}$. The $\mathrm{HP}$ was $-90 \mathrm{mV}$. Figure 10b presents original recordings of $I_{K 1}$ measured before and after superfusion of the myocytes with the drug (left panel) and the corresponding I-V relationships of $\mathrm{I}_{\mathrm{K} 1}$ before and after the superfusion with the drug measured on the average of $n=5$ cells (right panel). The 
mentioned current recordings and corresponding I-V relationship clearly indicates that GYKB-6635 did influence significantly the steady state currents (at $-100 \mathrm{mV},-2366 \pm 258 \mathrm{pA}$ for control and $-2238 \pm 220 \mathrm{pA}$ after application of the drug, respectively, $\mathrm{n}=17, \mathrm{p}=\mathrm{N}$.S.) suggesting the lack of effect of GYKB-6635 on $\mathrm{I}_{\mathrm{K} 1}$.

\section{Effect of GYKB-6635 on the rapid and slow components of the delayed rectifier potassium} current $\left(I_{K r}\right.$ and $\left.I_{K s}\right)$

The left panels of Figures 11a and 11b show typical $\mathrm{I}_{\mathrm{Kr}}$ and $\mathrm{I}_{\mathrm{Ks}}$ current traces recorded in dog ventricular myocytes. $\mathrm{I}_{\mathrm{Kr}}$ and $\mathrm{I}_{\mathrm{Ks}}$ were examined by using test pulses of 1000 $\mathrm{ms}\left(\mathrm{I}_{\mathrm{Kr}}\right)$ or $5000 \mathrm{~ms}\left(\mathrm{I}_{\mathrm{Ks}}\right)$ in duration to between $-20 \mathrm{mV}$ and $+50 \mathrm{mV}\left(\mathrm{I}_{\mathrm{Kr}}\right)$ or $-10-60 \mathrm{mV}\left(\mathrm{I}_{\mathrm{Ks}}\right)$ from the HP potential of $-80 \mathrm{mV}$. A short prepulse to $-40 \mathrm{mV}$ (100 ms long when measured $\mathrm{I}_{\mathrm{Kr}}$, and $20 \mathrm{~ms}$ long when measured $\mathrm{I}_{\mathrm{Ks}}$, respectively) was applied for inactivating fast sodium channel $\left(\mathrm{I}_{\mathrm{Na}}\right)$. The pulse frequency was $0.05 \mathrm{~Hz}\left(\mathrm{I}_{\mathrm{Kr}}\right)$ or $0.1 \mathrm{~Hz}\left(\mathrm{I}_{\mathrm{Ks}}\right)$. The decaying tail current at $-40 \mathrm{mV}$ after the test pulse was assessed as $\mathrm{I}_{\mathrm{Kr}}$ (Figure 11a) or $\mathrm{I}_{\mathrm{Ks}}$ (Figure 11b).

The amplitudes of the $\mathrm{I}_{\mathrm{Kr}}$ and $\mathrm{I}_{\mathrm{Ks}}$ tail currents have been determined as the difference between the peak tail current and the holding current level at $-40 \mathrm{mV}$. When measured $\mathrm{I}_{\mathrm{Kr}}$, HMR-1556 (500 nM) were used to completely block $\mathrm{I}_{\mathrm{Ks}}$, while dofetilide $(1 \mu \mathrm{M})$ was added to the nutrient solution when studied $\mathrm{I}_{\mathrm{Ks}}$.
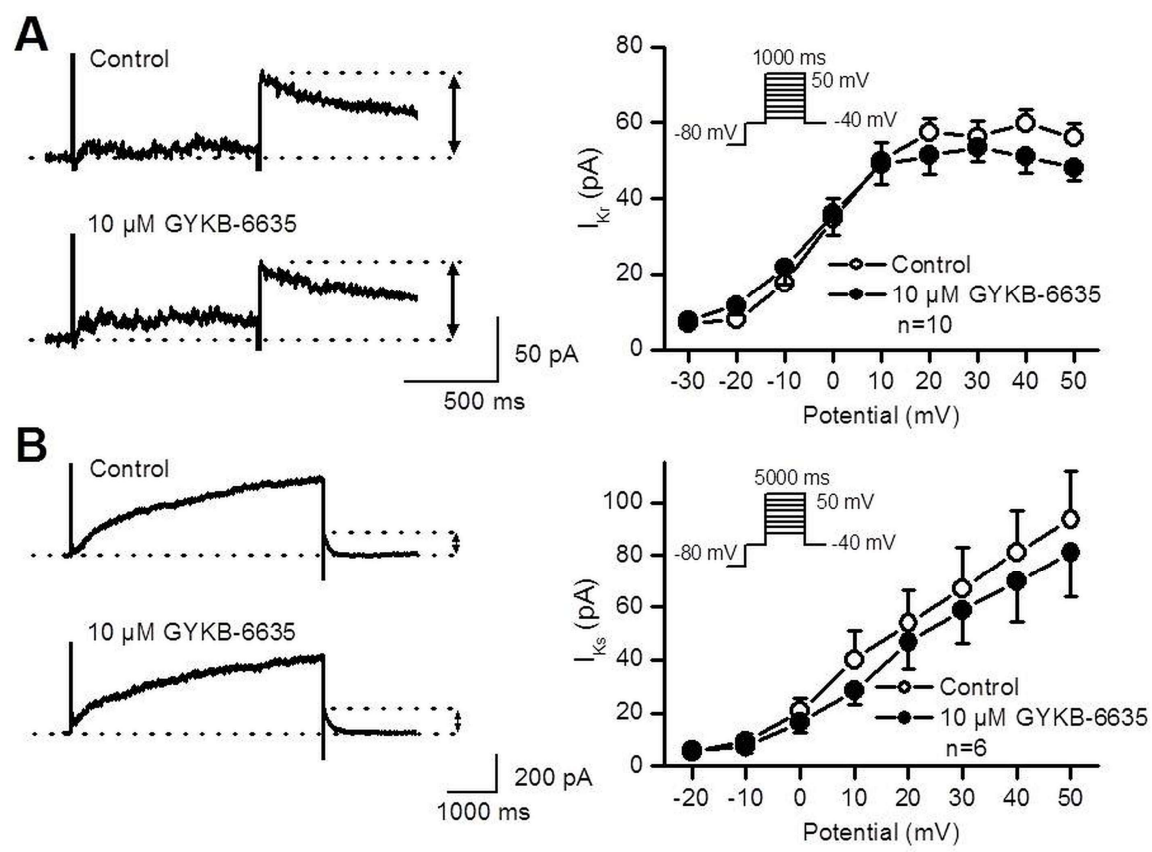

Figure 11. Lack off effect of GYKB-6635 on rapid and slow components of delayed rectifier $\left(\mathrm{I}_{\mathrm{Kr}}\right.$ and $\mathrm{I}_{\mathrm{Ks}}$ ) potassium currents. (a). Left panels indicate original $\mathrm{I}_{\mathrm{Kr}}$ current traces before and after superfusion with $10 \mu \mathrm{M}$ GYKB-6635. Right panel illustrates the average I-V relation of $\mathrm{I}_{\mathrm{Kr}}$ in the absence and presence of $10 \mu \mathrm{M}$ GYKB-6635 in 10 experiments $(n=10, p=N . S$.). (b). Left panels indicate original 
$\mathrm{I}_{\mathrm{Ks}}$ current traces before and after superfusion with $10 \mu \mathrm{M}$ GYKB-6635. Right panel illustrates the average I-V relation of $\mathrm{I}_{\mathrm{Ks}}$ in the absence and presence of $10 \mu \mathrm{M}$ GYKB-6635 in 10 experiments $(n=10, p=N . S$.). Insets show applied voltage protocols. Values represent \pm SEM on both I-V curves.

The right panels of the same Figures 11a and 11b show the corresponding I-V relationship of the $I_{K r}$ and $I_{K s}$ tail currents. These diagrams clearly show that neither $I_{K r}$ tail amplitudes (at $+30 \mathrm{mV}, 56.3 \pm 4.2 \mathrm{pA}$ for control and $53.5 \pm 3.5 \mathrm{pA}$ after application of the drug, respectively, $\mathrm{n}=10, \mathrm{p}=\mathrm{N} . \mathrm{S}$.) nor $\mathrm{I}_{\mathrm{Ks}}$ tail (at $+50 \mathrm{mV}, 93.6 \pm 14.5 \mathrm{pA}$ for control and $80.9 \pm 12.5$ after application of the drug, respectively, $n=6, p=N . S$.) amplitudes were affected by the high concentration of $10 \mu \mathrm{M}$ GYKB-6635 suggesting the lack of effect of the drug on $\mathrm{I}_{\mathrm{Kr}}$ and $\mathrm{I}_{\mathrm{Ks}}$ currents.

\subsubsection{Effect of selective NCX inhibition on the AP waveform and repolarization}

The effect of NCX inhibition on the cardiac ventricular action potential waveform was studied in dog cardiac ventricular preparations, by applying $1 \mu \mathrm{M}$ concentrations of GYKB6635. At this concentration the drug inhibited more than $60 \%$ of the forward and reverse NCX without influencing the other transmembrane currents, ie. it could be considered as a selective pharmacological tool to study the influence of NCX inhibition on cardiac ventricular action potential. As Figure 12a shows NCX inhibition failed to significantly affect dog multicellular papillary muscle action potential parameters including maximal rate of depolarization $\left(\mathrm{V}_{\max }\right)$, while pacing at a constant pacing cycle length of $1000 \mathrm{~ms}$, either the action potential waveform or action potential duration $\left(\mathrm{APD}_{90}\right)$ at all.

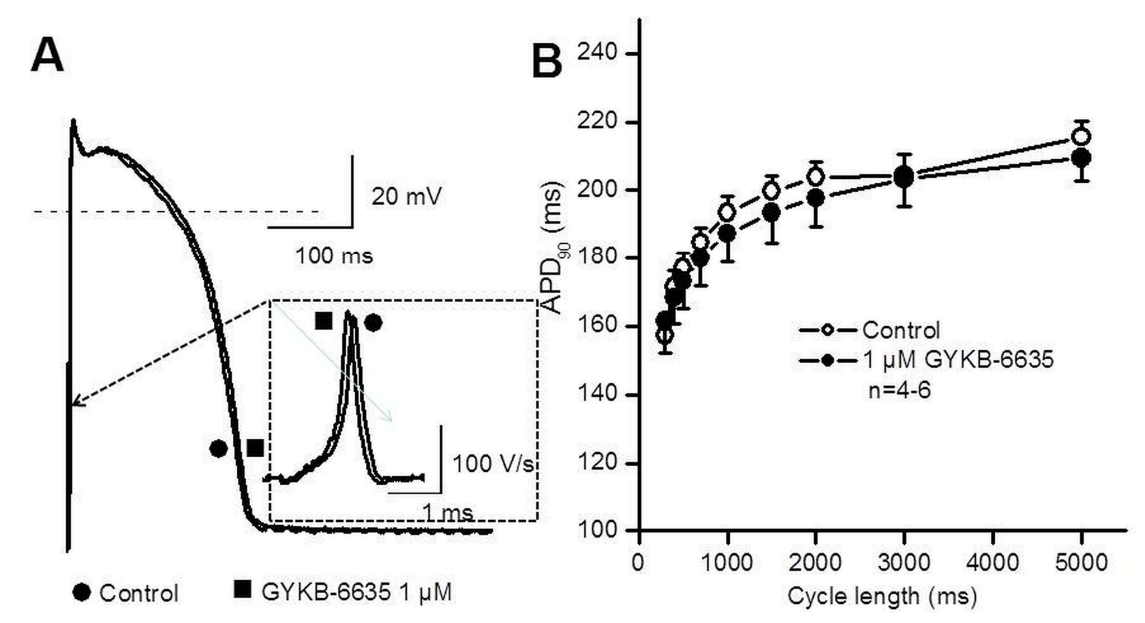

Figure 12. (a) Effect of selective NCX blockade by GYKB-6635 $(1 \mu \mathrm{M})$ on the action potential in dog intact right papillary muscle. The stimulation frequency was $1 \mathrm{~Hz}$. Inset shows with a better time scale the maximal rate of rise of the action potential upstroke $\left(\mathrm{V}_{\max }\right.$ measured in $\left.\mathrm{V} / \mathrm{s}\right)$ at the basic cycle lengths of $1000 \mathrm{~ms}$. (ㅁ) $)$. Frequency dependent effect of NCX inhibition (by $1 \mu \mathrm{M}$ GYKB) on action 
potential duration $\left(\mathrm{APD}_{90}\right)$ in canine ventricular papillary muscles. Abscissa= Pacing cycle length; ordinate $=$ percentile changes in $\mathrm{APD}_{90}$. Bars represent $\pm \mathrm{SEM}$.

Table 4 summarizes the result of the investigation of the effect of GYKB-6635 on all studied action potential parameters at the cycle length of $1000 \mathrm{~ms}$.

Table 4. Effect of NCX blockade by GYKB-6635 $(1 \mu \mathrm{M})$ on the AP characteristics in dog right ventricular endocardial muscle (measured at the stimulation frequency of $1 \mathrm{~Hz}$ )

\begin{tabular}{|l|c|c|c|c|c|c|}
\hline \multirow{2}{*}{ Parameter } & $\mathrm{RMP}$ & $\mathrm{APA}$ & $\mathrm{V}_{\max }$ & $\mathrm{APD}_{90}$ & $\mathrm{APD}_{50}$ & $\mathrm{APD}_{25}$ \\
\cline { 2 - 7 } & $\mathrm{mV}$ & $\mathrm{mV}$ & $\mathrm{V} / \mathrm{s}$ & $\mathrm{ms}$ & $\mathrm{ms}$ & $\mathrm{ms}$ \\
\hline \hline Control & $-86.8 \pm 1.4$ & $107.1 \pm 2.1$ & $189.7 \pm 20.6$ & $207.4 \pm 3.5$ & $173.2 \pm 4.7$ & $126.7 \pm 6.7$ \\
\hline $\begin{array}{l}\text { GYKB-6635, } \\
1 \mu \mathrm{M}\end{array}$ & $-85.7 \pm 1.8$ & $106.7 \pm 2.5$ & $186.9 \pm 17.4$ & $198.4 \pm 7.4$ & $166.1 \pm 8.4$ & $120.8 \pm 8.9$ \\
\hline
\end{tabular}

$\mathrm{RMP}=$ resting membrane potential; $\mathrm{APA}=$ action potential amplitude; $\mathrm{V}_{\max }=$ maximal rate of depolarization; $\mathrm{APD}_{25}, \mathrm{APD}_{50}, \mathrm{APD}_{90}=$ action potential duration at 25,50 and $90 \%$ repolarization time. $n=4-6 ; p=N . S$.; Values represent mean \pm SEM.

A similar lack of discernible effects of NCX inhibition on $\mathrm{APD}_{90}$ and $\mathrm{V}_{\max }$ were observed in dog ventricular muscle over a wide range of pacing cycle lengths (300-5000 ms) after $1 \mu \mathrm{M}$ GYKB-6635 administration (Figure 9b and Figure 12).

\subsubsection{Ouabain induced arrhythmias in isolated guinea-pig hearts}

The presence of ouabain $(5 \mu \mathrm{M} / \mathrm{L})$ induced ventricular arrhythmias such as extrasystole, bigeminia, salvo, tachycardia and ventricular fibrillation in isolated guinea-pig hearts. In the control group the first arrhythmias, such as extrasystole and bigeminia developed around the second minutes (Figure 13). Several minutes later ventricular tachycardia appeared, that followed by fibrillation around the fourth minutes after starting ouabain administration.

GYKB-6635 $(1 \mu \mathrm{M})$ pre-treatment significantly delayed the time to the development of ventricular fibrillation, compared to the control response (by $18 \%$, from $4.17 \pm 0.41, \mathrm{n}=5$ in controls $v s 6,07 \pm 0.69$ in the presence of drug, $\left.\mathrm{n}=5,{ }^{*} \mathrm{p}<0.05\right)$. There was a discernible, but statistically not significant difference between the two groups in appearance of other arrhythmias (VEB and VT) (Table 5 and Figure 13). 
Table 5. Effect of GYKB-6635 $(1 \mu \mathrm{M})$ in ouabain $(5 \mu \mathrm{M})$ induced arrhythmias in isolated guinea pig hearts.

\begin{tabular}{|l|c|c|c|c|}
\hline Group & $\mathrm{n}$ & VEB (min) & VT (min) & VF (min) \\
\hline \hline Control & 5 & $1,73 \pm 0,43$ & $3,10 \pm 0,51$ & $4.17 \pm 0.41$ \\
\hline GYKB-6635, $1 \mu \mathrm{M}$ & 5 & $2,60 \pm 0,20$ & $4,05 \pm 0,39$ & $6,07 \pm 0.69^{*}$ \\
\hline
\end{tabular}

Note: $n$ : number of animals in the group; VEB: ventricular extrasystole and bigeminia; VT: ventricular tachycardia; VF: ventricular fibrillation; ${ }^{*} \mathrm{P}<0.05$. Values represent mean $\pm \mathrm{SEM}$.

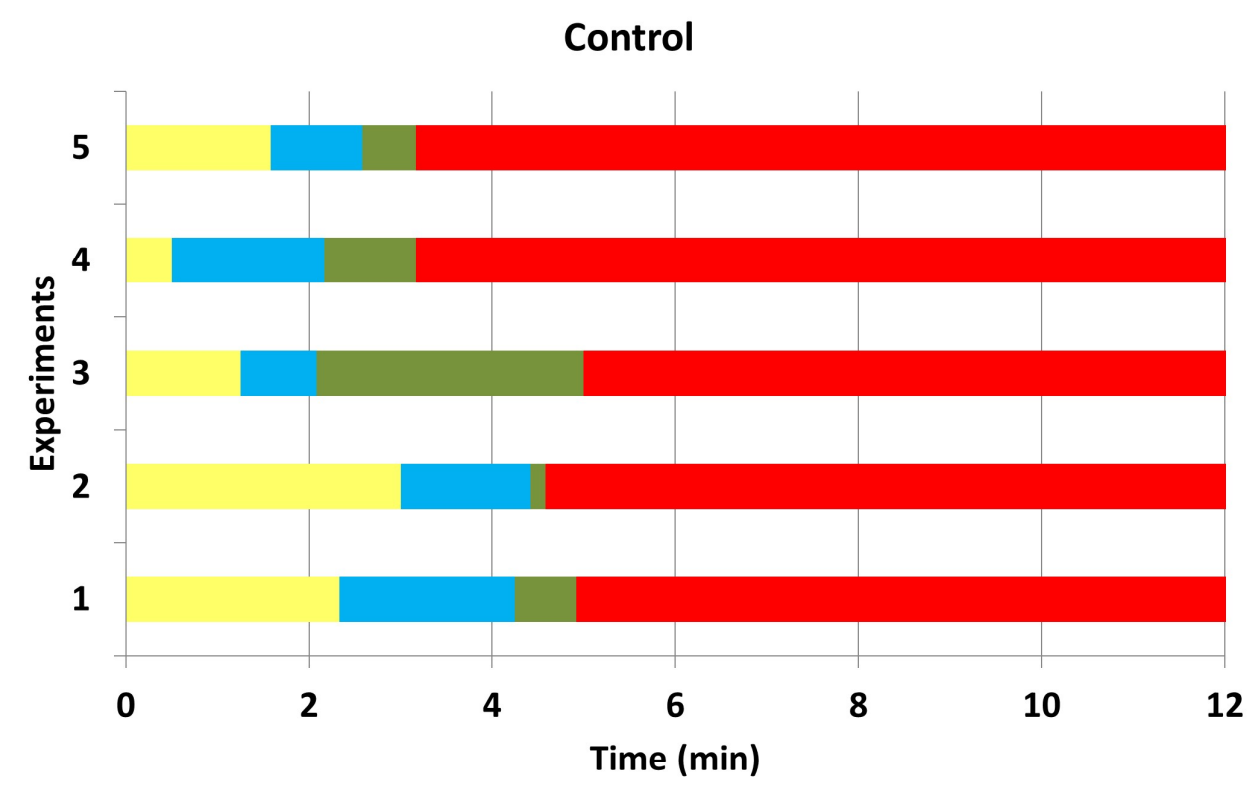

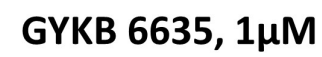

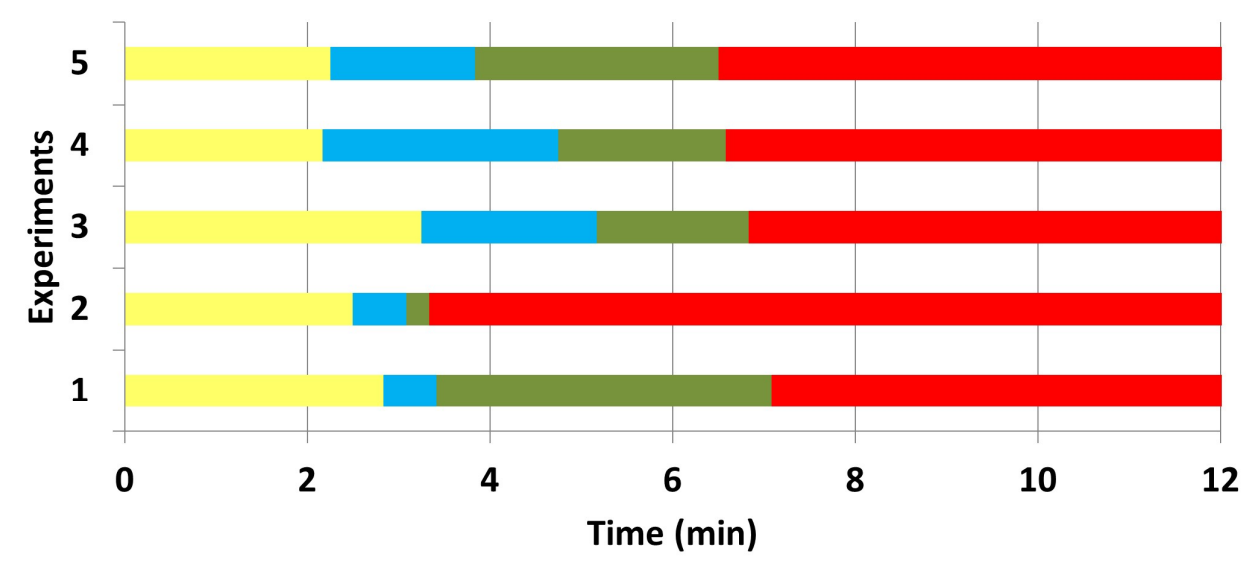

None $\square$ VEB $\square$ VT $\square$ VF

Figure 13. Effect of GYKB-6635 $(1 \mu \mathrm{M})$ in ouabain $(5 \mu \mathrm{M})$ induced arrhythmias in in isolated guinea pig hearts. Time to the development of different types of ventricular arrhythmias as ventricular extra beats (extra systoles and bigeminia, blue bars), ventricular tachycardia (green bars) and ventricular fibrillation (red bars) were measured on the ECG and depicted in the diagram. 


\section{Discussion}

\subsection{The effects of the expression of genes for Kir2.x ion channel isoforms in dilated cardiomyopathy}

To address the role of potassium channels in the pathomechanism of DCM, we compared the expression pattern of genes encoding the 1-pore Kir2.x channels in DCM and donor hearts, and levels of the synapse associated protein 97 (SAP97) were measured. For this purpose, cardiac left ventricular tissue samples were obtained from patients with DCM $(n=17)$ and from healthy donors $(n=31)$. Our major findings were the following: (i) we observed increased expression of Kir2.1 mRNA and protein and Kir2.3 mRNA, as opposed to significantly decreased levels of Kir2.2 and SAP97 mRNA and proteins in DCM patients compared with healthy control samples; (ii) immunofluorescence revealed changes in the tissue distribution of Kir2.x subunits and in their co-localization with SAP97; (iii) we showed for the first time that the gene for SAP97 exhibits an age-dependent expression in healthy hearts, and that other genes also have a temporally regulated expression pattern altered in cardiomyopathy.

Comparing the relative gene expression for Kir and 2-pore ion channels in ventricles, we observed decreased gene expression for Kir2.2, Kir6.1, and SUR2 but, interestingly, the mRNA level increased for Kir2.1, Kir2.3, and Kir2.4 in DCM patients compared with the healthy donors (Figure 3). Other authors have shown similar decreases in DCM for Kir6.1, which is known to be involved in the maintenance of vascular tone of microvessels (Borlak and Thum 2003; Soltysinska et al. 2009). However, in this study we have focused especially on the investigation of the gene expression changes underlying the $\mathrm{I}_{\mathrm{K} 1}$ current. Based on our data, and considering the reported contribution of 1-pore channels to $\mathrm{I}_{\mathrm{K} 1}$ current properties, we hypothesize that the decreased expression of Kir2.2 and the regulatory subunit SAP97 may account in large part for the decreased $\mathrm{I}_{\mathrm{K} 1}$ current in DCM. We propose that the observed Kir2.1 and Kir2.3 upregulation may serve as a compensatory mechanism to avoid the detrimental decrease of $\mathrm{I}_{\mathrm{K} 1}$ in cardiac disease.

\section{Outward components of the $I_{K I}$ current is elevated in DCM}

Our hypothesis is supported by the following data from the literature. Previously, 
Koumi et al. (1995) reported that the $\mathrm{I}_{\mathrm{K} 1}$ current decreases in cardiomyocytes with DCM. It is known that $\mathrm{I}_{\mathrm{K} 1}$ has an influence on the depolarization and repolarization phases of AP. In phase 0 , the $\mathrm{Na}^{+}$current is dominant over $\mathrm{I}_{\mathrm{K} 1}$, whereas $\mathrm{I}_{\mathrm{K} 1}$ and other voltage-gated potassium currents are dominant in repolarization phases 1-4 in cardiomyocytes. In phases 0,3 , and 4 , $\mathrm{I}_{\mathrm{K} 1}$ underlying by Kir2.x channels serves as a major current. As demonstrated by Warren et al. (2003), IK1 properties are determined mainly by rectification and $\left[\mathrm{K}^{+}\right]_{\mathrm{o}}$ sensitivity of the Kir2.1 isoform when Kir2.x heteromeric channels are formed. Furthermore, the outward components are higher in the left ventricle than in the atria or right ventricle (Dhamoon and Jalife, 2005). It has also been recently shown that the $I_{K 1}$ current formed by Kir2.1 channels displays strong inward rectification, but Kir2.3 inward rectification is incomplete and negative slope-conductance is noticeably less steep in an in vivo guinea pig model and in a rabbit model (Lodge and Normandin 1997; Warren et al. 2003; Rose et al. 2005). Further, when Kir2.x stable transformants were used to study the influence of homo- and heteromeric associations on $I_{K} 1$ current density, it was found that among the homomers, Kir2.1 produced the highest outward component, which decreased when Kir2.1 formed heteromers with other Kir2.x subunits (Schram et al. 2003; Muňoz et al. 2007). The importance of Kir2.1 was also supported by the observation that Kir2.1-/- knockout mice did not exhibit measurable $\mathrm{I}_{\mathrm{K} 1}$ (Zaritsky et al. 2001).

In our study, the expression level exhibited variability for Kir2.3, significantly decreased for Kir2.2, but increased for Kir2.1 mRNA and protein levels in DCM patients compared with healthy donors. These data are consistent with earlier reports on the increase of Kir2.1 mRNAlevels in end-stage heart failure of DCM or ischemic origin compared with donors (Borlak and Thum 2003; Soltysinska et al. 2009). Immunofluorescence and Western blot analysis also revealed decreased expression of Kir2.2 and Kir2.3, but increased deposition for Kir2.1 in the sarcolemma from DCM hearts (Figures 4a-4c and Figure 5a5b). One feasible explanation for the pathomechanism may be that the altered gene expression and tissue distribution of Kir2.x channels contribute to the altered $\mathrm{I}_{\mathrm{K} 1}$ current in DCM cells. Thus, we hypothesize that the increased ratio of Kir2.1 homomers or heteromers relative to all other Kir2.x homomer and heteromer ion channels translocated to the sarcolemma may account, at least in part, for the increased outward component during the progression of the disease. However, further investigations are required to prove this hypothesis.

\section{Kir2.2 isoform expression compared with other Kir2.x expression in DCM}

Koumi et al. (1995) detected a 50\% decrease in whole-cell current slope conductance 
of $\mathrm{I}_{\mathrm{K} 1}$ in ventricular myocytes of DCM patients versus donors. The AP had a longer duration and a slow repolarization phase with a low resting membrane potential. Kir2.2-/- knockout mice displayed a 50\% reduction in $\mathrm{I}_{\mathrm{K} 1}$ relative to that of the wild-type (Zaritsky et al. 2001), indicating that, apart from Kir2.1, Kir2.2 also highly contributes to $\mathrm{I}_{\mathrm{K} 1}$. In our study, we found that the mRNA levels were significantly reduced, not only for Kir2.2 but also for SAP97 in the ventricle of DCM patients compared with donors, and the same was true for the protein level of Kir2.2. Taken together, the data suggest that the declined currents in the plateau and terminal phase of AP could be due to the decreased expression of these ion channels and SAP97.

\section{Decreased SAP97 associated with Kir 2.2}

Ion channels are mobile molecules that can bind different regulatory factors, and their mobility can diminish with anchoring proteins in atrial cells. MAGUK proteins such as SAP97 are known to associate with Kir2.x isoforms in heart and brain samples (Leonuodakis et al. 2000; Vaidyanathan et al. 2010). In line with these reports, our immunofluorescence data showed that the Kir2.x channels colocalize with SAP97. Furthermore, we provided evidence that human SAP97 mRNA has an age-dependent expression in donor samples. Namely, SAP97 mRNA expression in healthy donor ventricles is 2 times higher at a younger age (between 10-40 years) than at an older age of life. This dramatic age-dependent decline was characteristic only of the control tissues and was not observed in DCM samples. In fact, samples of both young and old DCM patients equally showed reduced mRNA levels similar to that of old healthy donors. The largest change, over 50\% in the mRNA expression, was seen in middle-aged patients (31-50 years) versus donors. However, the difference between healthy and DCM samples disappeared above the age of 40 years.

The endogenous Kir2.x channels associate with SAP97, specifically with the Cterminal amino acids, forming signalling complexes (Leonuodakis et al. 2000). Kir2.1 strongly binds SAP97, and they show colocalization near the T-tubules. In donor samples, we also demonstrated colocalization of SAP97 with Kir2.2, while only partial colocalization was seen with Kir2.1 and Kir2.3 (not shown) in the plasma membrane. In agreement with the data of Dhamoon and Jalife (2005), the immunosignal for Kir2.1 was localized in the intercalated discs and the T-tubules. Kir2.2 was found mostly in the intercalated discs and partly at the lateral side of myocytes in the ventricle. In DCM samples, Kir2.2 decreased dramatically and the immunosignal for SAP97 also decreased in parallel. Furthermore, only partial colocalization was seen between Kir2.2 and SAP97 in the healthy plasma membrane, which 
decreased in DCM ventricles. On the other hand, the overlap between Kir2.2 and SAP97 immunofluorescence became more obvious, suggesting a better association of the 2 subunits These variations of ion channels in the cardiomyopathic heart raise the possibility that the complexes of assembled Kir2.x components differ in stoichiometry and (or) structure from those in healthy hearts.

Therefore, we may conclude that the SAP97 and Kir2.x ion channels may be novel target molecules in the diagnosis and effective treatment of cardiomyopathy.

\subsection{The investigation and comparison of the effects of several newly synthetized CNA analogues. The characterisation of GYKB-6635 as lead compound}

The investigation of the effects of several newly synthetized CNA analogues as NCX blockers

It is known that NCX, at the forward mode, extrudes $\mathrm{Ca}^{2+}$ from the cell to the extracellular space during diastole, at relatively low free cytoplasmic $\mathrm{Ca}^{2+}$ concentration and negative transmembrane potential.

Since the extrusion of one $\mathrm{Ca}^{2+}$ is coupled with $3 \mathrm{Na}^{+}$entering the cell, during the forward mode of the NCX net inward current is carried, which can cause substantial depolarization leading to arrhythmogenic early (EAD) and delayed (DAD) afterdepolarizations, especially when intracellular $\mathrm{Ca}^{2+}$ is elevated. (Volders et al, 2000, Pogwizd and Bers, 2002). Therefore, one may speculate that specific blockers of NCX could be potential antiarrhythmics in dysrhythmias related to $\mathrm{Ca}^{2+}$ overload by influencing dispersion of repolarization and refractoriness (Pogwizd and Bers, 2002).

There are well defined hypotheses concerning the important role of the NCX current in cardiac arrhythmogenesis. These hypotheses were formulated based on basic electrophysiological observations. According to the general view, in the "forward mode" NCX extrudes $\mathrm{Ca}^{2+}$ from the cell to the extracellular space at high intracellular $\mathrm{Ca}^{2+}$ concentration depending on voltage during the action potential and at gradually decreasing cytosolic concentration during the diastole at negative membrane potential. Since the extrusion of one $\mathrm{Ca}^{2+}$ is coupled with the entry of three $\mathrm{Na}^{+}$into the cell, the forward mode of the NCX results in a net inward depolarizing current. When the intracellular $\mathrm{Na}^{+}$transiently rises and the intracellular $\mathrm{Ca}^{2+}$ concentration is still low and/or the membrane potential is less negative at the beginning of the cardiac action potential and before the extensive release of $\mathrm{Ca}^{2+}$ from the sarcoplasmic reticulum, the NCX operates in the "reverse mode", ie. extruding $3 \mathrm{Na}^{+}$from and moving $1 \mathrm{Ca}^{2+}$ into the cell. This is called "reverse mode" which carries 
repolarizing net current through the sarcolemma (Clark et al, 1996; Egger et al, 1999b, Tóth et al, 2009). Importantly, "reverse mode" NCX function has also been implicated in arrhythmogenesis and myocardial injury due to its contribution to calcium overload during ischemia/reperfusion (Eigel and Hadley, 2001; Baczkó et al, 2003 and 2004).

This hypothesis could not be directly tested due to lack of potent and selective NCX inhibitors. This unmet need provides a rationale for pharmacologists and medicinal chemists to get more involved in NCX research by designing and developing novel compounds to modulate NCX activity.

During the past decade, the discovery of carbocyclic nucleosides possessing potent antiviral and antitumor activity has led to an increasing demand for the production of new chiral, alicyclic nucleoside analogues (De Clerq E, 2005; Schneller, 2002; Ichikawa and Kato, 2001). Many articles and patents focused on the antiviral and anticancer activity of carbocyclic nucleosides, however, their cardioprotective activity were described in few cases only (Szakonyi and Fülöp, 2010).

Therefore, in the present study carbocyclic nucleoside analogues (CNA) as potential novel selective inhibitors of NCX current and their effect on DAD related and ischemia-reperfusion (IR) induced cardiac arrhythmias are investigated. The structures of these CNA compounds basically differ from the already known selective NCX blockers, like KB-R7943 and SEA-0400 or from ORM-10103 (Jost et al. 2013). The starting molecule having the name of formula (I) had the following structure: 4-amino-1-[((1R,2S,3S,5R)-2,3-dihydroxy-6,6-dimethylbicyclo[3.1.1] heptan-2-yl)methyl]pyrimidin-2(1H)-one.

Several CNA compounds according to formula (I) and of with reversed stereochemistry, i.e. reference compounds were synthetized from witch ten compounds were investigated in more details. The main finding of this study was that three CNA compounds (GYKB-6635, GYKB-6704 and GYKB-6707) effectively inhibit the NCX current at micromolar concentration ranges (Table 3). The most potent compound seemed to be GYKB6635 , therefore this compound has been selected for further analysis. The potential antiarrhythmic potency of GYKB-6635 compound was also investigated in detail.

The main finding of this study was that GYKB-6635 a newly synthetized compound at micromolar concentration ranges effectively inhibited the NCX current (Figure 8). This inhibitory effect was highly selective, since the drug at $10 \mu \mathrm{M}$ (10-fold higher concentration than the effective NCX inhibiting concentration) did not affect any major transmembrane currents determining cardiac action potential such as L-type $\mathrm{I}_{\mathrm{CaL}}$ current (Figure 9a), fast sodium current determined as $V_{\max }$ (Figure 9b and inset of Figure 12a) and the main 
repolarizing potassium currents $\left(\mathrm{I}_{\mathrm{kr}}, \mathrm{I}_{\mathrm{ks}} \mathrm{I}_{\mathrm{to}}\right.$ and $\mathrm{I}_{\mathrm{K} 1}$, Figures 10 and 11). NCX inhibition by application of $1 \mu \mathrm{M}$ GYKB6635 failed to significantly affect dog multicellular papillary muscle action potential parameters including maximal rate of depolarization $\left(\mathrm{V}_{\max }\right)$, while pacing at a constant pacing cycle length of $1000 \mathrm{~ms}$, either the action potential waveform or action potential duration (APD90) at all (Table 4 and Figure 12).

In the present study, the selective blocking effect of the GYKB-6635 compound proved to be effective against DAD related arrhythmias, since in isolated Langendorff perfused heart experiments prevented disturbances of the heart rhythm in ouabain induced arrhythmias in guinea pigs (Table 5 and Figure 13).

Previous studies exploring selective NCX inhibition brought up two major points: the possible positive inotropic effect which could represent a novel strategy in the treatment of heart failure and the putative antiarrhythmic effect. Earlier, due to the lack of potent and selective NCX blockers these hypotheses could not be directly and properly tested. The first promising and credited "selective" NCX blockers were KB-R7943 and SEA-0400.). Indeed, both SEA-0400 and KB-R7943 were shown to potently inhibit the NCX current at micromolar concentration range. In addition, KB-R7943 abolished experimental arrhythmias (Elias et al. 2001; Watano et al. 1999), while in another previous study it was demonstrated that SEA-0400 effectively decreased the magnitude of both DADs and EADs in dog cardiac preparations (Nagy et al, 2004]. Nonetheless, the proposed selectivity of both KB-R7943 and SEA-0400 were seriously questioned by studies revealing that at micromolar concentrations both blockers inhibit the L-type calcium current as well (Sipido et al. 2000; Tanaka et al. 2002, Birinyi et al. 2005; Acsai et al. 2007; Antoons et al. 2012).

Therefore, in earlier studies the antiarrhythmic effects of NCX inhibition could not be safely separated from the antiarrhythmic effects of their inhibition of other transmembrane currents including $\mathrm{I}_{\mathrm{CaL}}$. The positive inotropic effect was first tested by Hobai et al. (2004) in canine heart failure model applying the NCX inhibitory peptide XIP, which was able to restore the SR $\mathrm{Ca}^{2+}$ load and release. Ozdemir et al. (2008) also reported positive inotropic effect of SEA-0400 in a mouse heart failure model. The NCX inhibitor SN-6 has similar profile to that of SEA-0400, but it is more potent (Iwamoto et al. 2004). However, other study questioned its selectivity and claimed that SN-6 impairs contractility and $\mathrm{Ca}^{2+}$ handling (Ghandi et al. 2013).

The most promising results were published recently with another NCX inhibitor ORM-10103, which exhibits significantly improved selectivity for NCX compared to SEA0400 (Jost et al. 2013; Terracciano and Hancox 2013). In this study it was reported that 
ORM-10103 effectively blocked both forward and reverse NCX current at submicromolar concentrations. In addition, the amplitudes of pharmacologically induced early and delayed afterdepolarizations were significantly decreased by ORM-10103 in a concentrationdependent manner. The compound was fairly selective since it did not affect the most important transmembrane ion transports controlling the cardiac AP including repolarization. However, the compound also moderately inhibited $\mathrm{I}_{\mathrm{Kr}}$ at a concentration range close to its maximal inhibitory effect on NCX, which limited the use of ORM-10103 as a tool to test the effect of NCX inhibition on cardiac ventricular repolarization (Jost et al. 2013).

The possible therapeutic implication of our study appears to be rather complex. It is tempting to speculate that suppression of EADs and DADs may be antiarrhythmic both in the ventricles and the atria (Chen et al. 2000) during $\mathrm{Ca}^{2+}$ overload such as in heart failure and at early stages of atrial flutter and fibrillation, especially when potassium currents may have been downregulated (van Wagoner and Nerbonne 2000; Yue et al. 1997) and the NCX current upregulated (Studer et al. 1994). Also, it was considered that upon reperfusion following myocardial ischaemia, $\mathrm{Ca}^{2+}$ influx occurred via the $\mathrm{NCX}$ in the reverse mode contributing to $\mathrm{Ca}^{2+}$ overload and release of $\mathrm{Ca}^{2+}$ from the sarcoplasmic reticulum and thereby causing cardiac arrhythmias (Levi et al. 1993). Thus, blocking reverse mode NCX can also be beneficial (Baczkó et al. 2003; Eigel and Hadley 2001; Schäfer et al. 2001). In addition, the positive inotropic effect of the inhibition of the forward mode of the NCX improve myocardial function and, as such, it may be also beneficial.

The antiarrhythmic protective effect of GYKB-6635 against DAD related arrhythmias, in ouabain induced arrhythmias in guinea pigs is a new and interesting finding, since the previously used NCX blocker compounds (KB-R7943, SEA-0400 and ORM-10103) were not investigated at organ level. This is the first study that demonstrated that a highly selective NXC blocker was able to effectively prevent cardiac arrhythmias evoked in a pharmacological experimental model of cardiac arrhythmia. 


\section{Conclusions and potential significance}

The conclusions and main findings of the present thesis are as follows:

1) The endogenous Kir2.x channels associate with SAP97 forming signalling complexes. The Kir2.1 strongly binds SAP97, and they show co-localization near the T-tubules. In undiseased adult ventricle, KCNJ2, KCNJ12 and KCNJ4 (Kir2.1-2.3) genes were expressed at high level; while the expression of KCNJ14 (Kir2.4) gene was low. In DCM, the levels of Kir2.1 and Kir2.3 were upregulated but those of Kir2.2 channels were downregulated. These adaptations could offer a new aspect for the explanation of the generally observed physiological and molecular alterations found in DCM. The SAP97 and Kir ion channels may be novel target molecules in the diagnosis and effective treatment of cardiomyopathy.

2) We have demonstrated in vitro the potential inhibitory NCX blocking effect and of several carbocyclic nucleoside analogues (CNA). The structures of these CNA compounds basically differ from the already known selective NCX blockers, like KB-R7943, SEA0400 and ORM-10103.

3) GYKB-6635 is the first compound that inhibits forward and reverse mode of the NCX current at submicromolar concentrations, and does not affect any other important transmembrane mechanisms involved in $\mathrm{Ca}^{2+}$-homeostasis and cardiac repolarization. In addition GYKB-6635 compound proved to be effective against DAD related arrhythmias, since in isolated Langendorff perfused heart experiments prevented disturbances of the heart rhythm in ouabain induced arrhythmias in guinea pigs.

4) We may concluded that GYKB-6653 is a new and highly selective NCX inhibitor compound that may be suitable to test whether NCX blockade offers beneficial antiarrhythmic effects. Further studies are needed using both in vitro and in vivo methods to elucidate the potential therapeutic targets and, in a wider sense, the possible beneficial effects of specific NCX inhibition. 


\section{References}

1. Acsai K, Kun A, Farkas AS, Fülöp F, Nagy N, Balázs M, Szentandrássy N, Nánási PP, Papp JG, Varró A, Tóth A (2007). Effect of partial blockade of the $\mathrm{Na}^{+} / \mathrm{Ca}^{2+}$-exchanger on $\mathrm{Ca}^{2+}$ handling in isolated rat ventricular myocytes. Eur J Pharmacol, 576: 1-6.

2. Antoons G, Willems R, Sipido KR (2012). Alternative strategies in arrhythmia therapy: evaluation of $\mathrm{Na} / \mathrm{Ca}$ exchange as an anti-arrhythmic target. Pharmacol Ther, 134: 26-42.

3. Baczkó I, Giles WR, Light PE. (2004). Pharmacological activation of plasma-membrane $\mathrm{K}_{\text {ATP }}$ channels reduces reoxygenation-induced $\mathrm{Ca}^{2+}$ overload in cardiac myocytes via modulation of the diastolic membrane potential. Brit J Pharmacol, 141: 1059-1067.

4. Baczkó I, Giles WR, Light PE. (2003). Resting membrane potential regulates $\mathrm{Na}^{+}-\mathrm{Ca}^{2+}$ exchangemediated $\mathrm{Ca}^{2+}$-overload during hypoxia-reoxygenation in rat ventricular myocytes. $J$ Physiol, 550: $889-898$.

5. Barrans JD, Allen PD, Stamatiou D, Dzau VJ, Liew CC (2002). Global gene expression profiling of end-stage dilated cardiomyopathy using human cardiovascular based cDNA microarray. $\mathrm{Am} \mathrm{J}$ Pathol, 160: 2035-2043.

6. Bers DM (2002). Cardiac excitation-contraction coupling. Nature, 415: 198-205.

7. Bers DM (2000). Calcium fluxes involved in control of cardiac myocyte contraction. Circ Res, 87: 275-281.

8. Bessieres M, Chevrier F, Roy V, Agrofoglio LA (2015). Recent progress for the synthesis of selected carbocyclic nucleosides. Fut Med Chem, 7: 1809-1828.

9. Birinyi P, Acsai K, Bányász T, Tóth A, Horváth B, Virág L, Szentandrássy N, Magyar J, Varró A, Fülöp F, Nánási PP (2005). Effects of SEA-0400 and KB-R7943 on $\mathrm{Na}^{+} / \mathrm{Ca}^{2+}$ exchange current and L-type $\mathrm{Ca}^{2+}$ current in canine ventricular cardiomyocytes. Naunyn Schmiedebergs Arch Pharmacol, 372: 63-70.

10. Borlak J and Thum T (2003). Hallmarks of ion channel gene expression in end-stage heart failure. FASEB J, 17: 1592-1608.

11. Chen YJ, Chen SA, Chang MS, Lin CI (2000). Arrhythmogenic activity of cardiac muscle in pulmonary veins of the dog: implication for the genesis of atrial fibrillation. Cardiovasc Res, $\mathbf{4 8}$ : 265-273.

12. Choi Y, Moon HR, Yoshimura V, Marquez VE (2003). Recent advances in the synthesis of confortnationally locked nucleosides and their success in probing the critical question of conformational preferences by their biological targets. Nucleosides, Nucleotides Nucleic Acids, 22: $547-557$.

13. Clark RB, Bouchard RA, Giles WR (1996). Action potential duration modulates calcium influx, $\mathrm{Na}^{+}-\mathrm{Ca}^{2+}$ exchange, and intracellular calcium release in rat ventricular myocytes. Ann NY Acad Sci, 779: 417-429.

14. Csanády M, Faragó M, Forster T, Högye M, Piros Gy. (1991). Study of the course of inheritance of dilated familial cardiomyopathy. Eur Heart J, 12: 191.

15. Curtis MJ, Hancox JC, Farkas A, Wainwright CL, Stables CL, Saint DA, Clements-Jewery H, Lambiase PD et al. (2013). The Lambeth Conventions (II): guidelines for the study of animal and human ventricular and supraventricular arrhythmias. Pharmacol \& Therapeut, 139: 213- 248.

16. De Clerq E (2005). John Montgomery's legacy: Carbocyclic adenosine analogues as Sah hydrolase inhibitors with broad-spectrum antiviral activity. Nucleosides, Nucleotides Nucleic Acids, 24: 1395-1415.

17. Dhamoon AS, Jalife J (2005). The inward rectifier current ( $\left.\mathrm{I}_{\mathrm{K} 1}\right)$ controls cardiac excitability and and is involved in arrhythmogenesis. Heart Rhythm, 2: 316-324.

18. Egger M, Niggli E (1999a). Regulatory function of $\mathrm{Na}-\mathrm{Ca}$ exchange in the heart: milestones and outlook. J Membr Biol, 168: 107-130.

19. Egger M, Ruknudin A, Lipp P, Kofuji P, Lederer WJ, Schulze DH, Niggli E (1999b). Functional expression of the human cardiac $\mathrm{Na}^{+} / \mathrm{Ca}^{2+}$ exchanger in $\mathrm{Sf} 9$ cells: rapid and specific $\mathrm{Ni}^{2+}$ transport. Cell Calcium, 25: 9-17. 
20. Eigel BN, Hadley RW (2001). Antisense inhibition of $\mathrm{Na}^{+} / \mathrm{Ca}^{2+}$ exchange during anoxia/reoxygenation in ventricular myocytes. Am $J$ Physiol Heart Circ Physiol, 281: H2184-H2190.

21. Elias CL, Lukas A, Shurraw S, Scott J, Omelchenko A, Gross GJ, Hnatowich M, Hryshko LV (2001). Inhibition of $\mathrm{Na}^{+} / \mathrm{Ca}^{2+}$ exchange by KB-R7943: transport mode selectivity and antiarrhythmic consequences. Am J Physiol Heart Circ Physiol, 281: H1334-H1345.

22. Gaborit N, Wichter T, Varró A, Szüts V, Lamirault G, Eckardt L, Paul M, Breithardt G, SchulzeBahr E, Escande D, Nattel S, Demolombe S (2009). Transcriptional profiling of ion channel genes in Brugada syndrome and other right ventricular arrhythmogenic diseases. Eur Heart J, 30: 487-496.

23. Gaborit N, Le Bouter S, Szuts V, Varro A, Nattel S, Escande D, Demolombe S (2007). Regional and tissue specific transcript signatures of ion channel genes in the normal human. $J$ Physiol London, 582: 675-693.

24. Gandhi A, Siedlecka U, Shah AP, Navaratnarajah M, Yacoub MH, Terracciano CM (2013). The effect of SN-6, a novel sodium-calcium exchange inhibitor, on contractility and calcium handling in isolated failing rat ventricular myocytes. Cardiovasc Ther, 31: e115-124

25. Hibino H, Inanobe A, Furutani K, Murakami S, Findlay I, Kurachi Y (2010). Inwardly Rectifying Potassium Channels: Their structure, function, and physiological roles. Physiol Rev, 90: 291-366.

26. Hilgemann DW (2004). New insights into the molecular and cellular workings of the cardiac $\mathrm{Na}^{+} / \mathrm{Ca}^{2+}$ exchanger. Am J Physiol Cell Physiol, 287: C1167-C1172.

27. Hobai IA, Maack C, O'Rourke B (2004). Partial inhibition of sodium/calcium exchange restores cellular calcium handling in canine heart failure. Circ Res, 95: 292-299

28. Hobai IA, Khananshvili D, Levi AJ (1997). The peptide "FRCRCFa", dialysed intracellularly, inhibits the $\mathrm{Na} / \mathrm{Ca}$ exchange in rabbit ventricular myocytes with high affinity. Pflugers Arch. 433, 455-463.

29. Ichikawa E, Kato K (2001). Sugar-modified nucleosides in past 10 years, a review. Curr. Med. Chem, 8, 385-423.

30. Iwamoto $T$, Inoue $Y$, Ito $K$, Sakaue $T$, Kita $S$, Katsuragi $T$ (2004). The exchanger inhibitory peptide region-dependent inhibition of $\mathrm{Na}^{+} / \mathrm{Ca}^{2+}$ exchange by SN-6 [2-[4-(4nitrobenzyloxy)benzyl]thiazolidine-4-carboxylic acid ethyl ester], a novel benzyloxyphenyl derivative. Mol Pharmacol, 66: 45-55

31. Jefferies JL and Towbin JA (2010). Dilated cardiomyopathy. Lancet, 375: 752-762.

32. Jost N, Virág L, Bitay M, Takács J, Lengyel Cs, Biliczki P, Nagy ZA, Bogáts G, Lathrop DA, Papp JGy, Varró A (2005). Restricting excessive cardiac action potential and QT prolongation: a vital role for $\mathrm{I}_{\mathrm{Ks}}$ in human ventricular muscle. Circulation, 112, 1392-1399.

33. Jost N, Nagy N, Corici C, Kohajda Z, Horváth A, Acsai K, Biliczki P, Levijoki J, Pollesello P, Koskelainen T, Otsomaa L, Toth A, Papp JGy, Varró A, Virág L (2013). ORM-10103, a novel specific inhibitor of the sodium/calcium exchanger, decreases early and delayed afterdepolarization in the canine heart. BrJ Pharmacol, 170: 768-778.

34. Karle CA, Zitron E, Zhang W, Wendt-Nordahl G, Kathöfer S (2002). Cardiac inwardly-rectifying $\mathrm{K}^{+}$channel Kir2.1b is inhibited by direct protein kinase $\mathrm{C}$-dependent regulation in human isolated cardiomyocytes and in an expression system. Circulation, 106: 1493-1499.

35. Koumi S, Backer CL, Arentzen CE (1995). Characterization of inwardly rectifying K+ channel in human cardiomyocytes. Alterations in channel behaviour in myocytes isolated from patients with idiopathic dilated cardiomyopathy. Circulation, 92: 164-174.

36. Kumamoto H, Deguchi K, Wagata T, Furuya Y, Odanaka Y, Kitade Y, Tanaka H (2009). Radical-mediated stannylation of vinyl sulfones: access to novel 4'-modified neplanocin A analogues. Tetrahedron, 65, 8007-8013.

37. Lakshmi R, Bateman TD, McIntosh MC (2005). A convenient 3-step synthesis of (R)-7hydroxycarvone from $(S)$-alpha-pinene. J Org Chem, 70: 5313-5315.

38. Lavallée P, Bouthillier G (1986). Efficient conversion of $(1 R, 5 R)-(+)$-alpha-pinene to $(1 S, 5 R)-(-)-$ nopinone. J. Org. Chem. 51: 1362-1365.

39. Leonoudakis D, Conti LR, Radeke CM, McGuire LM, Vandenberg CA (2004). A multiprotein trafficking complex composed of SAP97, CASK, Veli, and Mintlis associated with inward rectifier Kir2 potassium channels. J Biol Chem, 279: 19051-19063. 
40. Leonuodakis D, Mailliard WS, Wingerd KL, Clegg DO, Vandenberg CA (2000). Inward rectifier potassium channel Kir2.2 is associated with Synapse-Associated Protein SAP97. J Cell Sci, 114: 987-998.

41. Levi A, Brooksby P, Hancox J (1993). One hump or two? The triggering of calcium release from the sarcoplasmic reticulum and the voltage dependence of contraction in mammalian cardiac muscle. Cardiovasc Res, 27: 1743-1757.

42. Lodge NJ, Normandin DE (1997). Alterations in $\mathrm{I}_{\mathrm{tol}}, \mathrm{I}_{\mathrm{Kr}}$ and $\mathrm{I}_{\mathrm{K} 1 \mathrm{~d}}$ ensity in the BIO TO-2 strain of syrian myopathic hamsters. J Mol Cell Cardiol, 29: 3211-3221.

43. Lytton $\mathrm{J}$ (2007). $\mathrm{Na}^{+} / \mathrm{Ca}^{2+}$ exchangers: three mammalian gene families control $\mathrm{Ca}^{2+}$ transport. Biochem J, 406:365-82.

44. Magee WP, Deshmukh G, Deninno MP, Sutt JC, Chapman JG, Tracey WR (2003). Differing cardioprotective efficacy of the $\mathrm{Na}^{+} / \mathrm{Ca}^{2+}$ exchanger inhibitors SEA0400 and KB-R7943. Am J Physiol Heart Circ Physiol, 284: H903-H910.

45. Marban E (2002). Cardiac channelopathies. Nature, 415: 213-218.

46. Matyugina ES, Khandazhinskaya AL (2014). 5'-Norcarbocyclic nucleoside analogues. Russ Chem Bull, Int Ed, 63: 1069-1080.

47. Melman A, Gao ZG, Kumar D, Wan TC, Gizewski E, Auchampach JA, Jacobson KA (2008). Design of $(\mathrm{N})$-methanocarba adenosine 5'-uronamides as species-independent A3 receptorselective agonists. Bioorg Med Chem Lett, 18: 2813-2819.

48. Muňoz V, Vaidyanathan R, Tolkacheva EG, Dhamoon AS, Taffet SM, Anumonwo JMB (2007). Kir2.3 isoform confers pH sensitivity to heteromeric Kir2.1/Kir2.3 channels in HEK293 cells. Heart Rhythm, 4: 487-496.

49. Nagy ZA, Virág L, Tóth A, Biliczki P, Acsai K, Bányász T, Nánási P, Papp JG, Varró A. (2004). Selective inhibition of sodium-calcium exchanger by SEA-0400 decreases early and delayed afterdepolarization in canine heart. Br J Pharmacol, 143:827-831.

50. Nattel S, Duker G, Carlsson L (2008). Model systems for the discovery and development of antiarrhythmic drugs. Prog Biophys Mol Biol, 98, 328-339.

51. Nattel S, Carlsson L (2006). Innovative approaches to anti-arrhythmic drug therapy. Nat Rev Drug Discov, 5, 1034-1049.

52. Nattel S, Singh B.N (1999). Evolution, mechanisms, and classification of antiarrhythmic drugs: focus on class III actions. Am J Cardiol, 84: 11R-19R.

53. Ozdemir S, Bito V, Holemans P, Vinet L, Mercadier JJ, Varró A, et al. (2008). Pharmacological inhibition of $\mathrm{Na} / \mathrm{Ca}$ exchange results in increased cellular $\mathrm{Ca}^{2+}$ load attributable to the predominance of forward mode block. Circ Res, 102: 1398-1405

54. Pfaffl MW (2001). A new mathematical model for relative quantification in real-time RT-PCR. Nucleic Acids Res, 29: e45.

55. Philipson KD, Nicoll DA (2000). Sodium-calcium exchange: a molecular perspective. Annu Rev Physiol, 62: 111-133.

56. Piecha D, Muratoglu S, Mörgelin M, Hauser N, Studer D, Kiss I, Paulsson M, Deák F (1999). Matrilin-2, a large, oligomeric matrix protein, is expressed by a great variety of cells and forms fibrillar networks. $J$ Biol Chem, 274: 13353-13361.

57. Pogwizd SM (2003). Clinical potential of sodium-calcium exchanger inhibitors as antiarrhythmic agents. Drugs, 63: 439-452.

58. Pogwizd SM, Bers DM (2002). Calcium cycling in heart failure: the arrhythmia connection. $J$ Cardiovasc Electrophysiol, 13: 88-91.

59. Pogwizd SM, Schlotthauer K, Li L, Yuan W, Bers DM (2001). Arrhythmogenesis and contractile dysfunction in heart failure. Roles of sodium-calcium exchange, inward rectifier potassium current, and residual -adrenergic responsiveness. Circ Res, 88: 1159-1167.

60. Reeves JP (1998). $\mathrm{Na}^{+} / \mathrm{Ca}^{2+}$ exchange and cellular $\mathrm{Ca}^{2+}$-homeostasis. J Bioenerg Biomembrane, 30: $151-160$.

61. Rodriguez JB, Comin MJ (2003). New progresses in the enantioselective synthesis and biological properties of carbocyclic nucleosides. Mini Rev Med Chem, 3: 95-114.

62. Rook MB (2007). Physiologic function of $\mathrm{I}_{\mathrm{K} 1}$ requires a combination of Kir2 isoforms. Heart Rhythm, 4: 497-499.

63. Rose J, Armoundas AA, Tian Y, DiSilvestre D, Burysek M, Halperin V, O'Rourke B, Kass DA, 
Marban E, Tomaselli GF (2005). Molecular correlates of altered expression of potassium currents in failing rabbit myocardium. Am J Physiol Heart Circ Physiol, 288: H2077-H2087.

64. Schäfer C, Ladilov Y, Inserte J, Schäfer M, Haffner S, Garcia-Dorado D, Piper HM (2001). Role of the reverse mode of the $\mathrm{Na}^{+} / \mathrm{Ca}^{2+}$ exchanger in reoxygenation-induced cardiomyocyte injury. Cardiovasc Res, 51, 241-250.

65. Scheidl F (1982). Catalytic rearrangements of alpha-pinene-epoxide in the presence of aluminium alkoxides. Synthesis, (09): 728-728.

66. Schneller SW (2002). Carbocyclic nucleosides (carbanucleosides) as new therapeutic leads. Curr Top Med Chem, 2, 1087-1092.

67. Schram G, Pourrier M, Wang Z, White M, Nattel S (2003). Barium block of Kir2 and human cardiac inward rectifier currents: evidence for subunit-heteromeric contribution to native currents. Cardiovasc Res, 59: 328-338.

68. Singh BN (1999). Current antiarrhythmic drugs. An overwiew of mechanisms of action and potential clinical utility. $J$ Cardiovasc Electrophysiol, 10, 283-301.

69. Singh BN (1972). A fourth class of anti-dysrhythmic action? Effect of verapamil on ouabain toxicity, on atrial and ventricular intracellular potentials, and on other features of cardiac function. Cardiovasc Res, 6: 109-119.

70. Singh BN, Vaughan Williams EM (1970). A third class of anti-arrhythmic action. Effect on atrial and ventricular intracellular potentials, and other pharmacological actions on cardiac muscle, of MJ 1999 and AH 3474. Br J Pharmacol, 39: 675-687.

71. Sipido KR, Volders PG, de Groot SH, Verdonck F, Van de Werf F, Wellens HJ, Vos MA (2000). Enhanced $\mathrm{Ca}^{2+}$ release and $\mathrm{Na} / \mathrm{Ca}$ exchange activity in hypertrophied canine ventricular myocytes: potential link between contractile adaptation and arrhythmogenesis. Circulation, 102: 2137-2144.

72. Soltysinska E, Olesen SP, Christ T, Wettwer E, Varró A, Grunnet M, Jespersen T (2009). Transmural expression of ion channels and transporters in human nondiseased and end-stage failing hearts. Pflugers Arch, 459: 11-23.

73. Studer R, Reinecke H, Bilger J, Eschenhagen T, Böhm M, Hasenfuss G, Just H, Holtz J, Drexler $\mathrm{H}$ (1994). Gene expression of the cardiac $\mathrm{Na}^{+}-\mathrm{Ca}^{2+}$ exchanger in end-stage human heart failure. Circ Res, 75: 443-453.

74. Szabó G, Szentandrássy N, Bíró T, Tóth BI, Czifra G, Magyar J, Bányász T, Varró A, Kovács L, Nánási PP (2005). Asymmetrical distribution of ion channels in canine and human left-ventricular wall: epicardium versus midmyocardium. Pflugers Arch, 450: 307-316.

75. Szakonyi Z, Hetényi A, Fülöp F (2008). Synthesis and application of monoterpene-based chiral aminodiols. Tetrahedron, 64: 1034-1039.

76. Szakonyi Z, Fülöp F (2010). Carbocyclic nucleosides from enantiomeric, $\alpha$-pinane-based aminodiols. Tetrahedron: Asymmetry, 21: 831-836.

77. Szentandrássy N, Bányász T, Biró T, Szabó G, Toth BI, Magyar J, Lázár J, Varró A, Kovács L, Nánási PP (2005). Apico-basal inhomogeneity in distribution of ion channels in canine and human ventricular myocardium. Cardiovasc Res, 65: 851-860.

78. Tanaka H, Nishimaru K, Aikawa T, Hirayama W, Tanaka Y, Shigenobu K (2002). Effect of SEA0400, a novel inhibitor of sodium-calcium exchanger, on myocardial ionic currents. $\mathrm{Br} J$ Pharmacol, 135: 1096-1100.

79. Terracciano CM, Hancox JC (2013). ORM-10103: a significant advance in sodium-calcium exchanger pharmacology? Br J Pharmacol, 170: 765-767.

80. The Sicilian Gambit contributors (1991). A new approach to the classification of antiarrrhythmic drugs based on their actions on arrhythmogenic mechanisms. Task Force of the Working Group on Arrhythmias of the European Society of Cardiology. Circulation, 84, 1831-1851.

81. Tóth A, Kiss L, Varró A, Nánási PP (2009). Potential therapeutic effects of $\mathrm{Na}^{+} / \mathrm{Ca}^{2+}$ exchanger inhibition in cardiac diseases. Curr Med Chem, 16: 3294-3321.

82. Ugliarolo E A, Lantaño B, Moltrasio GY, Moglioni AG (2009). An efficient approach to homochiral indane nucleosides. Tetrahedron: Asymmetry, 20, 1848-1853.

83. Vaidyanathan R, Taffet SM, Vikstrom KL, Anumonwo JMB (2010). Regulation of cardiac inward rectifier potassium current $\mathrm{I}_{\mathrm{K} 1}$ by synapse-associated protein-97. $J$ Biol Chem, 285: 28000-28009. 
84. Van Wagoner DR, Nerbonne JM (2000). Molecular basis of electrical remodeling in atrial fibrillation. J Mol Cell Cardiol, 32: 1101-1117.

85. Venetucci LA, Trafford AW, O'Neill SC, Eisner DA (2007). $\mathrm{Na} / \mathrm{Ca}$ exchange: regulator of intracellular calcium and source of arrhythmias in the heart. Ann N Y Acad Sci, 1099: 315-325.

86. Voigt N, Li N, Wang Q, Wang W, Trafford AW, Abu-Taha I, Sun Q, Wieland T, Ravens U, Nattel S, Wehrens XH, Dobrev D (2012). Enhanced sarcoplasmic reticulum Ca2+ leak and increased $\mathrm{Na}^{+}-\mathrm{Ca}^{2+}$ exchanger function underlie delayed afterdepolarizations in patients with chronic atrial fibrillation. Circulation, 125: 2059-2070.

87. Volders PG, Vos MA, Szabo B, Sipido KR, de Groot SH, Gorgels AP, Wellens HJ, Lazzara R (2000). Progress in the understanding of cardiac early afterdepolarizations and torsades de pointes: time to revise current concepts. Cardiovasc Res, 46: 376-392.

88. Walker MJ, Curtis MJ, Hearse DJ, Campbell RW, Janse MJ, Yellon DM, Cobbe SM, Coker SJ, Harness JB, Harron DW, et al. (1998). The Lambeth Conventions: guidelines for the study of arrhythmias in ischaemia infarction, and reperfusion. Cardiovasc Res, 22: 447-455.

89. Warren M, Guha P, Berenfeld O, Zaitsev A, Anumonwo JMB, Dhamoon AS, Bagwe S, Taffet $\mathrm{SM}$, Jalife J (2003). Blockade of the inward rectifying potassium current terminates ventricular fibrillation in the guinea pig heart. J Cardiovasc Electrophysiol, 14: 621-631.

90. Watano T, Harada Y, Harada K, Nishimura N (1999). Effect of $\mathrm{Na}^{+} / \mathrm{Ca}^{2+}$ exchange inhibitor, KBR7943 on ouabain-induced arrhythmias in guinea-pigs. Br J Pharmacol, 127: 1846-1850.

91. Yang T, Roden DM (1996). Extracellular potassium modulation of drug block of $\mathrm{I}_{\mathrm{Kr}}$. Implications for torsade de pointes and reverse use-dependence. Circulation, 93: 407-411.

92. Yue L, Feng J, Gaspo R, Li GR, Wang Z, Nattel S (1997). Ionic remodeling underlying action potential changes in a canine model of atrial fibrillation. Circ Res, 81: 512-525.

93. Zaritsky JJ, Redell JB, Tempel BL, Schwarz TL (2001). The consequence of disrupting cardiac inwardly rectifying $\mathrm{K}^{+}$current $\left(\mathrm{I}_{\mathrm{K} 1}\right)$ as revealed by the targeted deletion of the murine Kir2.1 and Kir2.2 genes. J Physiol, 533: 697-710.

94. Zvara A, Szekeres G, Janka Z, Kelemen JZ, Cimmer C, Puskás LG (2005). Over-expression of dopamine D2 receptor and inwardly rectifying potassium channel genes in drug-naive schizophrenic peripheral blood lymphocytes as potential diagnostic markers. Dis Markers, 21: 61-69. 


\section{Acknowledgements}

I am very grateful to Professor Julius Gy. Papp MD, DSc, academician, for his continuous support, his kindness and critical reading of my manuscripts, his inspirational comments and constructive criticism were always of help and are greatly appreciated, and to Professor András Varró $\boldsymbol{M D}, \boldsymbol{D S} \boldsymbol{c}$ for providing me the opportunity for research as $\mathrm{PhD}$ student at the Department of Pharmacology and Pharmacotherapy, University of Szeged and the helpful discussions were exceptionally useful during my work.

I am especially thankful to my PhD supervisor Dr. Norbert Jost, for personal guidance and for introducing me to the fascinating world of cardiac cellular electrophysiology. I always enjoyed his optimistic attitude to the scientific problems. Without his continuous support, never-failing interest and eagerness to discuss new ideas, plans and findings throughout these years, this $\mathrm{PhD}$ study could have hardly come to an end.

I am indebted to Professor Ferenc Fülöp (Institute of Pharmaceutical Chemistry, Faculty of Pharmacy) and his colleagues for the synthesis of the GYKB compounds.

Dr. Claudia Corici and Zsófia Kohajda are sincerely thanked for excellent collaboration during the years, for the many hours of splendid discussions and helpful scientific lessons.

I wish to thank my senior colleagues Dr. László Virág and Dr. András Tóth and my other junior ( $\mathrm{PhD}$ students and postdocs) colleagues, Dr. Károly Acsai András Horváth, Dr. Norbert Nagy, Kinga Oravecz and Dr. János Prorok for their continuous support and help in my work, for creating a cheerful and social milieu in the laboratory, and to Mrs. Zsuzsanna Molnár and Mr. Gábor Girst for their helpful technical assistance.

I also wish to thank my parents, to Whom I want to dedicate this thesis, for their endless love, trust and support.

This work was supported by the grants from the Hungarian Scientific Research Fund (OTKA NK-104331, NN-109904 and ANN-113273) the National Research Development and Innovation Office (K-119992, GINOP-2.3.2-15-2016-00006 and GINOP-2.3.2-15-201600012), the National Office for Research and Technology - Gábor Baross and Ányos Jedlik Programmes (REG-DA-09-2-2009-0115-NCXINHIB and NKFP_07_01-RYT07_AF), HURO Cross-Border Cooperation Programmes (HURO/1001/086/2.2.1_HURO-TWIN) and the Hungarian Academy of Sciences. 


\section{ANNEXES}

Publication related to the subject of the $\mathrm{PhD}$ thesis 